\title{
DeVelopment of a Natural GaS SYSTEMS ANALYSIS MODEL (GSAM)
}

\section{ANNUAl TeChNiCAL RePORT CONTRACT YEAR SIX}

For:

U.S. Department of Energy Federal Energy Technology Center Morgantown, West Virginia Under Contract Number: DE-AC21-92MC28138

By:

ICF Resources Incorporated Fairfax, Virginia

\section{$\Rightarrow$ ICF KAISER}

July 1998 


\section{Development of a Natural Gas SYSTEMS ANALYSIS MODEL (GSAM) \\ ANNUAl TeCHNICAL RePORT CONTRACT YeAR SIX}

For:

U.S. Department of Energy

Federal Energy Technology Center

Morgantown, West Virginia

Under Contract Number: DE-AC21-92MC28138

By:

ICF Resources Incorporated

Fairfax, Virginia

July 1998 


\section{DISCLAIMER}

This report was prepared as an account of work performed by an agency of the United States Government. Neither the United States Government nor any agency thereof, nor any of their employees makes any warranty, express or implied, or assumes any legal liability or responsibility for the accuracy, completeness or usefulness of any information, apparatus, product or process disclosed, or represents that its use would not infringe privately owned rights. Reference herein to any specific commercial product, process or service by trade name, trademark, manufacture or otherwise does not necessarily constitute or imply an endorsement, recommendation, or favoring by the United States Government or any agency thereof. The views and opinions of authors expressed herein do not necessarily state or reflect those of the United States Government or any agency thereof. 


\section{TABLE OF CONTENTS}

ABSTRACT

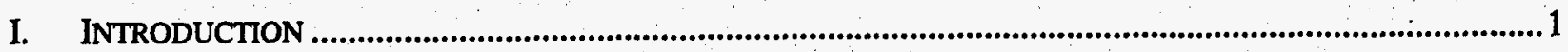

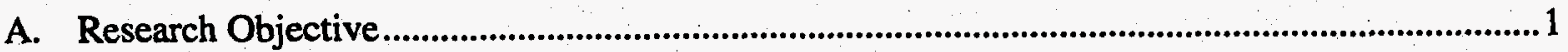

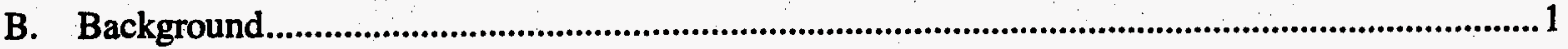

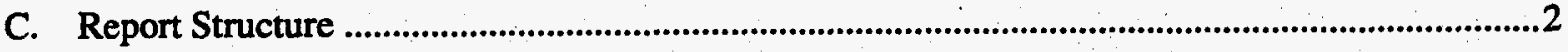

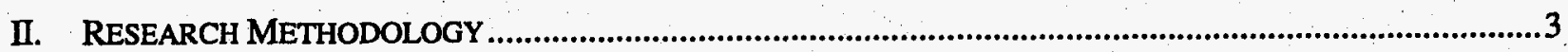

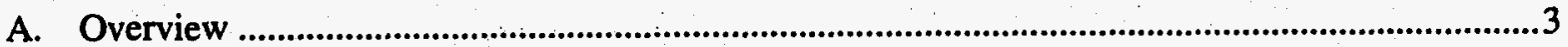

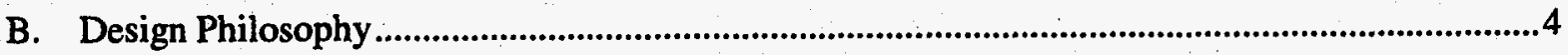

C. Methodology Overview and System Capabilities ....................................................................5

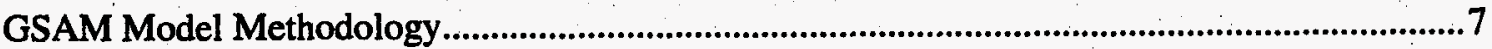

Demand and Integrating Module Methodology ...................................................................13

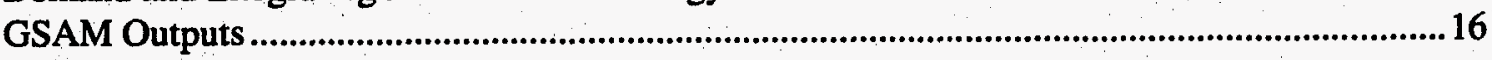

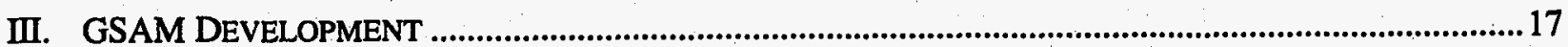

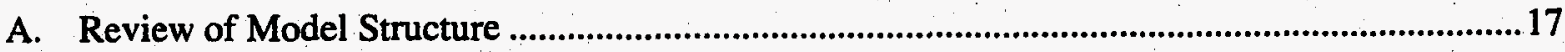

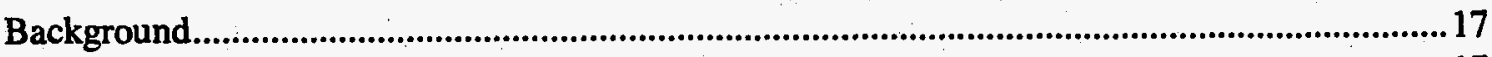

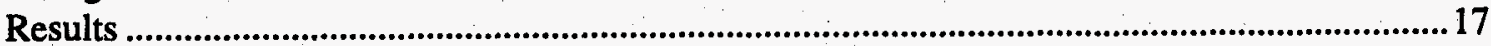

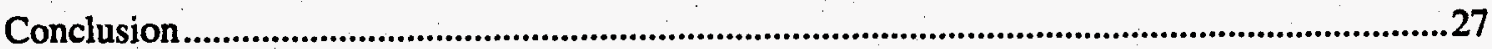

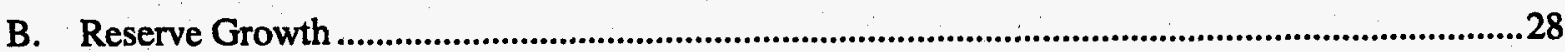

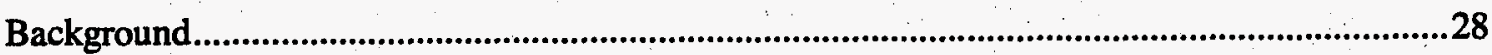

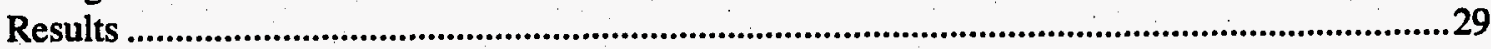

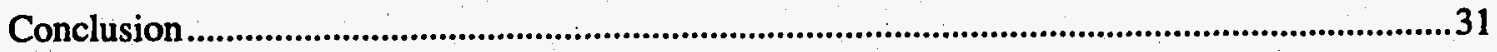

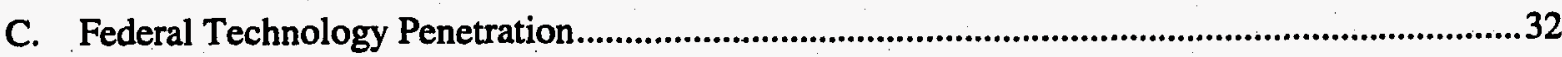

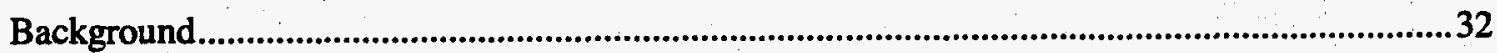

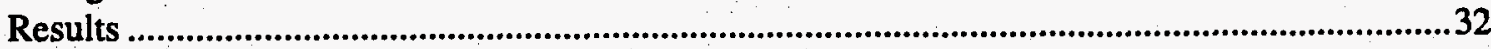

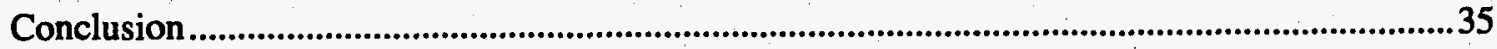

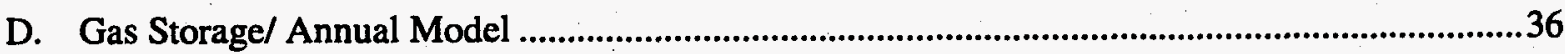

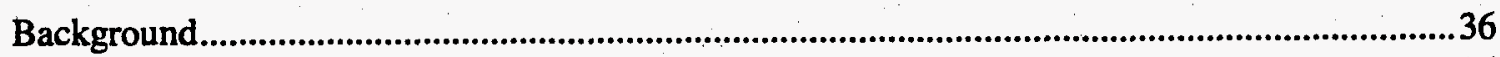

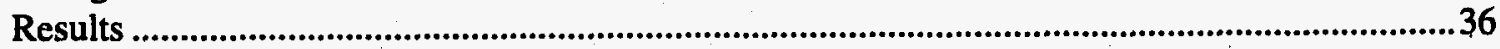

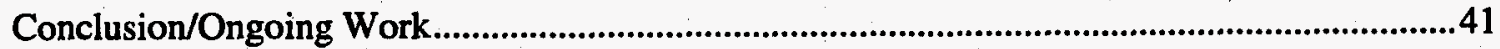

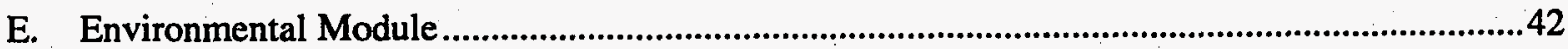

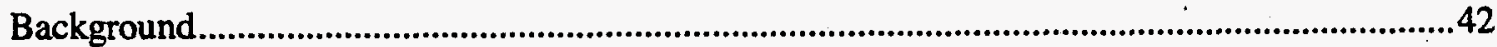

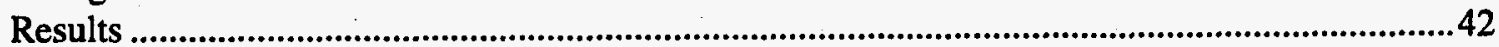

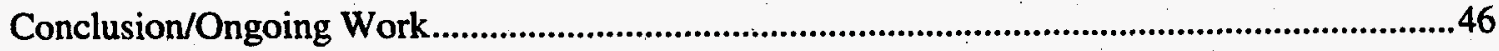




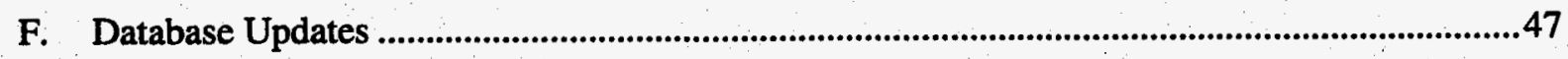

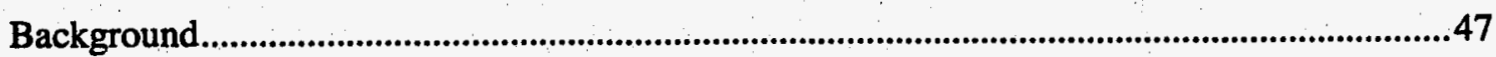

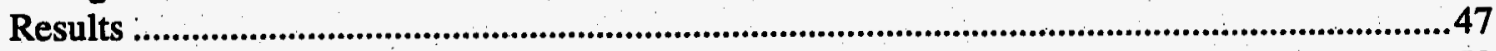

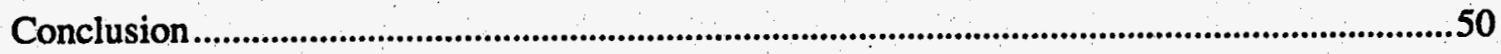

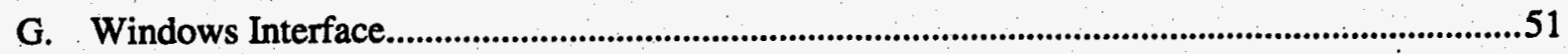

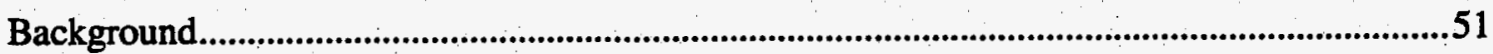

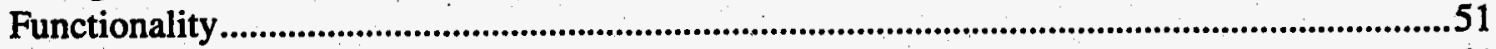

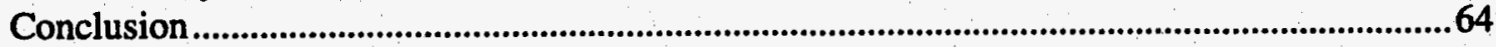

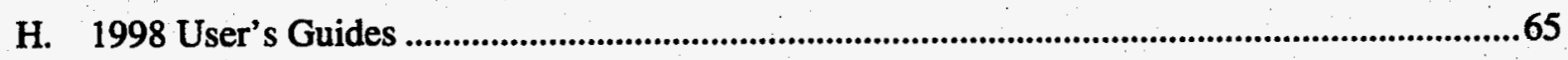

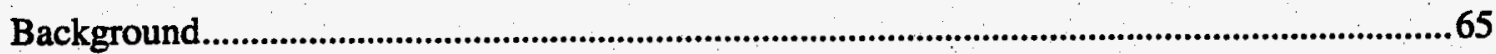

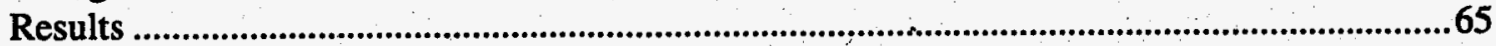

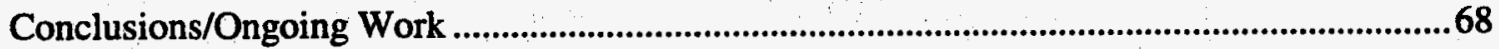

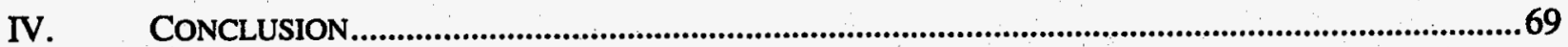




\section{TABLE OF CONTENTS \\ (CONTINUED)}

\section{LIST OF FIGURES/TABLES}

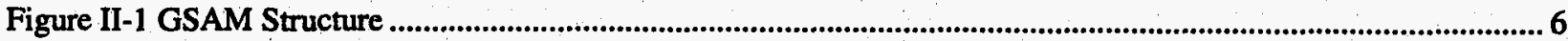

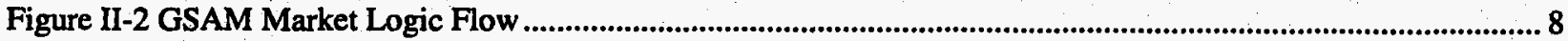

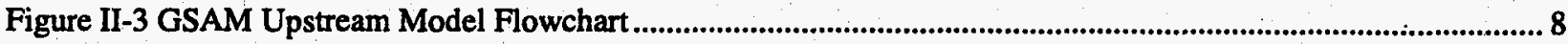

Figure II-4 Major Components of the ICF Gas Modeling System ...................................................................................... 12

Figure II-5 Analysis of Natural Gas Resources by GSAM Analytical Modules and Databases................................... 12

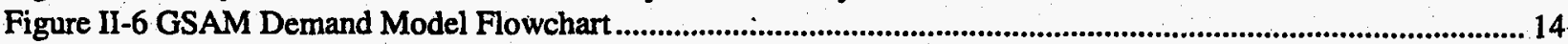

Figure II-7 GSAM Transportation and Supply/Demand Region Map ...................................................................... 15

Figure III-1 Permeability-Net Pay vs. Development MASP* for Undiscovered Tight Reservoirs ............................... 26

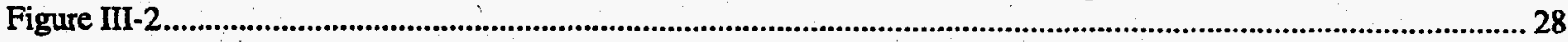

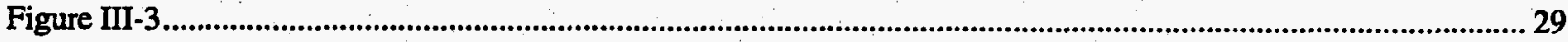

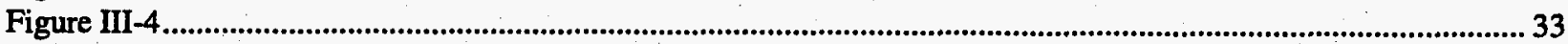

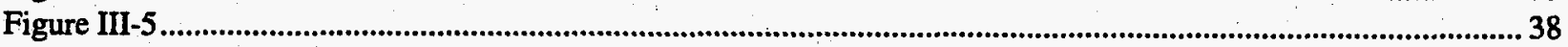

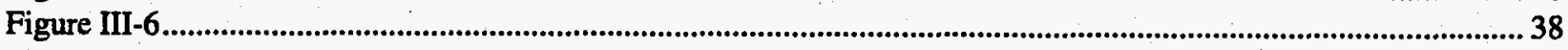

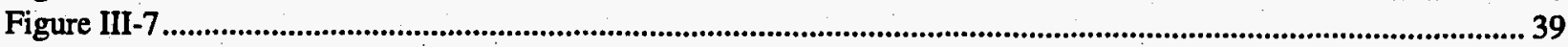

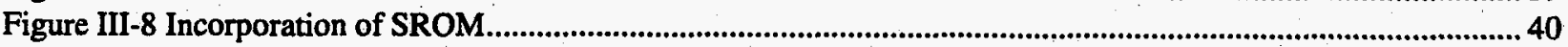

Figure III-9 Structure of the DOE Regulatory E\&P Air Model (DREAM) ................................................................43

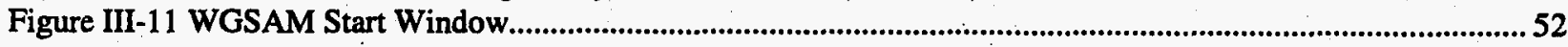

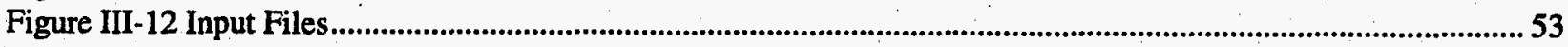

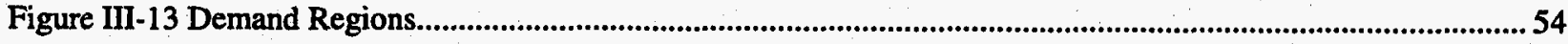

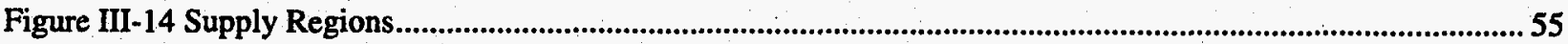

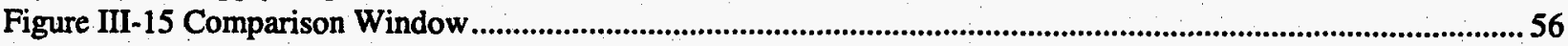

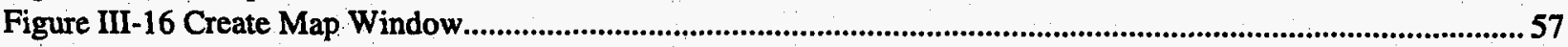

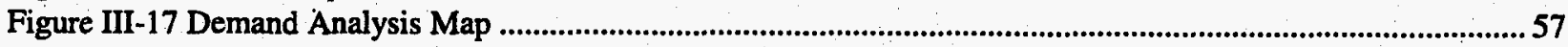

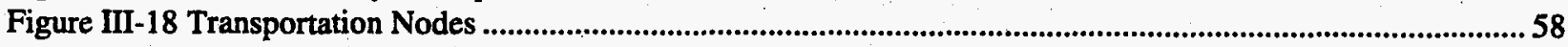

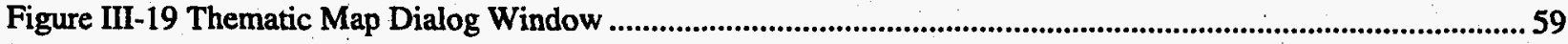

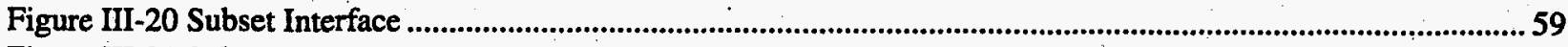

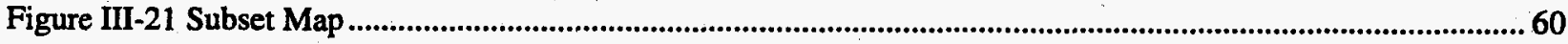

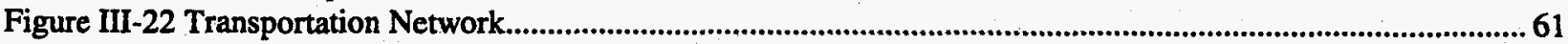

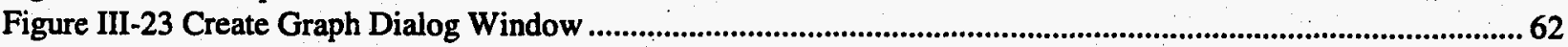

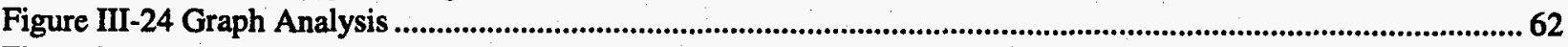

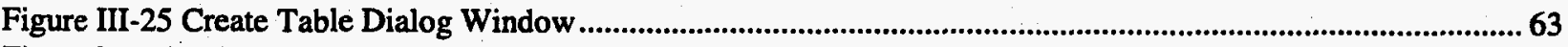

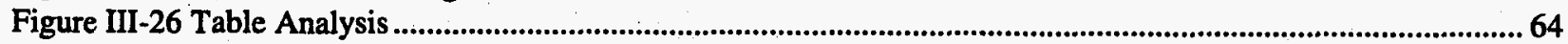

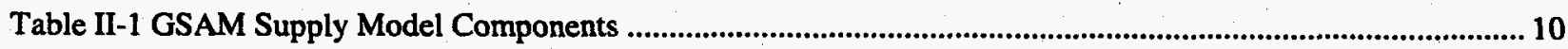

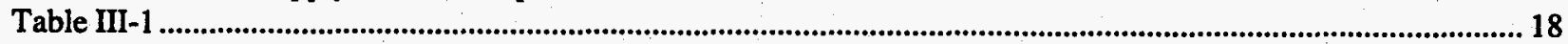

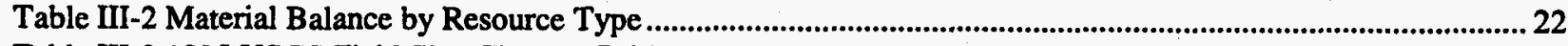

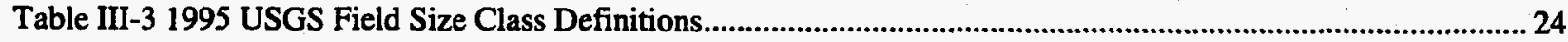

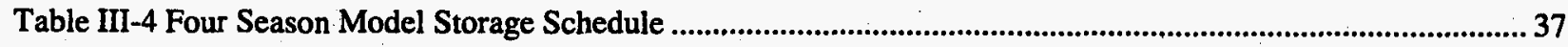

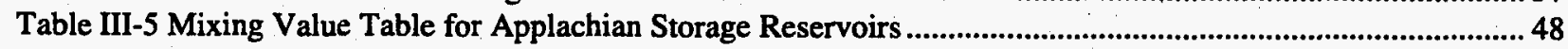

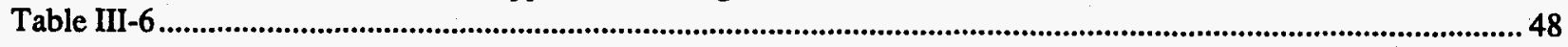

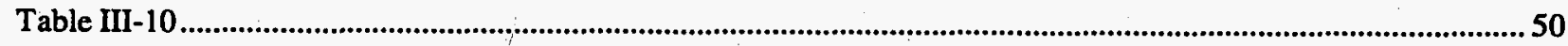




\section{AbStract}

North American natural gas markets have changed dramatically over the past decade. A competitive, cost-conscious production, transportation, and distribution system has emerged from the highly regulated transportation wellhead pricing structure of the 1980's. Technology advances have played an important role in the evolution of the gas industry, a role likely to expand substantially as alternative fuel price competition and a maturing natural gas resource base force operators to maximize efficiency. Finally, significant changes continue in regional gas demand patterns, industry practices, and infrastructure needs. As the complexity of the gas system grows so does the need to evaluate and plan for alternative future resource, technology, and market scenarios.

Traditional gas modeling systems focused solely on the econometric aspects of gas marketing. These systems, developed to assess a regulated industry at a high level of aggregation, rely on simple representation of complex and evolving systems, thereby precluding insight into how the industry will change over time. Credible evaluations of specific policy initiatives and research activities require a different approach. Also, the mounting pressure on energy producers from environmental compliance. activities requires development of analysis that incorporates relevant geologic, engineering, and project economic details. The objective of policy, research and development (R\&D), and market analysis is to integrate fundamental understanding of natural gas resources, technology, and markets to fully describe the potential of the gas resource under alternative future scenarios.

This report summarizes work over the past twelve months on DOE Contract DE-AC2192MC28138, Development of a Natural Gas Systems Analysis Model (GSAM). The products developed under this project directly support the Federal Energy Technology Center (FETC) in carrying out its natural gas $R \& D$ mission.

The objective of GSAM development is to create a comprehensive, non-proprietary, microcomputer model of the North American natural gas system. GSAM explicitly evaluates the key components of the system, including the resource base, exploration and development practices, extraction technology performance and costs, project economics, transportation costs and restrictions, storage, and end-use. The primary focus is the detailed characterization of the resource base at the reservoir and subreservoir level. This disaggregation allows direct evaluation of alternative extraction technologies based on discretely estimated, individual well productivity, required investments, and associated operating costs. GSAM's design allows users to evaluate complex interactions of current and alternative future technology and policy initiatives as they directly impact the gas market. 
GSAM development has been ongoing for the past five years. Key activities completed during the past year include:

- Performed a thorough review of model structure, resolved the "hump" in the production curve;

- Implemented the concept of reserve growth in the upstream Exploration and Production Module;

- Defined Federal lands in the GSAM database and added a Federal technology penetration curve to analyze Federal lands policy issues;

- Developed a 4-season storage routine, and added a 4-season model to the Demand Module;

- Performed the programming and initial testing of an annual model;

- Continued development of GSAM's separate Environmental Module;

- Completed development of a GSAM Windows interface;

- Updated the GSAM User's Guide; and

- Refined GSAM database with respect to Appalachian storage reservoirs and impurity information. 


\section{INTRODUCTION}

This report reviews the goals, work plan, and accomplishments of research under the Department of Energy (DOE) contract DE-AC21-92MC28138, Development of a Natural Gas Systems Analysis Model (GSAM). The work has been under way for six years, since June 22, 1992. Work previously performed under this contract included a review of existing and emerging technologies and a critique of other available models. ICF also completed the final design of the model, developed and tested the databases, entered various engineering and cost modules, updated market model interfaces, developed a metrics analysis of the FETC natural gas R\&D program, and conducted initial training on modeling methodology.

This report provides an overview of the activities to date and schedule for future testing, validation, and authorized enhancements. Its goal is to inform DOE managers of progress in model development and to provide a benchmark for ongoing and future research.

\section{A. RESEARCH OBJECTIVE}

The objective of this research effort is to create a comprehensive, non-proprietary, microcomputer model of the North American natural gas market. GSAM is designed to explicitly evaluate components of the natural gas system, including the entire in-place gas resource base, exploration and development technologies, extraction technology and performance parameters, transportation and storage factors, and end-use issues. The system can be used to evaluate alternative research and development (R\&D) activities and strategies under the direction of FETC. GSAM can now provide the analytical capability to estimate the impacts of Federal energy, tax, and environmental policy initiatives on domestic gas potential.

\section{B. BACKGROUND}

The domestic gas market has undergone dramatic economic and technical evolution in the past decade. This change in the way business is conducted has significant implications for the extraction potential of the natural gas resource, due to both upstream supply considerations and downstream demand requirements. DOE's natural gas research must address these new market realities.

The expanded design of GSAM, including environmental analysis capabilities and a more complete resource description, also meets important strategic objectives identified by DOE. To be utilized in today's market, technology advances must be environmentally sound and prudent. Also, more 
R\&D is being focused directly on environmental damage mitigation. As regulations become more complex, interrelated, and cumbersome, the analysis of environmental policy and R\&D activities will increase in importance. GSAM will be ready to assist DOE managers in program focusing and review.

DOE's Natural Gas Strategic Plan requires that R\&D activities be evaluated for their ability to provide adequate supplies of reasonably priced gas. GSAM provides the capability to assess potential and ongoing $R \& D$ projects using a full fuel cycle, cost-benefit approach. This method provides realistic, market-based assessments of benefits and costs of alternative or related technology advances. It can estimate both technical and commercial successes, quantifying the potential benefits to the market, as well as to other related research. GSAM, therefore, represents an integration of research activities and a method for planning and prioritizing efforts to maximize benefits and minimize costs.

\section{REPORT STRUCTURE}

This annual report summarizes the purpose, work, and results of research activities during the period of performance, July 1, 1997 to June 30, 1998. Section II describes the research methodology, including how it has progressed as DOE's strategic direction has shifted, and as new findings have focused model development efforts. Section III provides a discussion and summary of research activities for the major task assignments on which work has been done during the reporting period. Lastly, in Section IV, we summarize the work accomplished during this past year and the work we anticipate doing in the future on GSAM. 


\section{ReSEARCH Methodology}

\section{A. OVERVIEW}

The primary purpose of GSAM is to provide credible, valid empirical support to FETC R\&D program planning and policy assessment. This role has become increasingly important as DNGOI and other government and industry initiatives call for more detailed analysis of alternative strategies. Review and input from FETC has been sought to maximize future DOE use of GSAM's capabilities.

Where appropriate, GSAM development has adapted and consolidated many existing analysis models. Significant efforts were committed in order to define the analytical needs, assess what models and data are currently available, and develop logical, cost-effective methods to convert and link various elements into an integrated design. The focus of GSAM development, however, has not been limited to currently defined needs and analytical requirements, nor has the system been narrowly defined to address a confined set of conditions. Rather, the models, databases, reports, and input procedures have been developed to assure maximum flexibility.

Environmental compliance costs are expected to increasingly influence operator decisionmaking. Costs associated with land management, drilling waste disposal, emission controls, and underground injection control (UIC) are a function of the regulatory requirements imposed at various levels. GSAM has been enhanced to analyze the direct cost of environmental compliance on future investments and operating costs, the unique location of the reservoir, and the general operating conditions. The expanded analytical capability to determine increases in compliance costs as a function of the regulatory scenario imposed on operators in various regions has been fully developed. This capability has been added to all modules of GSAM.

Data development efforts have resulted in the creation of a comprehensive database of nonassociated gas reservoirs for analysis in GSAM. This included the licensing and incorporation of NRG Associates' Significant Oil and Gas Field of the United States and The Significant Oil and Gas Pools of Canada databases, the evaluation of the undiscovered resource based on the U.S. Geologic Survey assessment and Canadian Geology Survey reports, and the addition and calibration of reservoir characterization for Appalachia and offshore regions. The result has been the rapid development of a data source that has been used in support of the DOE program.

GSAM development has also been planned and designed to be timely and responsive. Development was significantly accelerated to provide analytical capabilities to assist DOE in planning 
new initiatives. Also, the final methodology developed and discussed below was selected because of the speed and flexibility it provided in completing this research.

\section{B. DESIGN PHILOSOPHY}

GSAM is constructed to prevent obsolescence and provide for ongoing enhancements. GSAM has been developed in discrete modules that are linked, but can be validated and used on a stand-alone basis. This design feature ensures updating and enhancing of the system as new information and procedures become available. Additionally, GSAM uses a series of component databases, each specifically designed to allow separate updates as new data become available. The database structures have been generated to ensure consistency among different segments. Source documentation for all data elements has also been completed.

Because the analyses needed for a full GSAM run are complex, GSAM incorporates modules that perform the computer intensive resource and reservoir-level modeling prior to the user-initiated GSAM run. Based on expected future analysis needs, alternative scenarios (e.g., various R\&D, tax, or market strategies) can be modeled using the GSAM Reservoir Performance Module. This allows the user to analyze multiple technology, policy, or tax situations and store results for future use. This potentially reduces GSAM run-times by more than 80 percent in evaluations of multiple R\&D in policy strategies. The preprocessor (Reservoir Performance Module) output data are configured to accommodate changes in market conditions that would require new analysis in traditional models. The full explanation of these concepts is described in the Model Development Topical Report.

GSAM models the upstream natural gas system at the level where operators make investment and technology selection decisions-- the individual prospect or reservoir. Each component of the upstream evaluation methodology accommodates this level of detail:

- The resource base is characterized as individual reservoirs with average effective reservoir properties and, for known reservoirs, complete drilling and production histories. These units are further subdivided where appropriate to reflect intra-reservoir heterogeneities.

- Engineering costs and investment requirements are derived based on region, depth, and operating conditions of each zone.

- Technology is characterized by reservoir performance (flow rates and ultimate recovery) and cost parameters that are associated with applying a group of technologies in the specified reservoir setting.

- Production modeling accounts for unique interactions of geology, technology, and operating practices that influence gas recovery rate and ultimate volume for individual wells and reservoirs. 
- Project economics are evaluated on an industry-standard after-tax pro-forma basis for both full and incremental project bases. The cost for a project is set at the level of the commonly used authorization for expenditure evaluated under explicit timing and amounts of capital, operating and tax costs, and revenue streams.

- Decision-making incorporates the inherent uncertainties and inefficiencies in technology performance and gas markets.

The components of GSAM can evaluate the inherent uncertainties in resource characterization, technology application, reservoir performance, market economics, and operator decision-making. Two important benefits of including explicit risk analysis in GSAM are to provide insights into the value of better information and to estimate the range of possible outcomes of current or proposed policies under alternative resource, technology, or market scenarios.

Analysis of downstream issues such as gas demand, transmission, storage, imports, additional gas sources, pipeline capacity additions, and inter-fuel competition which can directly offset upstream operations, are aggregated to the regional level. The GSAM Integrating Model uses a linear programming algorithm to balance demand in various regions based on available supplies. The model then estimates future gas price tracks by region in order to balance supply and demand while maximizing discounted total surplus. The model also estimates future expansion of gas transportation and storage capacities across the pipeline network. This market dynamic model is a key component of the assessment of future technology applications. It allows analyses to directly consider the market impact on future gas prices, and therefore on the project economics of recovery operations.

\section{METHODOLOGY OVERVIEW AND SYSTEM CAPABILITIES}

The domestic gas market is an integrated, commodity-based system of supply, transportation, and demand. Regulatory changes have dramatically altered the once highly regulated gas industry. Demand and supply of gas are influenced and limited by market conditions and regional boundaries established by the existing infrastructure. GSAM has been designed and developed to fully assess, both regionally and nationally, the benefits and costs associated with the flow of gas from the reservoir to various end-users. Figure II-1 provides a schematic overview of GSAM's major analytical components. Each of these GSAM components is summarized below.

The domestic gas resource is large, diverse, and widely dispersed, both geologically and geographically. E\&P efforts encompass a broad range of activities and technologies. Many of these are explicitly designed for the specific characteristics of particular prospects or resources. Each is designed to improve the producibility and economics of the domestic natural gas resource. To fully meet its 
objective and assist DOE R\&D managers, GSAM must consistently address both conventional and unconventional gas resources and the many processes used to find, extract, and process natural gas for sale.

GSAM's methodology evaluates each activity as an investment opportunity at the appropriate unit of analysis. Exploration is evaluated on a fully risked prospect basis. For exploration to be conducted, the expected value of the next discovery must exceed the full cost of finding hydrocarbons (including dry holes) and ultimately developing and producing the potential discovered reservoir(s). Once a reservoir has been discovered, development and production from that reservoir must generate expected revenues to cover the investments, operating costs, and risks of development. Each investment decision is approached from the view point of an operator determining if the investment is warranted.

Figure II-1

\section{GSAM Structure}

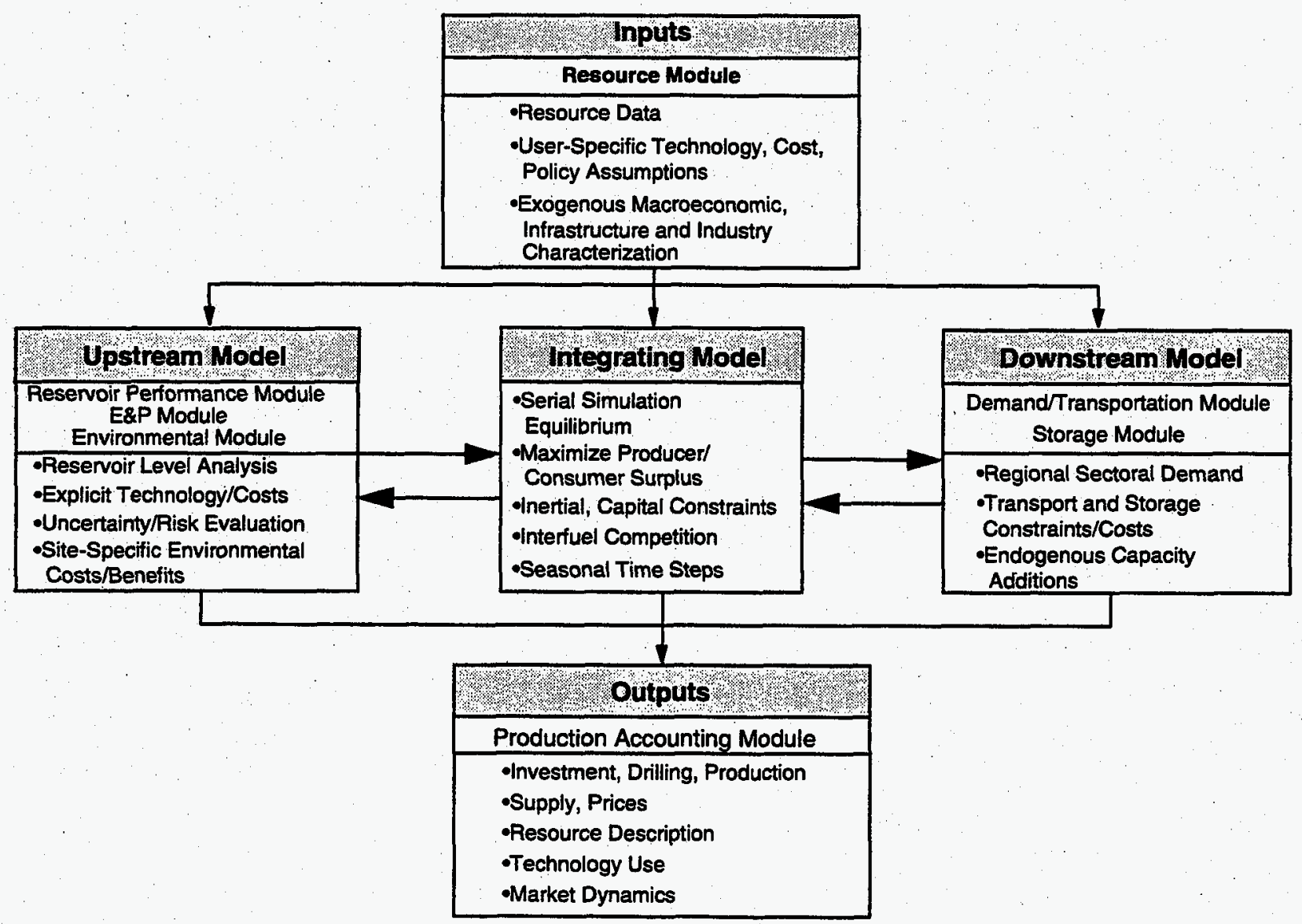


These evaluations integrate detailed information on reservoir geology, technology applications, productivity, costs, and market prices - the same information an operator in the field uses to select projects. Additionally, transportation and demand decisions are modeled from the viewpoint of the appropriate decision-maker, each attempting to maximize fully risked profit in a market context.

GSAM integrates these discrete decisions into a market framework. Investment decisions are evaluated based on contemporary market conditions (e.g., capital and rig availability, wellhead prices) consistent with the supply and demand of gas and the availability of infrastructure in various regions. E\&P activity that creates market imbalances (e.g., excess supply in a given region) must cover not only the direct extraction costs but also the additional costs of transporting the gas to its end-user. Based on aggregate activities in various supply and demand regions, GSAM equilibrates regional markets and prices over the forecast period. 'Figure II-2 displays a simple overview of GSAM's market balancing approach. The downstream model also explicitly addresses seasonal demand fluctuations that influence gas infrastructure, storage, and utilization capacity and investment decisions.

\section{GSAM Model Methodology}

The consistent evaluation of gas supply, demand, and transportation under alternative economic, technology, and regulatory conditions is the key objective of GSAM development. Figure II-3 provides a detailed view the logic flow of the Model. The integrated, modular design of data and analytical procedures maximizes flexibility in organizing, designing, implementing, and completing analyses. This structure also allows efficient model/data maintenance and enhancements in response to priorities derived from initial GSAM analyses and evolving gas R\&D program direction. 
Figure II-2

GSAM Market Logic Flow

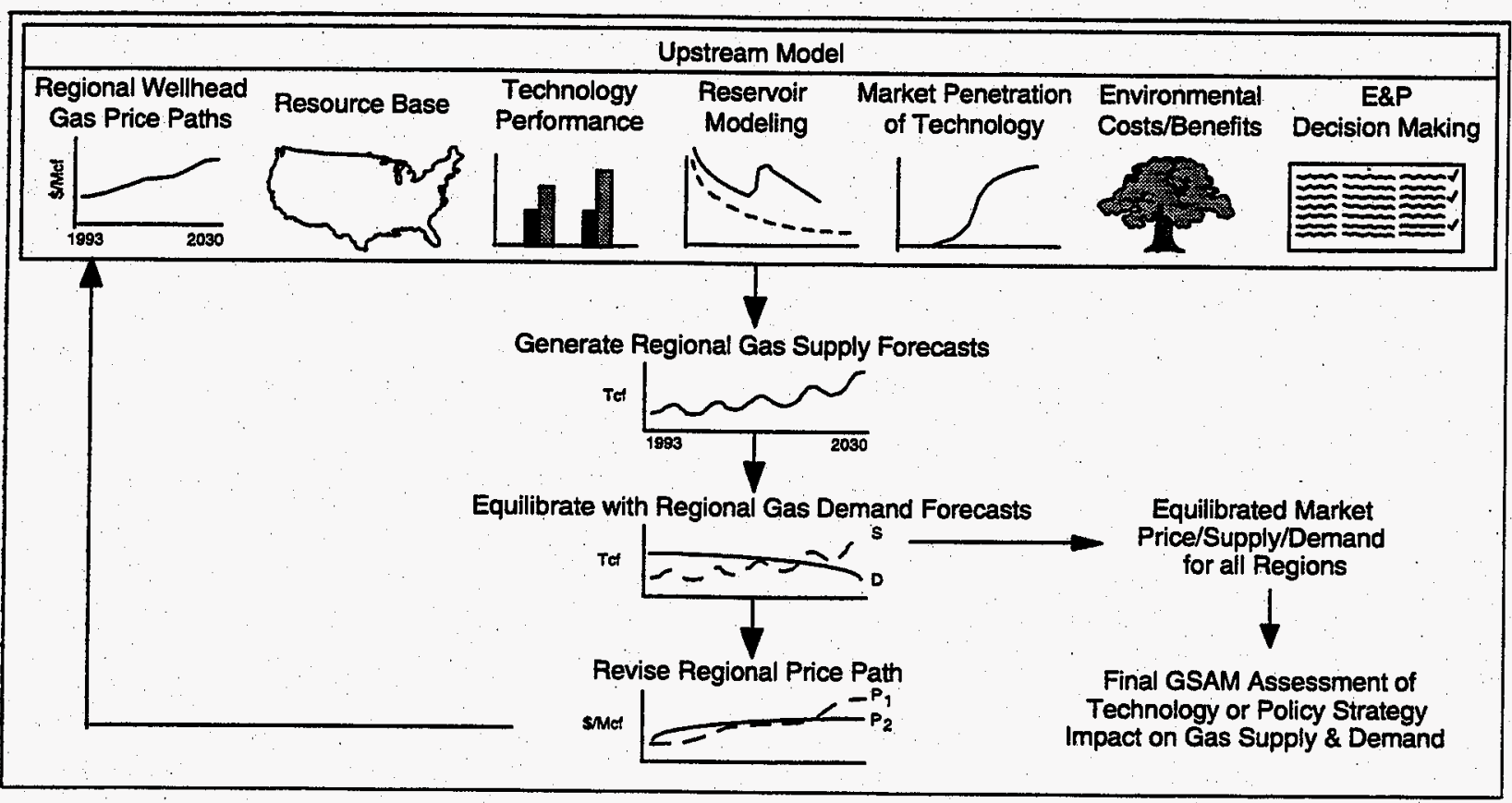

Figure II-3

GSAM Upstream Model Flowchart

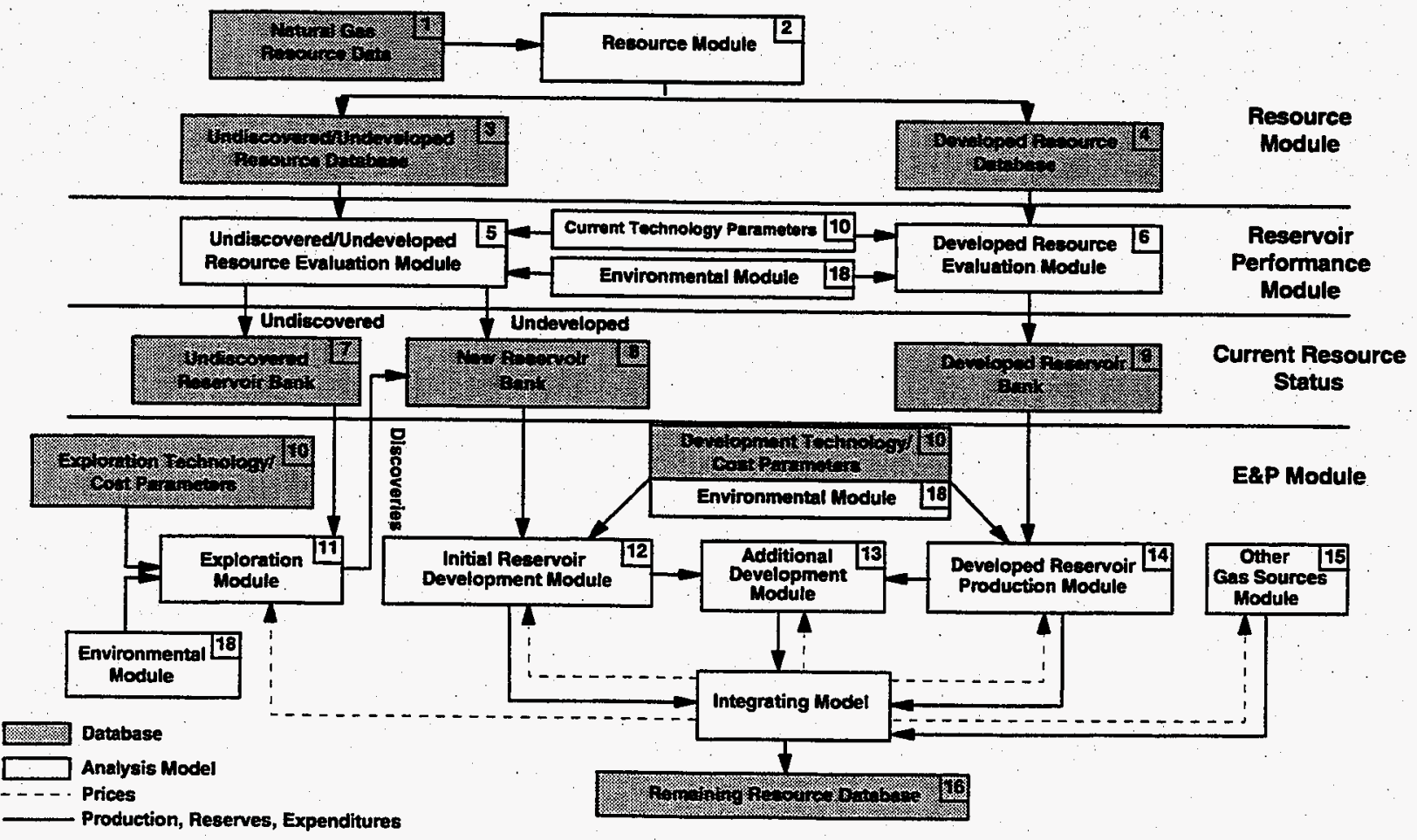


The remainder of this section provides an overview of the entire model. GSAM is grouped into the following modules:

- Resource Module. Translates reservoir properties into a prescribed GSAM data structure characterizing the North American gas resource base including existing and potential new storage projects. A parallel source database documents the origin or derivation of each data element;

- Reservoir Performance Module. Estimates future production from each gas reservoir based on the unique reservoir properties and technology conditions being considered. Performs summary economic analyses to provide a basis for analyzing investment alternatives;

- Storage Reservoir Performance Module. Characterizes storage reservoirs to predict both gas deliverability and injectivity, and associated economics;

- Exploration and Production Module. Simulates the exploration decisions and development schedules for individual reservoirs as a function of price and market constraints Computes annual gas production for each reservoir and aggregates this production to the play, regional, and/or national level;

- Production and Accounting Module. Calculates annual gas production, gross revenue, taxes, investments, operating costs, and operating profits, in addition to other pro-forma activities;

- Demand Module. Calculates the seasonal demand for gas in the residential, commercial, industrial, and electrical power generation sectors in distinct demand regions;

- Integrating Module. Balances supply, demand, and storage of gas in each North American region, and calculates market equilibrium prices and quantities.

Table II-1 provides descriptions of the individual modules and databases that comprise the entire Upstream Model.

The normal process of operating GSAM is shown in Figure II-4. GSAM design and development emphasizes the importance of proper accounting of resources by describing, quantifying, and evaluating the remaining domestic gas resource after production by selected technologies. The modular design provides an easy tracking capability within the model to monitor how technology is influencing gas recovery from various resource segments (Figure II-5). The Remaining Resource Database provides a balanced, accountable description of gas remaining to be recovered in various reservoir settings. These resources are targets for more aggressive $R \& D$ to overcome key physical or economic barriers to production. A key feature of GSAM is its ability to describe resources in terms of gas-in-place. Past reliance on recoverable gas as a unit of analysis has confounded the estimation of the impact of technology on reserve growth and recovery efficiency. 
Table II-1

GSAM Supply Model Components

1. Natural Gas Resource Data - Contains raw data on reservoir location rock and fluid properties, production, reserves, and development history.

2. Resource Module - Generates explicit and complete reservoir descriptions for known and undiscovered/undeveloped resources. Estimates characteristics and numbers of undiscovered reservoirs and the characteristics of known reservoirs (including, as appropriate, those reservoirs of record that are not explicitly identified in the database). Assigns individual reservoirs to fields and plays based on available information. Implements defaults as needed to pass complete reservoir descriptions to the Undiscovered/Undeveloped and Developed Resource Databases.

3. Undiscovered/Undeveloped Resource Database Comprehensive database that characterizes the numbers and properties of typical reservoirs of each field size class for each identified natural gas play. This database describes about 1,000 typical undiscovered reservoirs (100 significant gas plays with 10 size classes per play).

4. Developed Resource Database - Same format as the Undiscovered/Undeveloped Resource Database, but includes data on current developmentproduction status to define alternative future development options. This database includes an additional elements to account for associated dissolved gas in each region and any missing resource no accounted for in the raw data.

5. Undiscovered/Undeveloped Resource Evalua-tion Module - Estimates well recovery and economics for initial reservoir development (to "wide spacing") by size class and play under altemative technology and cost assumptions. Explicitly evaluates the effects of reservoir heterogeneity on production potential and economics. Estimates impact by evaluating three wells characterized by a distribution of those reservoir properties that affect storage and deliverability or other reservoir engineering components. The property distributions can be defined for each play type. Production profiles for initial development wells are stored for use in the analysis modules. Minimum acceptable supply prices for exploration, development, continued development, and continued operation are calculated and required elements stored for use in decision

analysis.
6. Developed Resource Evaluation Module - Evaluates known reservoirs to determine current development status and estimates potential for additional drilling, reserve addition, and production options. All reservoirs evaluated are either already developed to wide spacing, partially infilled, or approaching abandonment. Reservoirs are characterized based on current development status and incremental economics to continue current production and evaluate all possible additional development options. Fully characterized reservoirs are passed to the Developed Reservoir Bank.

7. Undiscovered Reservoir Bank - Contains information on all reservoirs not yet discovered or delineated by a new field wildcat well. Economic evaluation results, including required gas price to initiate exploration and development, and data on cost to continue development and production (in the event of decreased gas price), are contained in the file.

8. New Reservoir Bank - Contains all reservoirs discovered by the Exploration Module, including reservoirs that will be discovered by infield wildcats (new reservoirs in old fields). The file also contains economic analysis results including capital, drilling, sunk cost-basis required wellhead gas prices, indices to typical reservoir production profiles, and other data used to select newly discovered reservoirs for initial development. Reservoirs discovered by new field wildcats are aggregated in the bank by size class and play (roughly a 13 size class by 1,000 play matrix). In each model time period, successful new field wildcats "deposit" reservoirs to the bank and some portion of recently discovered neservoirs are "withdrawn" (i.e., developed).

9. Developed Reservoir Bank - Identical in structure to the Undiscovered and New Reservoir Banks. Provides development status of all known reservoirs and indicates the potential production and economics for alternative additional development options. Unlike the New Reservoir Bank that has "deposits" from the exploration module, Developed Reservoirs are only "deposited" once, at the beginning of the GSAM run. However, they are "withdrawn" rather rapidly since this bank feeds the Developed Reservoir Production Module, which implements ongoing development plans, and are then passed to the Additional Development Module. 
Table II-1

GSAM Supply Model Components (continued)

10. Technology/Cost/Geology Assumptions Represents user-specified or default technology performance assumptions, regional/resource-specific cost data, and geological assumptions on intrareservoir property distributions. Intrareservoir property distributions are specified based on geological appraisals of typical reservoirs in several generic play "types" (to be defined, but broadly based on lithology, depositional environment, or other gross factors that would significantly influence well-to-well distribution of reservoir properties). The technology assumptions used impact both the preprocessing modules, as well as the Exploration, Initial Development, Known Production, and Additional Development Modules. Technology advances can be modeled as either improved performance, reflected in higher volumes of gas production as predicted from type-curve analysis, improved economics, accelerated production, enhanced application over time (market penetration or decreased costs), or any combination.

11. Exploration Module - Estimates the distribution of reservoir size classes discovered by successful new field wildcats (NFW). The efficiency of exploration adopts traditional exploration modeling concepts as well as new, technology-dependent ones. Success is modeled as the relative proportions of reservoirs discovered in various size classes for each successful NFW. The distribution across size classes is based on remaining reserves in each class, aggregate volume/area as a proportion of each size class in a drilling area (prospects in several plays are usually tested in the same drilling program), and the ability of exploration technology to characterize those parameters that are size- or volume-related. The outputs of the modules are the composite (expected value) finding rate for the next successful NFW, the minimum wellhead gas price required to initiate exploration (including lease costs and dry holes), and the proportion of fields discovered in each size class. The Exploration Module "drills" NFW's in response to price signals and capital and drilling constraints issued by the Integrating Model. Exploration Module data outputs are passed to the New Reservoir Bank.

12. Initial Reservoir Development Module - "Develops" reservoirs in the New Reservoir Bank in response to price, demand, and constraint signals from the Integrating Model. Includes "suboptimization" algorithms to reflect imperfect demand and price signals as well as investment evaluation criteria other than minimum required price (e.g., reserve replacement, production maximization, differing utility functions, corporate distribution of investment opportunities). This module also handles major GSAM bookkeeping functions of vintaging production, capital expenses, and drilling
13. Additional Development Module - Estimates the capital, drilling, reserve addition, production, and required price for two development options in all known and newly discovered fields that have already been drilled to wide spacing: (1) infill (one drill-down only) and (2) recompletion of existing wells. Development options are based on data supplied by the Developed and Undiscovered/Undeveloped Resource Evaluation Modules. Since the combination of changing wellhead gas prices, technology availability, and reservoir depletion continuously alter development option economics, options are evaluated and characterized so that results of these evaluations can be adjusted without rerunning the reservoir and cost modules. This module implicitly contains an "additional reservoir development bank" that is similar in format and operation to the New and Undeveloped Reservoir Banks, but indicates as available only those development options that are technically feasible and economic at the appropriate time. Finally, as for other development modules in GSAM, no optimization of infill options is anticipated for a given reservoir. A reservoir is infilled if it is preferred relative to other currently available options for that reservoir, eliminating the consideration of a currently economic reservoir "waiting" for advanced technology or higher prices.

14. Developed Reservoir Production Module "Completes" the current development phase of reservoirs in the Developed Reservoir Bank in response to price, demand, and constraint signals from the Integrating Model. Determines appropriate levels of production from existing wells, and the future production profile to the point where additional development can take place. Provides for curtailment of current production in producing reservoirs if wellhead gas prices decrease or operating costs increase.

15. Other Gas Sources Module - Contains data and analytical modules on LNG, synthetics, associated gas and other potentially important or emerging sources of gas.

16. Remaining Resource Database - Repository for unproduced gas resource. Data on resource and marginal costs of next producible increment of gas for each identified reservoir are stored for future analysis. Provides full accounting of remaining gas resource by type (undiscovered, discovered/undeveloped, developed/uncontacted, contacted/uneconomic). Can be assessed during model run for quality control reasons or for further analysis (e.g., abandonments, evolving research targets, etc.). 
Figure II-4

Major Components of the ICF Gas Modeling System

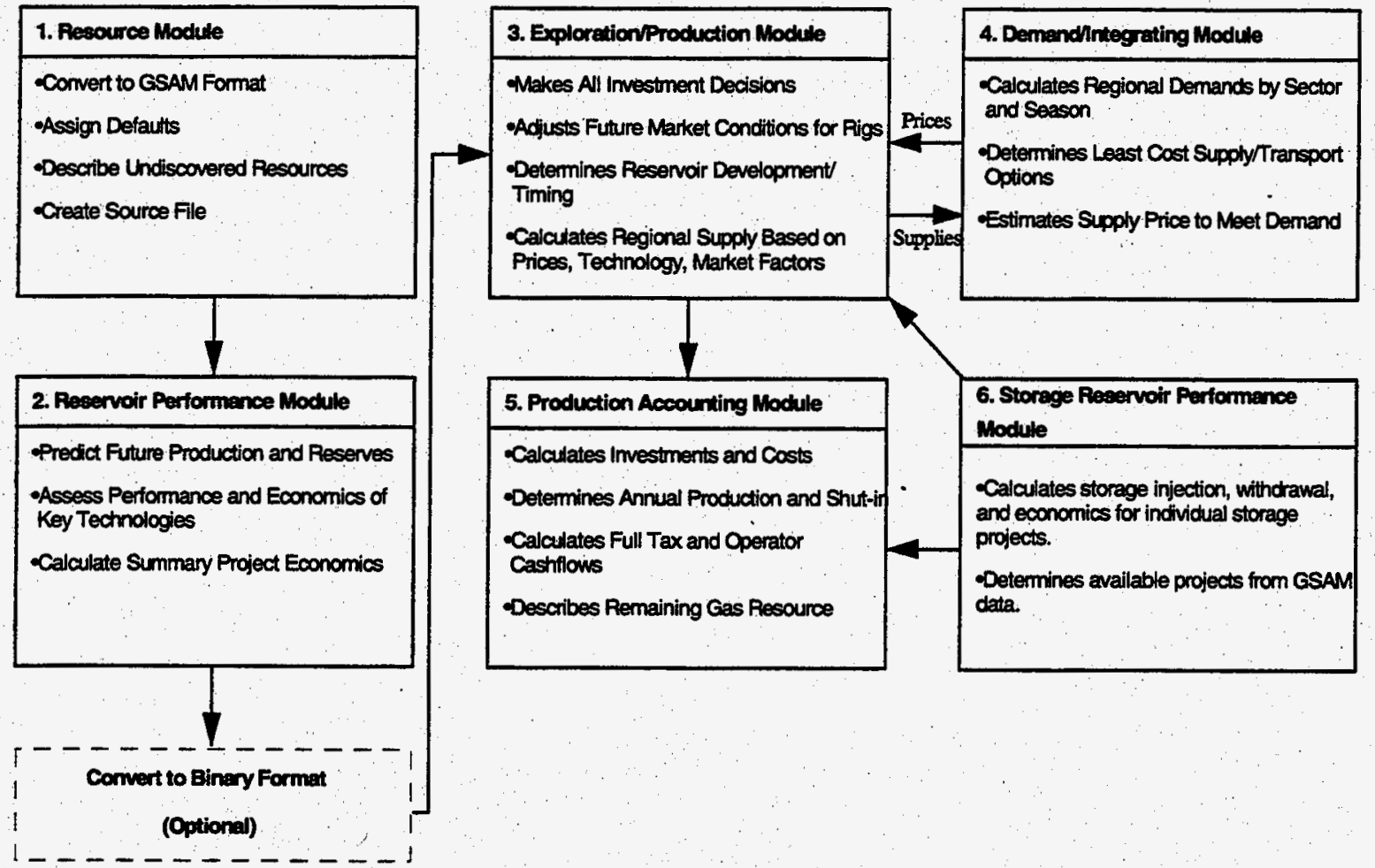

Figure II-5

Analysis of Natural Gas Resources by GSAM Analytical Modules and Databases

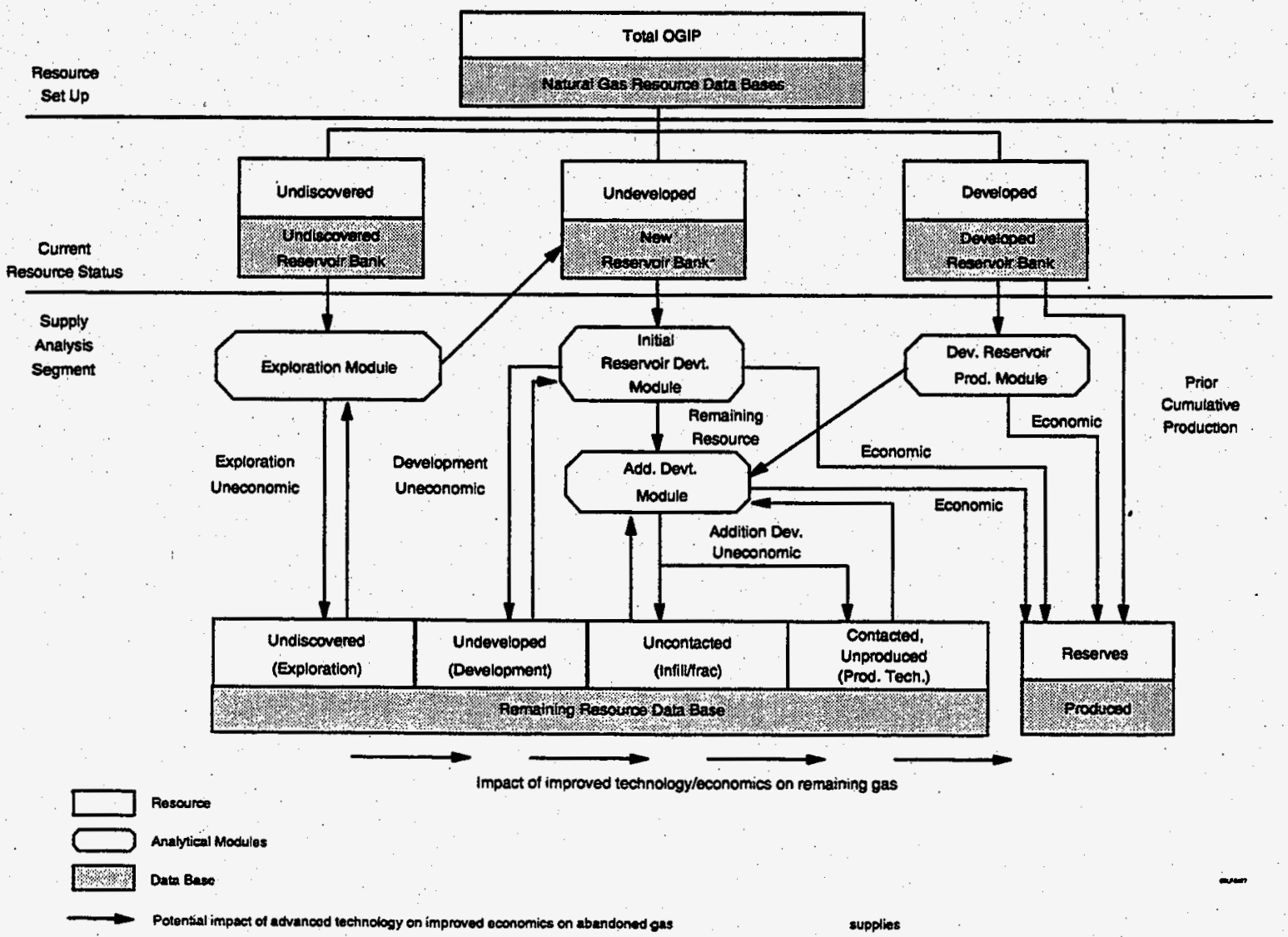


GSAM's modeling methodology provides a comprehensive evaluation of the natural gas resource and key E\&P issues by making major analytical advances in scope of analysis units, full volumetric accounting for gas resources, and efficient preprocessing that allows for more extensive analysis than was previously possible. However, these assessments will not be complete without further analysis and integration to determine how the market for natural gas impacts technology commercialization and reservoir profitability. The following sections describe how GSAM analyses can be integrated into the full-system gas market.

\section{Demand and Integrating Module Methodology}

Traditional technology appraisal methods that estimate the impact of new technology on selected resources are inadequate to derive the full benefits of R\&D. The GSAM methodology goes beyond evaluating gas supplies to explicitly modeling the full impact of technology and policy changes on the timing and magnitude of technology commercialization. Natural gas cost reductions due to improved technology may have limited value if they fail to stimulate production to meet market demand. Despite lower costs of producing specific segments of the resource, these supplies may ultimately be higher in cost to the end-user. To correctly and completely evaluate the market impact of various competing technologies and policies, GSAM includes a comprehensive model of the downstream (gas demand) segment. Figure II-6 displays the logic and data flow of GSAM's current end-use demand model.

Analysis of demand for natural gas includes regional assessment of consumption by sector. The GSAM methodology uses existing models of residential, commercial, industrial, and electric utility requirements for gas to determine demand within the demand regions. The end-use projections rely on user-specified macroeconomic parameters (e.g., population, economic growth, etc.) that directly influence the overall demand for natural gas. Inter-fuel competition is also explicitly analyzed within GSAM. End-users in the industrial and utility sectors have substantial fuel switching capacity, capable of using natural gas, oil, or coal as needed. GSAM explicitly analyzes the future impact of inter-fuel competition on regional and sectoral demand.

The Demand and Integrating Modules provide the breadth and depth of evaluation consistent with the role of GSAM in E\&P policy and R\&D planning and evaluation. The regional equilibration of supply and demand is accomplished to provide realistic estimates of North American gas market performance. 
Figure II-6

GSAM Demand Model Flowchart

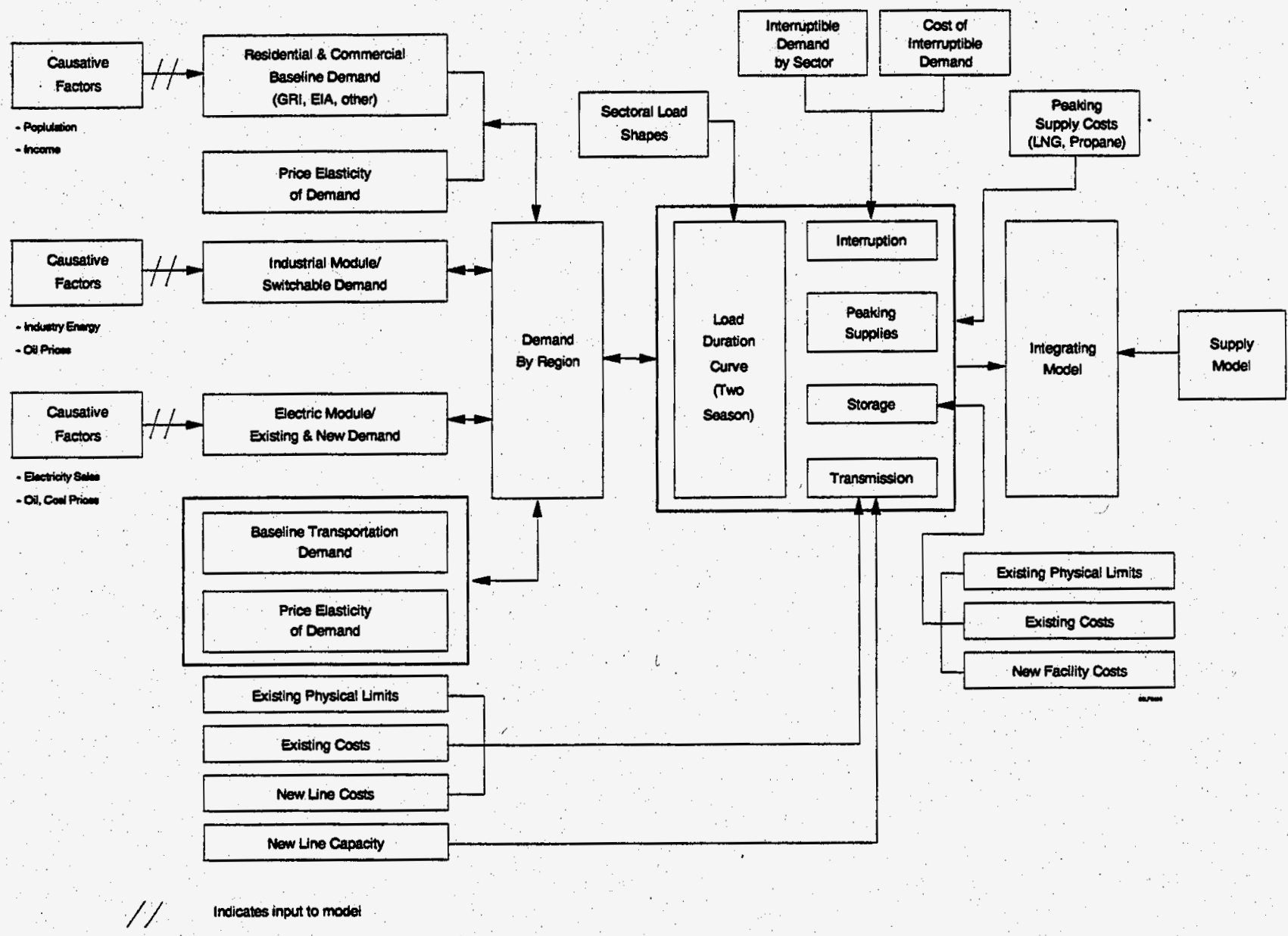

GSAM explicitly evaluates gas transportation and storage that are among the most important issues targeted by DOE's DNGOI. The ability of existing infrastructure to cost-effectively move gas to market is modeled by GSAM as transport links between supply and demand regions. In addition, the integrated approach provides for the evaluation of adding capacity or new service pipelines when market limitations and economics dictate, accounting for seasonal demand fluctuations and storage and other peaking options. The explicit evaluation of seasonality provides FETC a unique opportunity to evaluate storage reservoir performance, the need for additional capacity, and alternative strategies to merely developing more storage reservoirs.

The Integrating Module equilibrates annual gas prices and sales volumes over a multi-year period. The regional assessments of supply and demand must be reconciled to determine inter-regional gas flows and resulting regional gas prices. GSAM uses a linear programming technique to equilibrate 
gas price and volumes against physical capacity and economic constraints among and within supply regions, demand regions, and over transport links (Figure II-7).

The Demand and Integrating Modules also perform important accounting and equilibration of investments and available infrastructure, observing existing and probable future constraints. Similar to the Upstream and Downstream Models that provide input to it, the Integrating Module approaches decisions from an investor's viewpoint. It attempts to balance supply and demand in each region by the least-cost strategy that balances (fully risked) producer or consumer surplus, as appropriate. Figure II-7 shows the transportation infrastructure currently used in GSAM to estimate supply and demand balance.

Figure II-7

GSAM Transportation and Supply/Demand Region Map

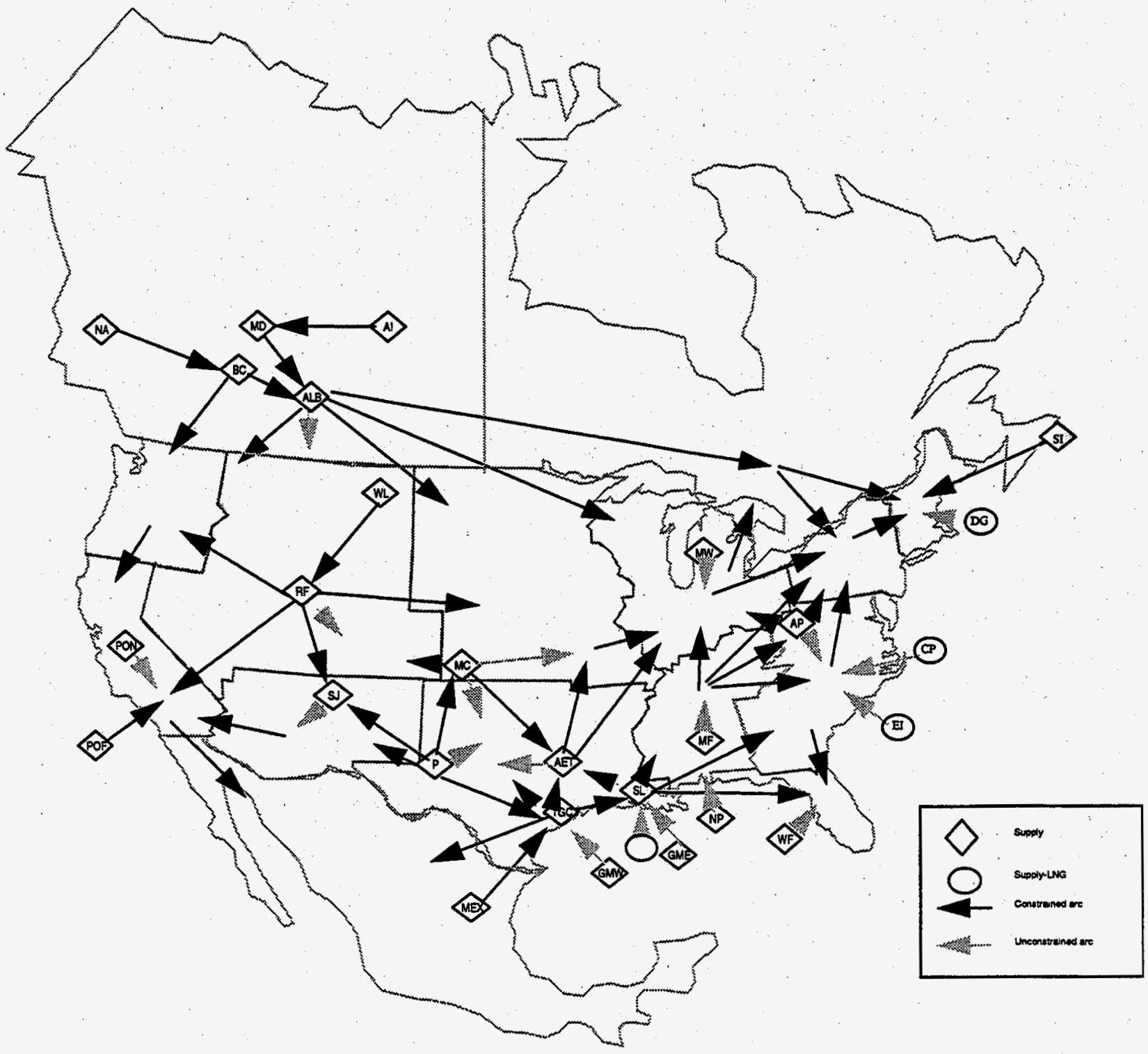




\section{GSAM Outputs}

The results from the Integrating Module provide a verifiable and credible basis to forecast future gas supplies and prices, based on user-specified E\&P technology and policy assumptions. However, it also captures the resulting market events that are likely to impact demand for gas. The reports generated from this integrated market evaluation provide valuable insights into strategies for maximizing the current and future value of the domestic gas resource.

GSAM output is designed and formatted for flexible use in post-processing and extended analysis. Tabular reports are structured to allow direct export for use by spreadsheets, databases, and graphics software. The output formats for the various modules ensure easy compatibility with other systems models and databases. Current research has designed a detailed graphical user interface (GUT) to display and analyze results of GSAM runs.

GSAM output includes significant detail on production, consumption, technology use, resource status, and gas price by region over time. Additional economic variables detailing operator-view economic pro forma, as well as public sector benefit analyses are also available from GSAM reports in the Production Accounting Module. The modular design provides the user with capabilities to focus analyses on items of interest and, by varying input or output options, create special application reports for use in further analysis. Additional information and flexible report formats are available to determine reservoir-specific production and economic summaries, regional, state or resource output, and national summaries.

Potentially most important and relevant to DOE are the GSAM summary outputs of technologyrelated variables. Technology summaries, including the number, types, costs, and benefits of various applications, are provided in standard reports. Technology market penetration and applicability in various regions or specific reservoir settings can be derived from these standard reports.

Quality control indicators are also included in all GSAM output. Internal consistency and external congruity provide users with assurance of data and model validity and plausibility. The level of disaggregation in GSAM provides the potential to generate output in formats similar to other, more aggregate models for direct comparison. 


\section{GSAM DEVELOPMENT}

GSAM research over the past year has substantially enhanced the accuracy, credibility, and scope of the system. This section documents the recent results and continuing efforts for GSAM development.

\section{A. REVIEW OF MODEL STRUCTURE}

\section{Background}

During the period of performance, July 1, 1997 - June 30,1998, some at DOE raised questions about the natural gas production profile produced by GSAM. In particular, concern was focused on the predicted decline in gas production after the year 2005. Various working groups were formed to examine specific parts of the model and explore what factors were causing this decline in production. Technology penetration, horizontal wells, as well as resource issues were investigated. The resource component was a series of questions and answers, given below.

\section{Results}

Presented below is a series of questions and answers developed in correspondence between ICF Resources and DOE. The questions from DOE in general dealt with the assumptions underlying GSAM's resource database.

1. Question: Which USGS estimate (5\%, 95\%, mean) for undiscovered resource should we compare the GSAM figures for undiscovered resources? Is GSAM actually $100 \mathrm{Tcf}$ short of USGS $95 \%$ ?

Response: GSAM resource values are based on the mean USGS estimates. In order to calculate the reserve values in GSAM's input resource base begin with the OGIP figures for the undiscovered reservoirs / pools in the GSAM regions, and use a $68 \%$ recovery factor to estimate the recoverable reserves equivalent. Table III-1 shows that the total undiscovered OGIP resource in GSAM is 834 Tcf. This translates to recoverable reserves of $567 \mathrm{Tcf}$, and when combined with 41 Tcf Associated-Dissolved gas estimates, the total gas recoverable reserve estimate in GSAM works out to 608 Tcf. This figure compares favorably with USGS mean undiscovered recoverable reserves estimate of 617 Tcf. This USGS estimate does not include the reserve growth value of $322 \mathrm{Tcf}$. 
Table III-1

\begin{tabular}{lc} 
GSAM Region & $\begin{array}{l}\text { Total } \\
\text { Resource }\end{array}$ \\
& (OGIP), TCF \\
\hline Appalachia & 103.9 \\
MAFLA Onshore & 28.5 \\
Mid-West & 19.0 \\
Arkla-East Texas & 15.6 \\
So-Louisiana & 15.3 \\
Texas Gulf Coast & 84.8 \\
Permian & 22.8 \\
Mid-Continent & 29.7 \\
San Juan & 57.3 \\
Rockies Foreland & 290.0 \\
Williston & 74.8 \\
Pacific Onshore & 9.8 \\
North Alaska & 82.5 \\
\hline & \\
Total Undiscovered & 833.8
\end{tabular}

2. Question: Are there any regions where there is a significant difference between the GSAM region and USGS region?

Response: GSAM has more regions than the USGS and its regions are distinct and different from the USGS regions in most cases. Therefore, a direct comparison with the USGS regions will not yield comparable values. GSAM regions, however, are comprised of distinct USGS plays, and a comparison at this level would result in identical values for the resource base.

It should also be noted that GSAM resource values do not include Associated-Dissolved gas estimates. Associated Dissolved gas estimates by various GSAM regions come from ICF Resources' COPM (Crude Oil Policy Model) and are added to the total resource estimates for each of the GSAM regions in the model.

3. Question: Why are there no undiscovered fractured or water drive reservoirs in GSAM?

Response: The characteristics of the undiscovered reservoirs are tied to the properties of the underlying geologic play. In GSAM, the properties for a play are assigned on the basis of the properties for the proved producing reservoirs in that play. The play is classified based on the resource type for the majority of the reservoirs in that play. Hence, if the majority of reservoirs in a play are conventional, the play is classified as conventional. To the best of our knowledge, none of the USGS plays which 
correspond to the GSAM plays are classified by USGS as being either water drive or naturally fractured. A new characterization based on recently available, updated NRG data may result in a different characterization.

4. Question: In the input database, there are large values in resource types 4 and 5 that do not appear in GSAM outputs. Why?

Response: The answer to this question is an extension of the previous response. The input database (for discovered proved resources) has reservoirs that are classified and evaluated as fractured or water drive reservoirs in the reservoir performance model based on the reservoir/geologic properties information from the NRG database. However, the play is classified based on the resource type of the majority of reservoirs in that play. As the E\&P Module categorizes by play, the output for the fractured and water drive type reservoirs in these plays gets placed in a bin according to the resource classification of the play. We are not aware of any published data that allows us to compare production forecasts for water drive and naturally fractured type reservoirs. EIA and GRI also have only one aggregate "conventional" classification for this resource type.

5. Question: Are the discovered tight reservoir values appropriate? What do we have to compare them with?

Response: All the discovered producing reservoir information built into the GSAM database originates from the NRG Associates' US Significant Oil and Gas Fields Database, which is a comprehensive database of all the domestic oil and gas fields. A reservoir is classified as tight if it has an effective horizontal permeability of less than 0.1 millidarcies.

6. Question: Is the predominance of size class 12 in the discovered reservoirs data for Appalachian basin of any importance?

Response: Not to the best of our knowledge.

7. Question: Does GSAM have undiscovered and discovered elements in the A-D gas category?

Response: The Associated-Dissolved gas information in GSAM is derived from the Crude Oil Policy Model (COPM). COPM has both proved and undiscovered production information, and hence the A-D gas in GSAM has both the discovered and undiscovered components to it. 
8. Question: Does GSAM truly explore fields or reservoirs? When it finds something, is it a single reservoir, or is it the largest reservoir in a field containing various smaller fields to be found during later development activities over the time frame suggested by USGS? Does the curve-fitting algorithm that estimate recoverable estimates by field size class work on fields or reservoirs?

Response: GSAM explores on a play level. It does not explore for an individual reservoir or accumulation. An exploration program is evaluated based upon the remaining population of reservoirs/accumulations in a play and the underlying technology and cost. In most instances an accumulation is a reservoir. The exception is with stacked reservoirs. This was recognized at the 1997 Peer Review and will be investigated as part of the current GSAM development.

The exploration program finds a Baysean distribution of reservoirs/accumulations in the play using sampling without replacement. Development only proceeds when an entire reservoir/accumulation becomes discovered.

The curve-fitting algorithm works on a reservoir/accumulation basis.

9. Question: How does GSAM convert EUR to OGIP? Does it use a constant value of $68 \%$ or does it vary?

Response: GSAM does not convert EUR to OGIP, but rather converts OGIP to EUR. Recoverable reserves in GSAM are calculated explicitly for each individual reservoir depending on the reservoir/geologic properties, the type curve used, and the type of technology used for developing the reservoir in the Reservoir Performance Module. The input to the GSAM modules only contains a resource-in-place estimate and the associated volumetric information. The Reservoir Performance Module calculates the technically recoverable reserve information explicitly for each individual reservoir.

10. Question: Does GSAM use consistent units (standard cubic feet of gas) throughout all its modules to account for the changes in gas volumes as pressures vary through the system?

Response: GSAM uses standard cubic feet of gas as the unit of analysis consistently throughout all its modules. In the Reservoir Performance Module, the type curve computation is performed at the reservoir conditions (reservoir temperature and pressure). In addition, the losses in the tubing are computed at the average reservoir pressure and temperature of the system. Once the flow computations are accomplished, the units are converted back to standard cubic feet for reporting purposes. 
11. Question: Does GSAM keep track of all gas resources through a run so that all the gas available for production in model year 1 can be accounted for as produced, in reserve, abandoned, etc., in the final model year (is a mass balance of gas maintained)?

Response: Yes, GSAM keeps track of all gas resources throughout a run and has a closed material balance at the end (see Table III-2)

12. Question: Why doesn't the USGS specify the tight resource as either discovered or undiscovered?

Response: The tight gas resources in GSAM undiscovered resource database compares well with the USGS estimates published in their CD-ROM DDS30. We have spoken with the USGS and they tell us that what USGS has captured in this publication is the remaining undiscovered reserves in the United States. Based on our conversation with USGS, we understand that the tight/CBM resources are indeed future reserves.

13. Question: Why doesn't GSAM separate discovered from undiscovered associated-dissolved gas?

Response: Only an oil model is appropriate to determine how much of the discovered and undiscovered associated-dissolved gas gets produced in association with the discovered and undiscovered crude oil production. Associated-dissolved gas estimates in GSAM are made available from COPM (Crude Oil Policy Model). This includes a projection of annual production, which GSAM layers to its projection of production from non-associated gas resources. Hence, while the distinction between undiscovered and discovered portions of the associated-dissolved gas might be relevant, it should be handled in COPM and not in GSAM. As stated earlier, GSAM itself does not explore and develop associated-dissolved gas resources.

14. Question: Does GSAM under-report OGIP for areas/resource types with low recovery factors and overestimate OGIP for areas/resource types with high recovery factors? The use of a national average of $68 \%$ recovery may cause a problem of this type.

Response: This issue has been discussed earlier (see Question 11). A play-based approach to determining the OGIP estimates is the technically sound methodology and can easily be represented in GSAM. 
Table III-2

Undiscovered Óriginal Gas in Place

Material Balance by Resource Type

(Tcf)

\begin{tabular}{|l|r|r|r|r|r|}
\hline & $\begin{array}{c}\text { Beginning } \\
\text { Undiscovered } \\
\text { Resource }\end{array}$ & $\begin{array}{c}\text { Newly } \\
\text { Discovered } \\
\text { Resource }\end{array}$ & $\begin{array}{c}\text { Calculated } \\
\text { Ending } \\
\text { Undiscovered } \\
\text { Resource* }\end{array}$ & $\begin{array}{c}\text { Reported } \\
\text { Ending } \\
\text { Undiscovered } \\
\text { Resource }\end{array}$ & $\begin{array}{r}\text { Reported - } \\
\text { Calculated }\end{array}$ \\
\hline Conventional & 310 & 90 & 220 & 220 & 0 \\
Tight & 455 & 294 & 161 & 161 & 0 \\
Associate-Dissolved & 0 & 0 & 0 & 0 & 0 \\
Natural Fracture & 0 & 0 & 0 & 0 & 0 \\
Water Drive & 0 & 0 & 0 & 0 & 0 \\
Coal and Shale & 70 & 47 & 23 & 23 & 0 \\
Analyzed Resource & 327 & 107 & 220 & 220 & 0 \\
Total US & 1162 & 537 & 625 & 625 & 0 \\
\hline
\end{tabular}

${ }^{*}$ Calculated $=$ Beginning - Discovered

Discovered/Undeveloped Original

Gas in Place (Tef)

\begin{tabular}{|l|r|r|r|l|r|r|}
\hline & $\begin{array}{c}\text { Beginning } \\
\text { Discovered } \\
\text { Resource }\end{array}$ & $\begin{array}{c}\text { Newly } \\
\text { Discovered } \\
\text { Resource }\end{array}$ & $\begin{array}{l}\text { Reveloped } \\
\text { Resource }\end{array}$ & $\begin{array}{l}\text { Calculated } \\
\text { Ending } \\
\text { Discovered } \\
\text { Resource* }\end{array}$ & $\begin{array}{c}\text { Reported } \\
\text { Ending } \\
\text { Discovered } \\
\text { Resource }\end{array}$ & $\begin{array}{l}\text { Reported - } \\
\text { Calculated }\end{array}$ \\
\hline Conventional & 50 & 90 & 110 & 30 & 29 & -1 \\
Tight & 74 & 294 & 280 & 88 & 87 & -1 \\
Associate-Dissolved & 0 & 0 & 0 & 0 & 0 \\
Natural Fracture & 0 & 0 & 0 & 0 & 0 \\
Water Drive & 0 & 0 & 0 & 0 & 0 \\
Coal and Shale & 9 & 47 & 49 & 0 & 0 \\
Analyzed Resource & 21 & 107 & 108 & 7 & 0 \\
Total US & 154 & 537 & 548 & 143 & 19 & -1 \\
\hline
\end{tabular}

${ }^{*}$ Calculated $=$ Beginning + Discovered - Developed

Reserves (Tof)

\begin{tabular}{|l|r|r|r|r|r|r|}
\hline Resource Type & $\begin{array}{c}\text { Initial } \\
\text { Reserves }\end{array}$ & $\begin{array}{c}\text { Reserve } \\
\text { Additions }\end{array}$ & $\begin{array}{c}\text { Cumulative } \\
\text { Production }\end{array}$ & $\begin{array}{c}\text { Calculated } \\
\text { Ending } \\
\text { Reserves }\end{array}$ & $\begin{array}{c}\text { Reported } \\
\text { Ending } \\
\text { Reserves }\end{array}$ & $\begin{array}{l}\text { Reported- } \\
\text { Calculated }\end{array}$ \\
\hline Conventional & 117 & 88 & 166 & 39 & 39 & 0 \\
Tight & 22 & 188 & 146 & 64 & 64 & 0 \\
Associate-Dissolved & 49 & 0 & 40 & 9 & 0 \\
Natural Fracture & 0 & 0 & 0 & 0 & 0 & 0 \\
Water Drive & 0 & 0 & 0 & 0 & 0 & 0 \\
Coal and Shale & 8 & 29 & 26 & 11 & 11 & 0 \\
Analyzed Resource & 37 & 74 & 96 & 15 & 15 & 0 \\
Total US & 234 & 378 & 474 & 138 & 138 & 0 \\
\hline
\end{tabular}

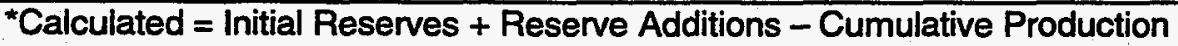


15. Question: A more documented and detailed comparison of the available data on reserves is needed.

Response: Reserves figures from GSAM and EIA are compared below:

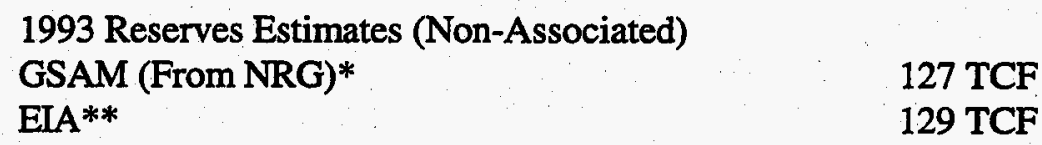

*Does not include Appalachia, Alaska

**U.S. Crude Oil, Natural Gas and Natural Gas Liquids Report (1993), excluding Appalachia and Alaska

16. Question: Does GSAM distribute the undiscovered resource appropriately among fields of various sizes? The correctness of the field size class assignments is in question. More information is needed in this area.

Response: Irrespective of the average field size that GSAM considers for each field size class, the total resource is not affected. As we have pointed out, each USGS field size class is a range, and the value that GSAM has inherited appears to be the higher end of this range. Since this number is used consistently across all the modules of GSAM, it should not make any difference to the resource base characterization in GSAM.

We have gone back to USGS recently, and learned that they had revised the field size class definitions for their 1995 assessment. The range of values for the field size classes used in their latest assessment was, unfortunately, not a part of the DDS 30 or 36 CD-ROMs. The Table is produced below for the information of the workgroup members. 
Table III-3

1995 USCS Field Size Class Definitions

\begin{tabular}{|cc|}
\hline Field Size Class & USGS Recoverable Reserves (BCf) \\
\hline 5 & $3-6$ \\
6 & $6-12$ \\
7 & $12-24$ \\
8 & $24-48$ \\
9 & $48-96$ \\
10 & $96-192$ \\
11 & $192-384$ \\
12 & $384-768$ \\
13 & $768-1536$ \\
14 & $1536-3072$ \\
15 & $3072-6144$ \\
16 & $6144-12288$ \\
17 & $>12288$ \\
\hline
\end{tabular}

17. Question: Can the resource type-by-play assignments in the EP module be improved so that GSAM outputs include gas volumes in the fractured and water-drive categories? The likely answer is yes. The EP module uses USGS resource type assignments for undiscovered plays, which don't include water drive and fractured; however, data from NRG on discovered fields in the play should indicate those plays that are likely to be dominated by water drive and fractured reservoirs.

Response: Neither USGS nor EIA distinguish between water drive and natural fractured resource in its Conventional Category. NRG data could be used to distinguish the resource types of the partially discovered plays; which could potentially be water drive or natural fractured or pure conventional. In case a play contains reservoirs of different resource types; the play could be split into sub-plays for each of the resource types, and then the sub-play characterization could be utilized to allocate the resources in the EP module.

18. Question: Does GSAM appropriately characterize the economics of undiscovered tight resources? Preliminary data suggest that these reservoirs are assigned surprisingly-low MASPs. Further work is needed to determine if this effect is real and appropriate, and whether corrective action is necessary.

Response: As part of the discussion of this topic, we have produced the attached Figure III-1, which plots development MASP as a function of permeability times net pay for both current and advanced technology. For current technology, it shows that a vast majority of the MASP's are above \$2/Mcf only large reservoirs with high $\mathrm{Kh}$ values have MASP below \$1/Mcf. With advanced technology, the number 
of reservoirs with MASP's less than $\$ 1 / \mathrm{Mcf}$ increases very much. We can discuss this during our conference call.

Also, we have taken a preliminary look at permeability and its impact on production. In the NRG database, data values for permeability are provided to the first decimal place. As a result permeability values for tight are either 0.1 millidarcies or zero. The resource module has a default for permeability when no value is provided in the database. Approximately $90+\%$ of the undiscovered tight reservoirs/accumulations have permeabilities of 0.1 .

We have performed a set of three runs using different permeability settings for the tight to test its sensitivity. The runs used permeabilities of $0.1,0.05$, and 0.01 . All results are relative to the base case in which the permeability was set to 0.1 . We found that with a permeability of 0.05 the production in the year 2010 was about $40 \%$ lower than the base case. With a permeability of 0.01 , the production was about $80 \%$ lower than the base case and about the same level as the 1995 production. We believe that this subject of resource properties should be discussed further. 


\section{Figure III-1}

Permeability-Net Pay vs. Development MASP* for Undiscovered Tight Reservoirs

\section{Current Technology}

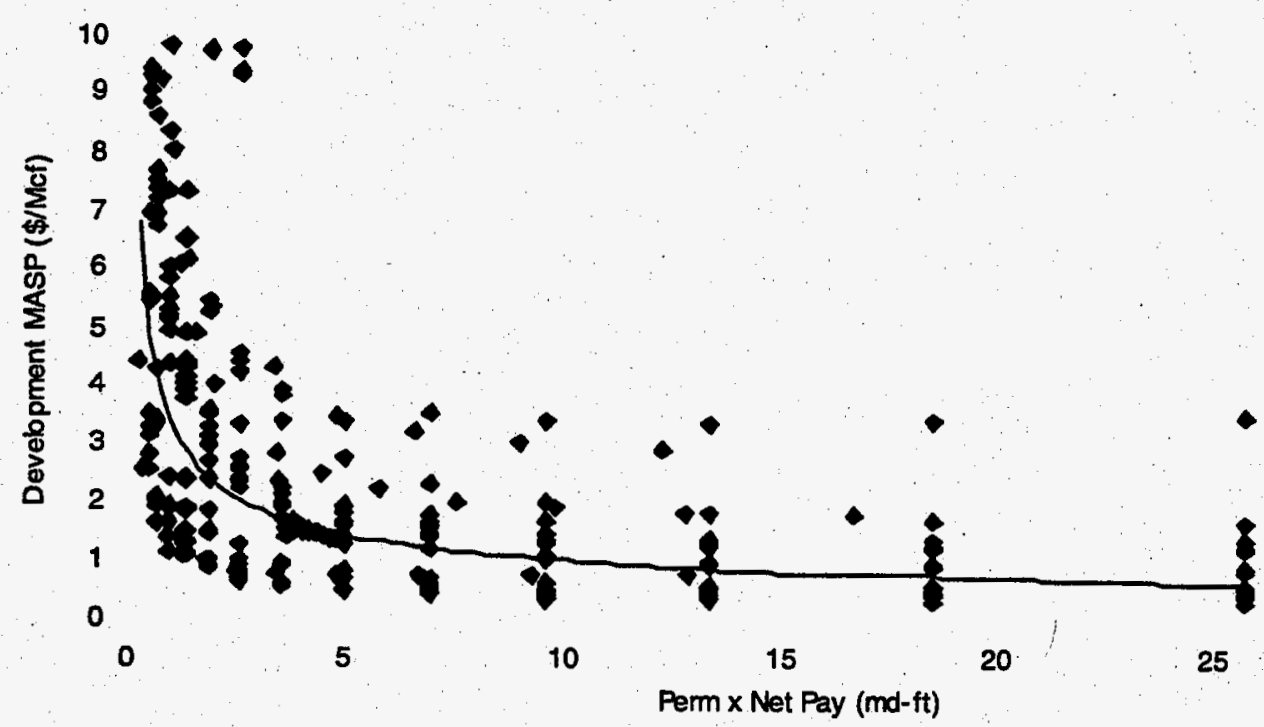

*Unadjusted for exploration and environmental costs

Advanced Technology

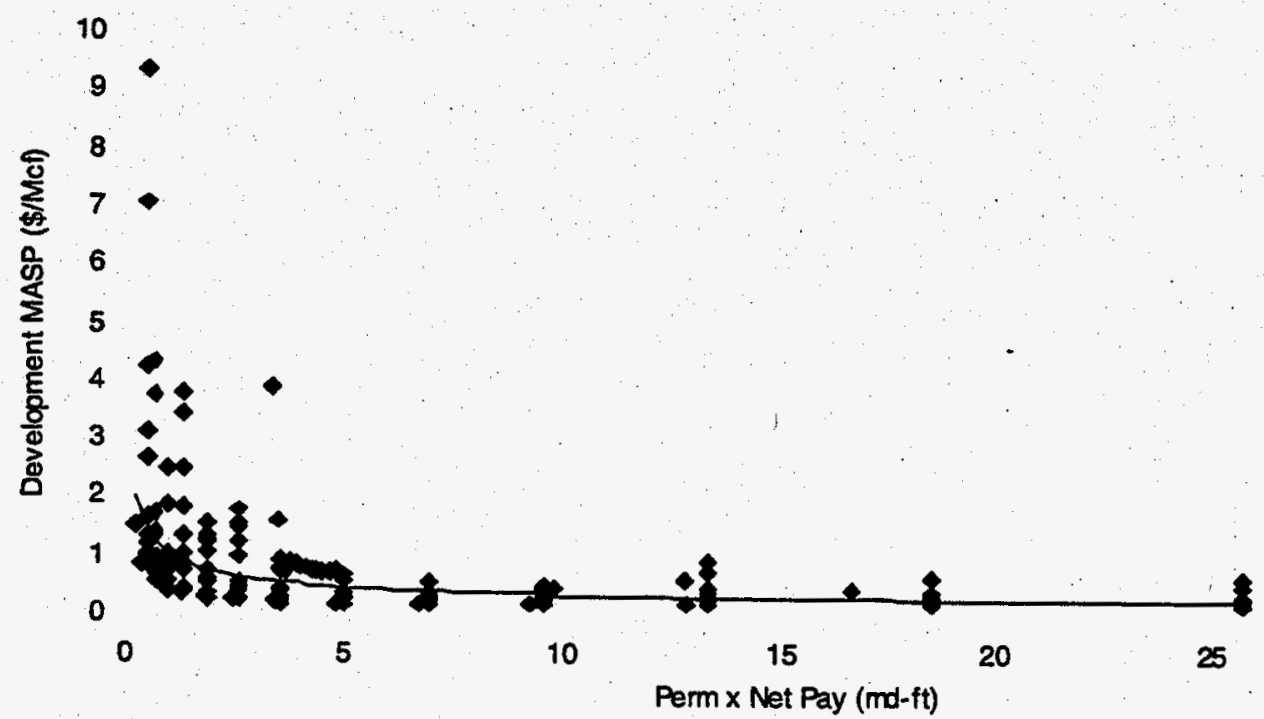

* Uhadjusted for exploration and environmental costs 


\section{Conclusion}

Through the investigation of horizontal wells, technology penetration curves, and the GSAM resource base, ICF and DOE were able to better understand and document some of the critical features of the model. These discussions led to a resolution of the "hump" issue, the predicted decline in the natural gas production profile after the year 2005. A thorough review of model structure, including some slight modifications to the Resource Module, and the incorporation of the concept of "reserve growth" in the supply model led ICF to the solution. See the next section of this report for a discussion on the new reserve growth routine in GSAM. 


\section{B. RESERVE GROWTH}

\section{Background}

Historically, the initial estimates of the recoverable reserves in newly discovered gas fields are significantly lower than what is ultimately recovered from these fields in their productive life. As time goes on, estimates of a gas field's ultimate recovery tend to increase. These typical increases in estimated ultimate recovery over time are termed "reserve growth". A typical case presented by USGS in a particular natural gas field illustrates this phenomenon. A gas field discovered in Texas in the mid1940's had, in 1977, an estimated ultimate recovery of 2.1 trillion cubic feet (TCF). By 1991, the estimated ultimate recovery of the field had increased to 3.1 TCF. Over the 15-year period reserve growth totaled 1 TCF of gas. ${ }^{1}$ This can be seen in Figure III-2.

\section{Figure III-2}

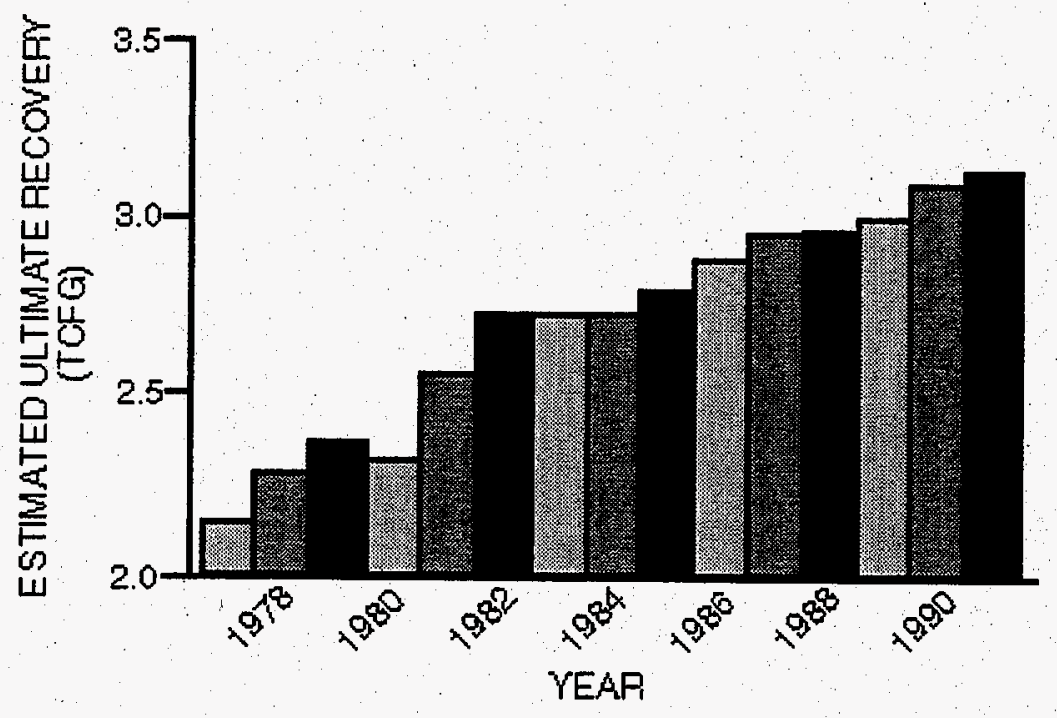

Increases such as those seen in this Texas gas field are typical of many U.S. gas fields. Figure III-3 shows the additions to U.S. proved reserves from 1978 to 1993 . The chart shows that reserve growth of natural gas in existing U.S. fields totaled 205 Tcf, while initial size estimates of new-field discoveries totaled only 31 Tcf.

\footnotetext{
${ }^{1}$ USGS Fact Sheet FS-202-96
} 


\section{Figure III-3}

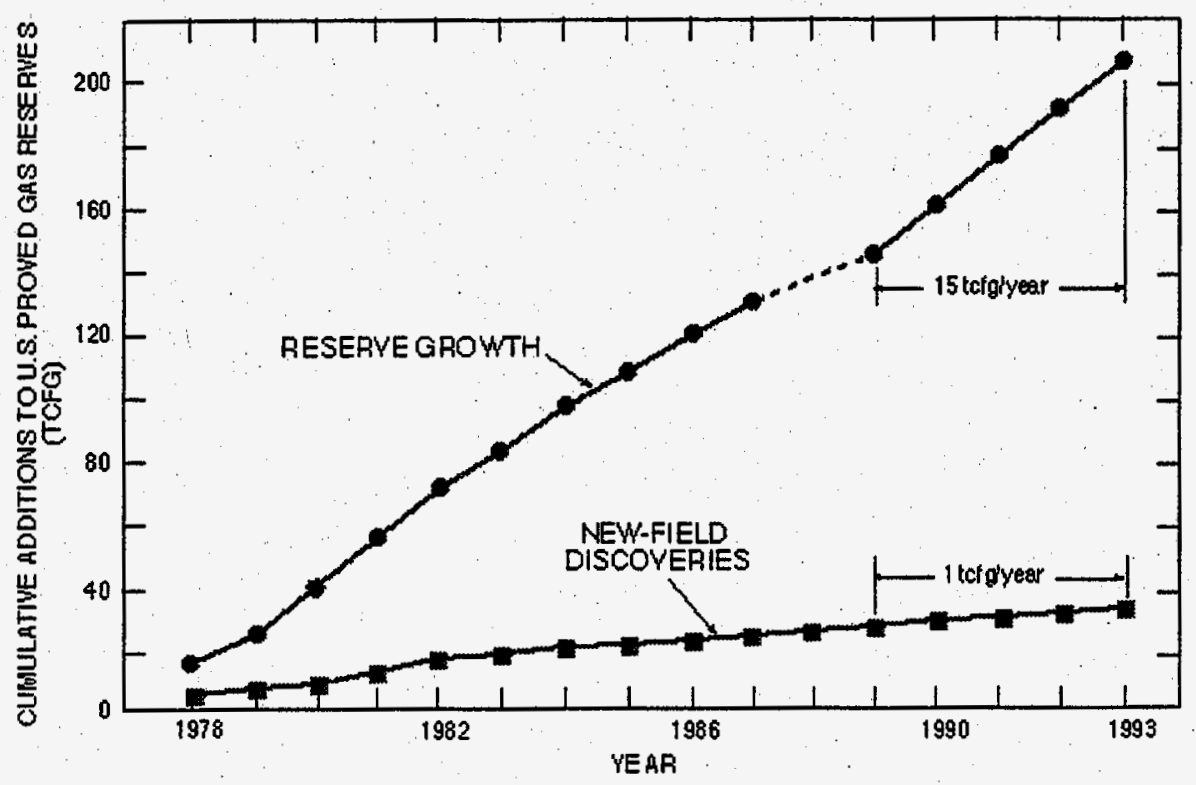

Reserve growth is caused by: 1) physical expansion of fields by areal extensions and development of new producing intervals, 2) improved recovery resulting from new technology, and 3) upward revisions based on production experience. ${ }^{2}$

Clearly reserve growth is a fundamental piece of the North American natural gas profile. Until GSAM development year six, there was no previous accounting for this phenomenon in the model. The Exploration and Production Module now, however, incorporates reserve growth in its calculations of North American natural gas production and the effected resource base.

\section{Results}

The reserve growth component of GSAM is designed in the following manner. A certain amount of resource is considered available to be assigned to reserve growth. This amount is calculated at the beginning of any GSAM run. A non-decreasing portion of this resource becomes available in succeeding time periods, according to a schedule set in an E\&P Module file.

More specifically, the functioning of this "new Exploration and Production Module" is as follows:

The E\&P Module file UNDBNK.SPC controls the amount of discovered undeveloped resource in the U.S., as well as a multiplier for the undiscovered resource. The file appears below: 


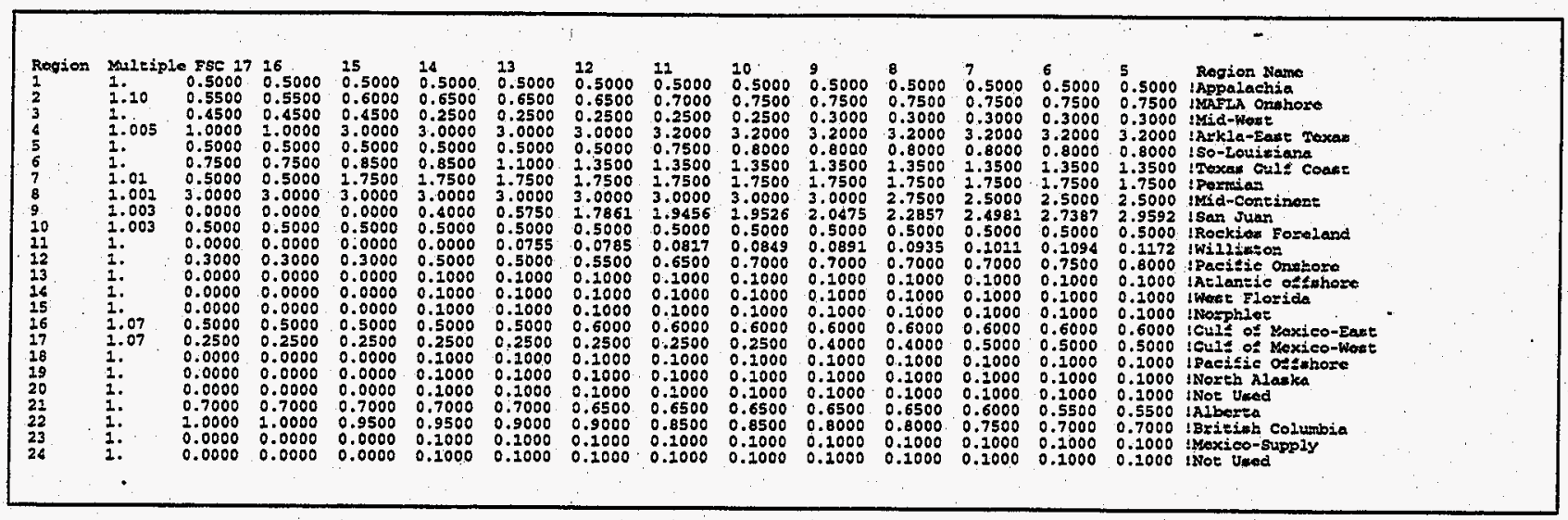

The left-hand side number in this file is the multiple. It is a factor that is applied to the undiscovered OGIP in every field size class, resulting in a revised estimate of the undiscovered resource in a region. The series of numbers to the right of this factor are also multipliers. These numbers are multiplied to the undiscovered number of reservoirs in a field size class to generate a new number for each field size class. This new number is the total amount available to be assigned to reserve growth over the entire GSAM run. Note that these right-hand side factors are on top of the left-hand side multiple, so that if, in a particular field size class and region, both of the multipliers are 2 , then the amount available for reserve growth is four times the original undiscovered resource estimate.

Production in the model can come from two sources: either discovered producing reservoirs or the drilling of discovered undeveloped resource. The discovered undeveloped resource in GSAM is "created" in one of two ways. It may come from exploration of undiscovered resource, or it may be from the resource base that is considered "available for reserve growth". Resource moves from the reserve growth category to the discovered undeveloped category by the "availability" schedule in the file RESAVRG.SPC. An example of some of the entries in this file appears below:

$\begin{array}{lrr}\text { W Drive } & 1995 & 6.0 \\ \text { Unconv } & 1995 & 8.0 \\ \text { Analyzed } & 1995 & 8.0 \\ \text { Conv } & 2000 & 16.0 \\ \text { Tight } & 2000 & 45.0 \\ \text { Rad Flow } 2000 & 21.0 \\ \text { Lin Flow } & 2000 & 16.0 \\ \text { W Drive } & 2000 & 16.0 \\ \text { Unconv } & 2000 & 10.0\end{array}$

\footnotetext{
${ }^{2}$ USGS Fact Sheet FS-202-96
} 
The number in this file is simply a multiplier indicating how much of the resource in the available for reserve growth category is to be placed into the discovered undeveloped category in any given year. In that the estimates of the ultimate recovery of reserves have historically grown over time, this routine in GSAM also grows reserves through time, and effectively models the concept of "reserve growth".

A more formal definition of the functioning of the new reserve growth routine follows:

For a single field size class in a single region, time period, and resource type,

$D P=f(D / U, D T E C$, economics $)$

and

$D / U=f(E T E C, D T E C, U)+R G * A R G_{t 0}$

and

$\mathrm{ARG}_{\mathfrak{t} 0}=\mathrm{LHS} * \mathrm{RHS} * \mathrm{U}$

Where:

$\mathrm{DP}=$ Production from discovered producing resource

$\mathrm{D} / \mathrm{U}=$ Discovered undeveloped resource

DTEC $=$ Development technology penetration rate

economics $=$ Production economics of reservoirs (MASP)

ETEC $=$ Exploration technology penetration rate

$\mathrm{U}=$ Undiscovered OGIP in a field size class

$\mathrm{RG}=$ Reserve growth schedule value from RESAVRG.SPC file

$A R G_{t 0}=$ Total resource available to be assigned to reserve growth

\section{Conclusion}

The incorporation of reserve growth was the primary factor in the solution to the "hump" issue, where GSAM predicted a decline in gas production after the year 2005. Allowing for this concept allowed the GSAM resource base grow in a fashion consistent with both the theory of reserve growth, and the continued increasing production of U.S. natural gas.

Reserve growth is a critical element in the dynamics of the North American natural gas market. Now that it has been incorporated into GSAM, the model is more able to make accurate predictions consistent with the trends in historical reserves data. 


\section{FEDERAL TECHNOLOGy PENEtRation \\ Background}

Many natural gas reservoirs in the United States are located on land owned by the Federal government. This land is leased to private producers, who extract the gas (or oil) from the Federal lands, in exchange for royalty payments. Because of Federal Government policy and other development issues, practices on these lands are inherently different from those not on Federal lands. A methodology was, therefore, developed in GSAM to treat reservoirs that are on Federal lands.

Several factors affect the extraction of gas from Federal lands. The Federal policy constraints, the competing desires of preservation and revenue, and other elements, lead to a development environment different from that on non-Federal lands. This is modeled in GSAM through a separate technology penetration curve for resource existing on Federal lands. It also aids in studying the impact of acceleration in technology penetration in reservoirs on Federal lands due to R\&D programs and initiatives of Federal Government agencies, such as DOE.

To arrive at a technology penetration rate on Federal lands, two steps were undertaken. The first involved assembling the location and reservoir property data (identifying which reservoirs were on Federally-owned land), and the second was the implementation of a Federal lands technology penetration curve into GSAM.

\section{Results}

\section{Data Gathering}

To incorporate separate technology penetration for reservoirs on separate Federal lands, reservoirs that are located on Federal lands were identified. The GSAM reservoir database is derived from the NRG Associates' Significant Oil and Gas Field Database. This database does not indicate whether a reservoir is on Federal land, so this data had to be obtained and incorporated.

The data on the geographic extent of Federal lands is from a working copy of Arc/Info coverage of Federal lands from the U.S. Geologic Survey. The link between the geography of the reservoirs and the 14,763 reservoirs in the NRG database was made by Earth Science Associates (ESA), which worked as a subcontractor on this task. For undiscovered reservoirs, a USGS-defined geologic play level 
distribution of undiscovered resources into those on the Federal portion of the play was incorporated into GSAM.

\section{Data Methodology}

For discovered gas resource, fields in the NRG database were placed into four Federal lands categories, based on the distance of field centroids from Federal lands boundaries. The four categories are below:

1. Fields greater than 10 miles within Federal lands,

2. Fields from $\mathbf{0}$ to 10 miles inside of Federal lands,

3. Fields from 0 to 10 miles outside of Federal lands, and

4. Fields greater than 10 miles outside of Federal lands.

This was done through the subcontractor, using the NRG data and the Arc/Info system. The categories are illustrated in the following diagram:

\section{Figure III-4}

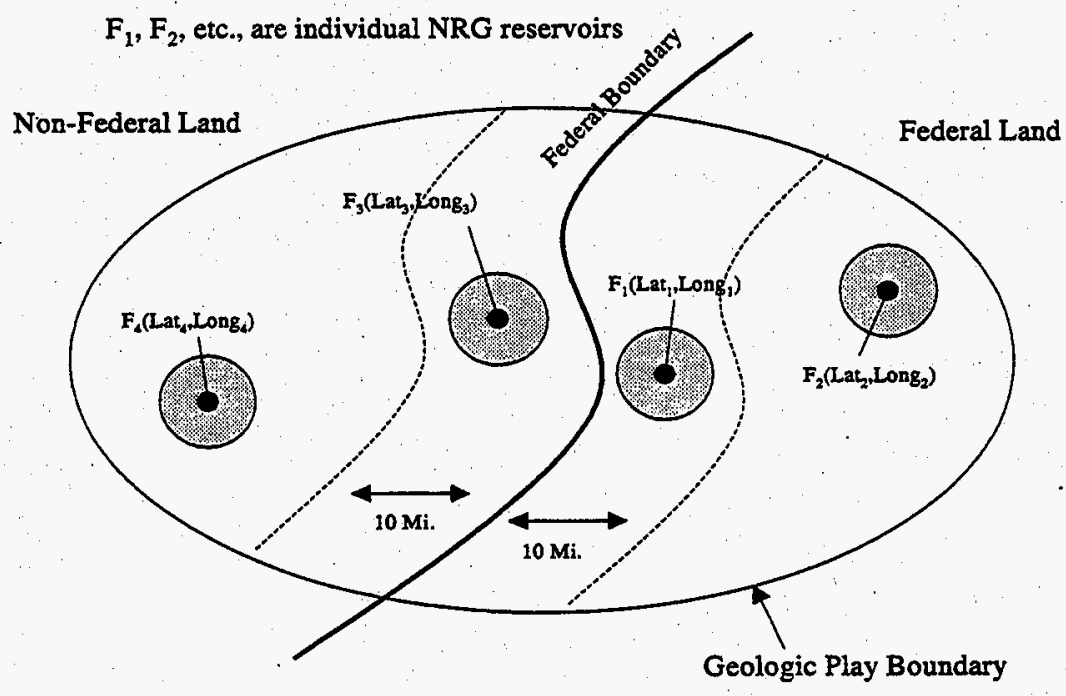

The discovered gas fields were placed into these categories because of the nature of gas fields. There could be a significant amount of gas in a field at some distances from the field centroid. This fact could lead to an incorrect estimate of the amount of gas located on Federal land. If, for example, a field's centroid is 2 miles inside a Federal boundary, a large amount of its gas could lie outside of the boundary, and vice-versa. If a field is more than 10 miles from a boundary, then it is a safe to assume that most if 
not all of the field's gas does not cross the boundary. This methodology leads to a simple estimate of the upper and lower bounds on the volume of gas that is on Federal land. The upper bound for this measure can be found by taking the volumes of all of the gas within Federal lands (both 10 miles and less than 10 miles within) and all of the gas on non-Federal land within 10 miles of the boundary. Similarly, the lower bound on the amount of gas on Federal land is the volume of the gas in all of the fields than are on Federal land at a distance of 10 miles or greater from the boundary.

Federal lands data for the undiscovered reservoirs used a different methodology. It was derived from USGS estimates by play of the percentage of oil and gas resources on Federal lands. These percentages considered the distribution of Federal lands relative to the geology of the play and to the distribution and intensity of exploration activity in the play.

\section{Implementation}

Discovered reservoirs are given a different treatment than undiscovered reservoirs in applying a Federal technology penetration curve.

Discovered producing reservoirs are assigned a Federal land indicator $(1$ or 0$)$ which identifies whether the reservoir is located on Federal land. The indicator is in the *.GSM data files.

The percentage of undiscovered reservoirs on Federal lands is derived from the USGS play-level percentages. All undiscovered accumulations, hence reservoirs, located in a play are assumed to have the same Federal percentage. For example, if USGS play 2356 contains $60 \%$ Federal resource (residing on Federally-owned land) then all reservoirs in this play are assumed to be $60 \%$ and $40 \%$ non-Federal. This percentage data resides in the Exploration and Production Module file PLY_DFN.SPC, and is read in the Reservoir Performance Module.

The Reservoir Performance Module transfers the Federal land data for discovered and undiscovered reservoirs to the Exploration and Production Module, where the Federal technology penetration routine is performed. The technology penetration rates for resource on Federal land are incremental, that is, they are applied on top of the exploration and development technology penetration rates already in the model. The increments are specified for all years, and are applied to all resource types. follows:

The effective technology penetration rate for either development or exploration is calculated as Effective Technology Penetration = 


$$
=b \operatorname{tpr} x(I-\text { fedfrac })+(b t p r+f e d i n c) x \text { fedfrac }
$$

Where: btpr $=$ base technology penetration rate

fedfrac $=$ Federal land fraction

fedinc $=$ Federal land technology penetration increment

Note that when a reservoir is completely on Federal land, the first term in the effective technology penetration equation becomes zero, so that the incremental technology penetration is simply added to the base. When a reservoir is not on Federal land, the second term in the equation becomes zero. In this case, the effective technology penetration rate is the same as the base technology penetration rate. For undiscovered reservoirs, the calculation is less intuitive. Assume that a play containing undsicovered reservoirs has $60 \%$ of its accumulations (reservoirs) on Federal land. Also assume that for a given year and resource type, there is a rate of $50 \%$ technology penetration, and a Federal increment of $10 \%$. Using these values in the formula yeilds:

$$
\begin{aligned}
& \text { Effective Technology Penetration }= \\
& =.5 \times .4+(.5+.1) \times .6=56 \%
\end{aligned}
$$

So that for this play with undiscovered accumulations, given a year and resource type, there is an effective technology penetration rate of $56 \%$.

\section{Conclusion}

The addition of federal lands data in the GSAM database and the incorporation of a federal technology penetration curve give GSAM even more versatility and scope when assessing policy decisions. GSAM is now poised to be a critical tool in the analysis of the complex issue of development policy on federal lands. 


\section{GAS StORAGE/ ANNUAL MODEL}

\section{Background}

Previous to the period of performance (July 1997- June 1998), GSAM modeled the supply and demand of natural gas based on a two seasons model. The first season was "winter", or the season when gas from storage reservoirs is extracted, and the second was "non-winter", or when gas is injected into storage reservoirs. In accordance with the recommendations of the Peer Review Workshop (see Annual Technical Report Contract Year 5, "Development of a Natural Gas Systems Analysis Model", p. 20), GSAM's treatment of storage reservoir performance was expanded from the 2-season model to a 4season model. This expansion led to the incorporation of a 4-season model in the Demand Module. In addition, commensurate with the recommendations of the Peer Review, the decline rate in storage reservoir extraction/injection rates were changed from $5 \%$ per year to $3 \%$ per year.

Also, previous to the period of performance, GSAM predicted the supply, demand and transportation flows of natural gas for every 5 years, beginning in 1995 (1993 was also used). That is, GSAM output contained data for, commonly, the years 1993, 1995, 2000, 2005, and 2010. Although a forecast for these years is valuable to policy planners and decision-makers, an even more valuable tool is an "annual model" in which predictions for prices, quantities, and other values in the North American natural gas marketplace occur every year. In what follows, the improvements to GSAM in both the storage and annual components are described.

\section{Results}

\section{Storage Model}

Gas storage is an important component of the natural gas industry. With the move towards less regulation in the electric power industry, gas storage will become even more critical. Gas-fired electric power plants will require reliable high capacity sources of gas available on short notice. High deliverability storage can fill that need. The industry experts at the February 1997 Peer Review Workshop felt that storage was an important component of GSAM and should be enhanced to improve GSAM's ability to model future storage needs in a changing natural gas marketplace. In addition, peak shaving needs could only be adequately modeled by using more than two seasons. The future role of LNG in the marketplace will likely depend on future needs of peak shaving. In this regard, the industry experts recommended the move to a 4-season model because of the importance of storage. 
The two-season structure of the GSAM Demand Module was adequate for simulating the effects that seasonal price changes have on seasonal gas demands and the effects that the total annual demand has on gas supply. However, two seasons do not adequately simulate the decisions that the gas industry must make regarding the capacity tradeoffs for pipelines, gas storage and peak shaving. With only two seasons, the calculations for using and adding storage capacity versus pipeline capacity favor pipeline capacity, and peaking capacity is not economic. The problem is that the average demand levels of two seasons fail to capture the dramatic short-term demands for gas that occur in cold winter periods. Adding two additional short-term seasons to the GSAM Demand (and Storage) Module addresses this problem.

GSAM now includes a four season model on the downstream side in which the number of days in each season are as follows:

Table III-4

Four Season Model Storage Schedule

\begin{tabular}{lll}
\hline Season & Description & Number of days \\
\hline 1 & & \\
2 & Possible storage extraction & 5 \\
3 & Possible storage extraction & 26 \\
4 & Possible storage extraction & 90 \\
\hline
\end{tabular}

In addition, the Storage Reservoir Operator Module (SROM) has been incorporated to simulate the economic behavior of storage reservoir operators. In SROM, for each reservoir, 3 extraction profiles (options) are analyzed.

In option 1 , the operator extracts gas for the first 5 days at the rate $E_{5}$, the next 26 days at the rate $E_{26}$, and the remaining 90 days at the rate of $E_{90}$. For the remaining 244 days gas is injected into the reservoir and it is assumed that the reservoir is brought back to the original condition after every re-fill. See Figure III-5 below. 
Figure III-5

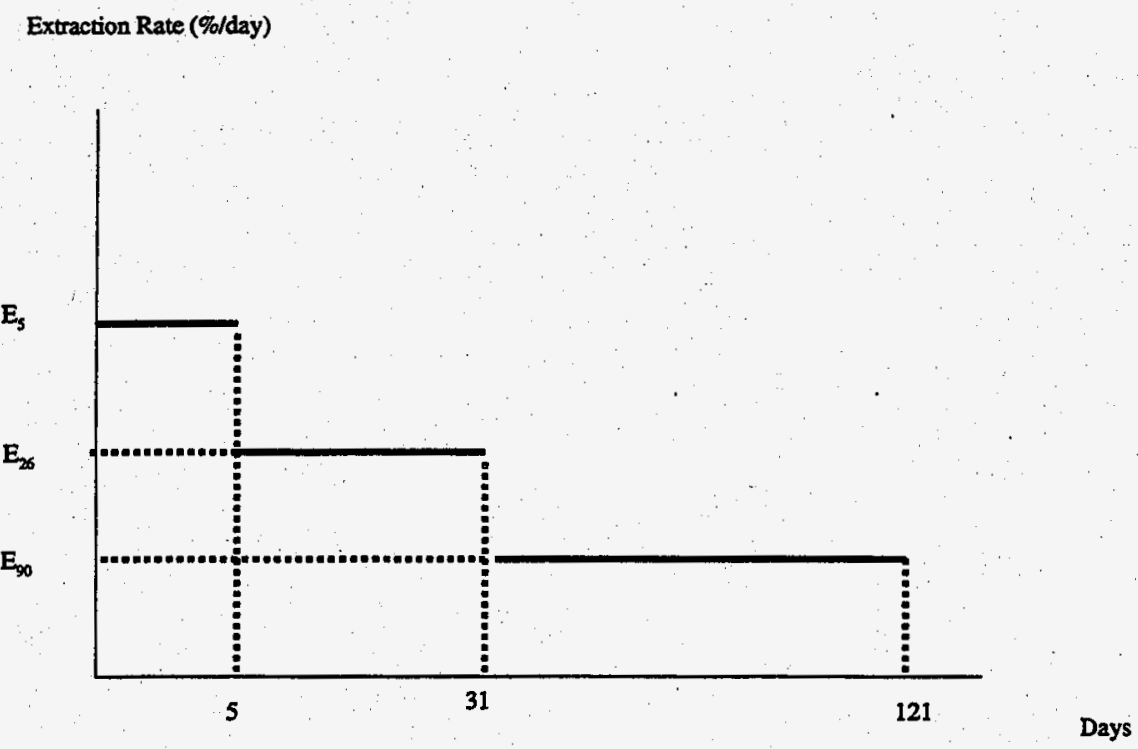

In option 2, the operator extracts gas for the first 31 days at the rate $E_{31}$ and the remaining 90 days at the rate of $E_{90}$. For the remaining 244 days gas is injected into the reservoir and it is assumed that the reservoir is brought back to the original condition after every re-fill. See Figure III-6 below.

Figure III-6

Extraction Rate (\%/day)

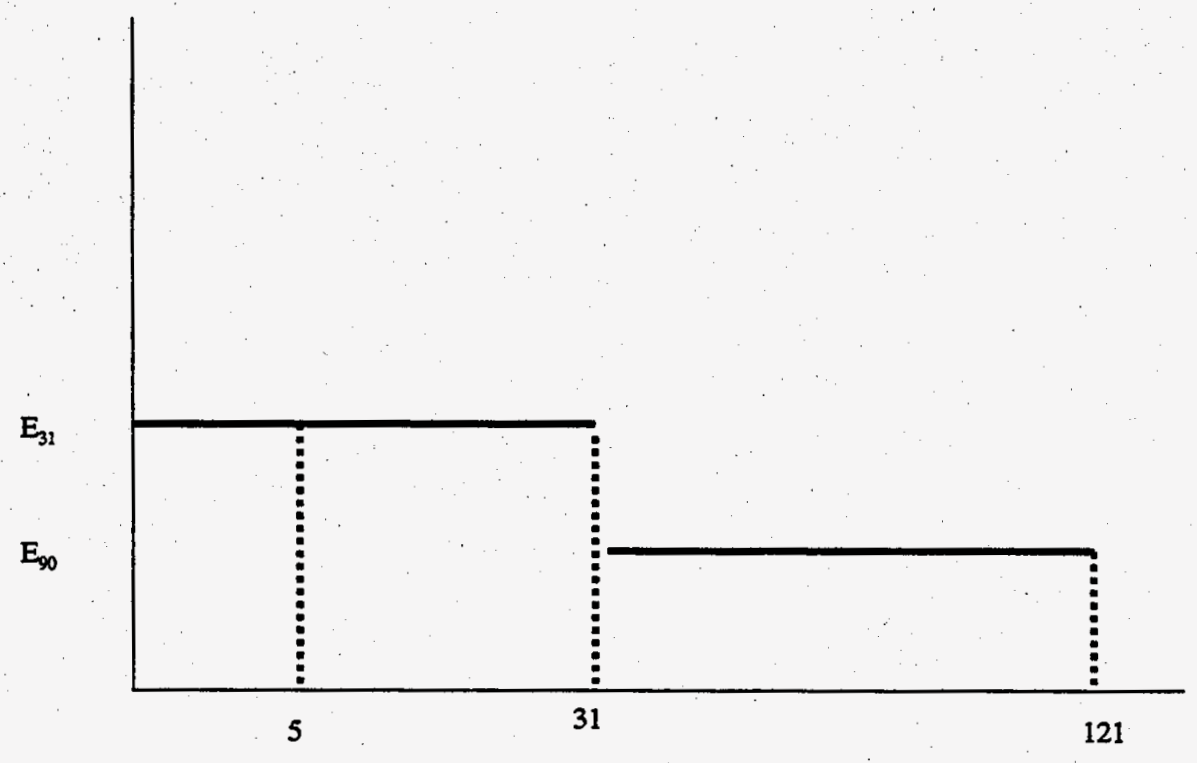

Days 
In option 3, the operator extracts gas for the full 121 days at the rate $E_{121}$. For the remaining 244 days gas is injected into the reservoir and it is assumed that the reservoir is brought back to the original condition after every re-fill. See Figure III-7 below.

Figure III-7

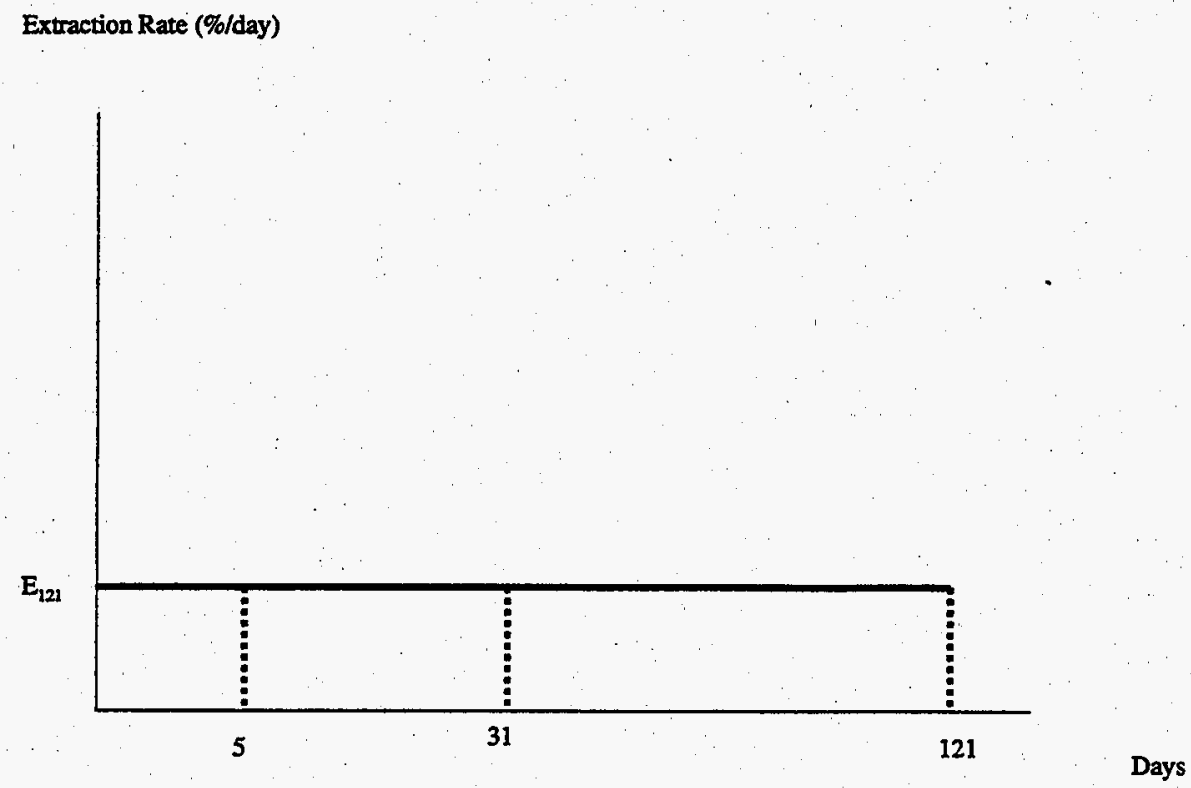

The seasonal prices are computed in GSAM's integrating LP as dual prices to the material balance constraints. These prices measure how much the market would be willing to pay for one additional unit of storage in a particular season, year, and region. Since these prices are computed as part of the LP solution but are needed before, an iterative scheme is required. Figure III- 8 describes this iterative approach. Note that the Storage Reservoir Performance Module (SRPM), an existing Module, is used to calculate reservoir-specific quantities such as extraction rates, levelized costs, etc. SRPM is run one time whereas the new module, SROM, is run before each integrating LP is to be solved. 
Figure III-8

Incorporation of SROM

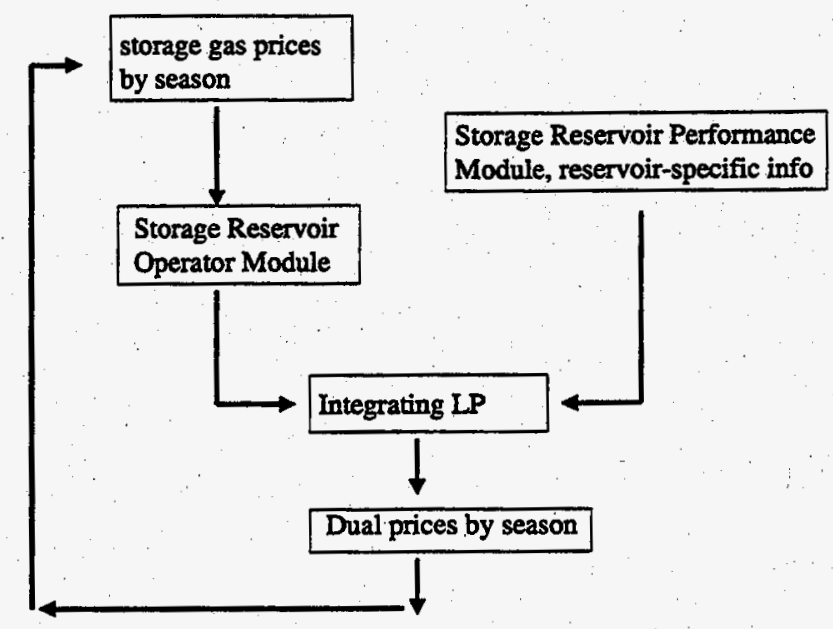

\section{Annual-Model}

The natural gas marketplace has constantly changing dynamics, and a more refined annual GSAM is a necessary tool in the attempt to capture the interactions. In particular, the interplay among the storage reservoirs, the above-ground storage (LNG, propane), and the pipelines relies on year-to-year decisions. If a storage reservoir is predicted to come on-line in 2003 , its activity in 2000 or 2005 in the previous version GSAM is a poor proxy for this specific date. Likewise, if a pipeline is estimated to expand in 2002, should this be reflected in the previous model's year 2000 or in 2005 ? It was this precision requirement for the storage reservoirs and the pipelines that led to the development of an annual GSAM.

The annual version of GSAM has two essential improvements: 1) estimates of outputs beginning in a user-specified year and 2) estimates for all years between the specified first year and end year. GSAM formerly began analysis starting in 1993 and ran normally to 2010. Any year from 1993 to 1997 may be used for a starting year, and the model is now configured to run to 2025 if desired.

The beginning year and ending year of analysis are specified in the file GEN_TML.SPC. All Demand and Integrating output files now have all data for all years presented.

The Exploration and Production (supply) Module was built to begin running from the year 1993. All data input to GSAM is in 1993 terms. If the E\&P Module were to "begin" in any year other than 1993, the resource base would be depleted in fashion inconsistent with historical depletion. To circumvent this, the Demand Module calculates demand, storage, etc. from the beginning year (i.e., 
1997), but when prices are fed to the supply side, static historical prices are given in a data file for the years 1993 to the year before the beginning year of analysis. In this fashion, the E\&P Module's production depletes the resource in a consistent manner leading to the beginning year of analysis.

In the development progress of the annual GSAM model, a new LP solver was integrated to solve the much larger LP. Both the 4-season model and the annual model add a large numbers of variables and constraints to the Integrating Module's linear program.

\section{Conclusion/Ongoing Work}

The testing and validation effort continues for the 4-season, annual GSAM model. While the programming is complete and the data files have been tailored to this new model structure, testing and refinement of the annual, 4-season-based GSAM is ongoing. 


\section{E. ENVIRONMENTAL MODULE}

\section{Background}

The GSAM Environmental Module is a suite of regulatory models being developed to allow DOE to (1) estimate the impacts of various environmental initiatives on the natural gas E\&P sector and (2) provide detailed analyses of the costs and benefits of proposed or anticipated regulations that may have significant effects on the gas E\&P industry. These models support the DOE Office of Fossil Energy's mission of maximizing the recovery of U.S. oil and gas resources through research and development and by working to reduce the costs of effective environmental protection.

The most recent addition to the GSAM Environmental Module's suite of models is known as the DOE Regulatory E\&P Air Model (DREAM). Much of the activities conducted under the GSAM environmental task over the last year has focused on the development of DREAM. The design of DREAM is seen as a prototype for development of future additions to the GSAM Environmental Module.

\section{Results}

DREAM uses detailed gas well-level data to construct bottom-up estimates of both the costs and benefits of regulations related to air emissions from E\&P operations. DOE believes that because of the diversity of the oil and gas exploration and production industry, this higher level of resolution is essential for capturing the full range of costs and benefits that may be realized by either technology development or regulatory proposals.

DREAM consists of a Cost Module and a Benefits Module. In addition to these two components of DREAM, the Cost Module was designed to provide inputs to GSAM. Together, the DREAM and GSAM allow DOE to estimate the effects that increased compliance costs have on oil and gas production, well abandonment rates, and the size of economic reserves. Figure III-9 provides an overview of the model structure and its linkages to the oil and gas supply models. The subsections that follow the exhibit provide additional description of the both the Cost Module and the Benefits Module. 
Figure III-9

Structure of the DOE Regulatory E\&P Air Model (DREAM)

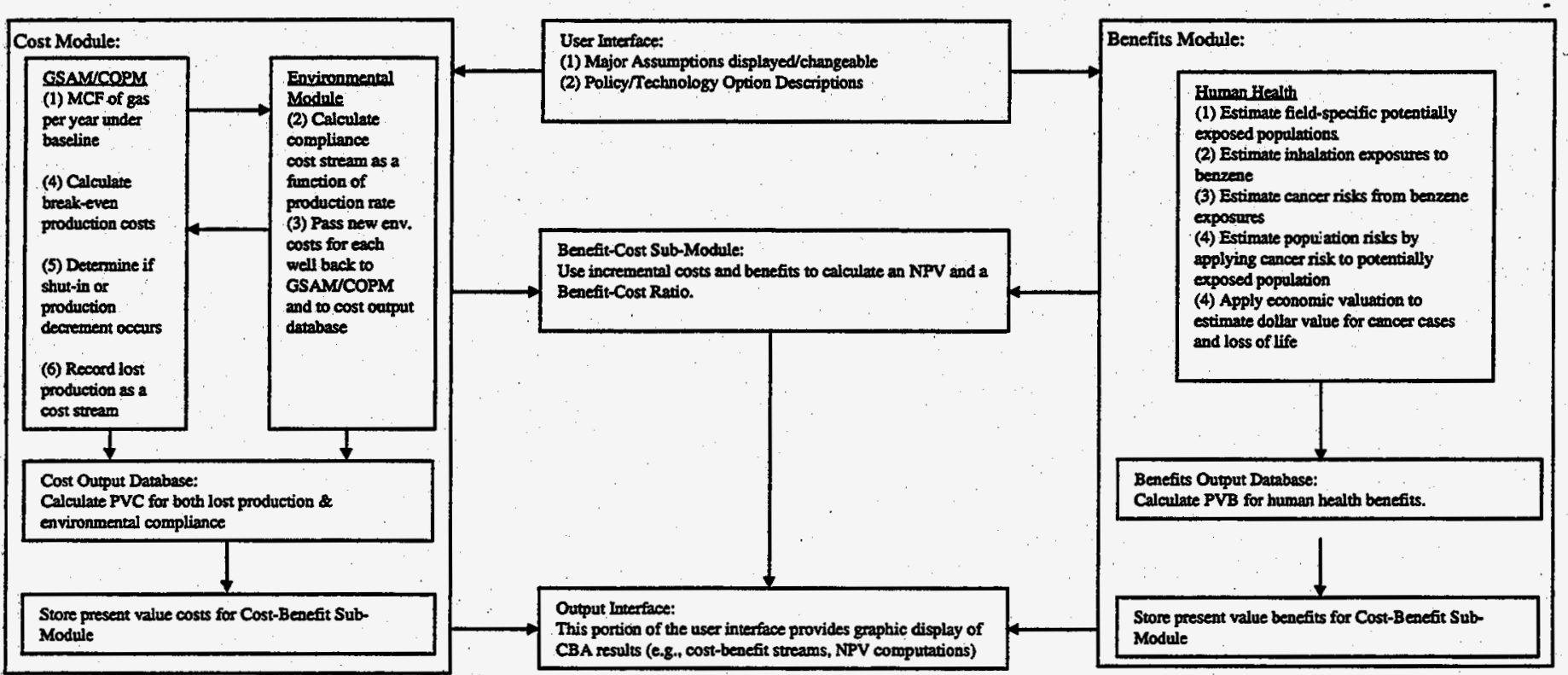

\section{Description of the DREAM Cost Module}

The DREAM Cost Module uses an engineering-based approach to estimate the volume of hazardous air pollutant (HAP) emissions, to determine appropriate design capacities for control technologies, to calculate field-specific costs for various control options, and to select the most costeffective control technology that meets the requirements of the regulation. Each of these is calculated as a function of oil and gas production rates at individual oil and gas fields. The final output of the DREAM Cost Module is a present value social cost of the regulation.

The emissions from each emission source are modeled using reduced forms of previously existing models (the same models used by EPA in its technical analysis). For example to calculate uncontrolled emissions from glycol dehydrators, the GRI-GLYCALC model was repeatedly run to produce a data set of emissions as a function of production volume. This data set was then used to generate a series of regression equations that were incorporated into DREAM. Following a similar methodology, the API E\&P TANKS Model was used to estimate flash emissions from condensate tank batteries.

Design capacities and unit costs for individual control technologies were obtained from vendors of the control technology or from EPA reports (e.g., the Gas Star Factsheet on Vapor Recovery Units). 
The unit costs (both capital and annual) were estimated based on the anticipated production of individual oil and gas fields through the year 2010 under a baseline scenario.

Once the cost of each feasible control technology at an individual field is calculated in the model, the control technology producing the highest net present value and meeting the control requirements of the regulation is selected. In some cases, this requires that multiple control technologies be applied at a single source. For example, during summer months in southern states, the removal efficiency of aircooled condensers on glycol dehydrators may be insufficient to meet the 95 percent removal requirement. ${ }^{3}$ In these cases, a flare may be needed to bring the source into compliance with the standard.

The final component of the Cost Module is the calculation of monitoring, inspection, record keeping, and reporting costs. These costs are calculated using the same basic approach and unit costs as used by EPA in its Background Information Document for the Exploration and Production Maximum Achievable Control Technology Regulation. As with other costs, however, these costs were estimated as a function of production rates at individual gas fields.

The total costs for each year at each existing gas production well are passed to GSAM to estimate the impacts of increased environmental compliance costs on future oil and gas production, reserve depletion, and well abandonment rates. In a post-processing step (i.e., following the completion of a GSAM model run that applies the costs estimated by DREAM), the lost production estimates are converted to costs by multiplying the production decrement by DOE's 1998 Annual Energy Outlook (AEO98) future oil and gas price estimates. The job effects of the lost production are estimated using regional economic multipliers from the U.S. Department of Commerce Regional Input-Output Modeling System (RIMS II).

\section{Description of the DREAM Benefits Module}

The DREAM Benefits Module calculates the social benefits of regulatory alternatives in terms of avoided illness and avoided loss-of-life resulting from reduced exposures to emissions from oil and gas production operations. The model estimates population cancer risk on a gas-field-specific basis. To do this, the model includes a simple Gaussian air dispersion model that models the dispersion of emissions downwind from the production field. This dispersion model uses meteorological data from the nearest

\footnotetext{
3 The Clean Air Act requires that major source control technologies meet a 95 percent HAP reduction. Under the proposed regulation, area sources would also have to meet this 95 percent HAP reduction requirement.
} 
weather station so that dispersion estimates are based on the prevailing weather-conditions at each location.

Following the air dispersion estimates, the inhalation cancer risk for the highest risk HAP being emitted (in this case, benzene) is calculated. Both the air dispersion and risk modeling components of DREAM are taken directly from EPA's Priority Assessment Model, which is a screening-level risk assessment model used as part of EPA's Continuous Release Emergency Release Notification System (CR-ERNS). Cancer risks are estimated at three user-specified distances from the field $(1,3$, and 5 miles were used in the current analysis).

The cancer risks estimated at these distances are then applied to the location-specific populations within each distance ring to estimate the expected number of cancers that would occur under various scenarios. By convention, it is assumed that 60 percent of the people estimated to get cancer in the analysis eventually die from the disease.

In a cost-benefit analysis, total economic changes are examined to determine the effect of a change in policy. For this reason, economists need to place a dollar value on non-economic entities. An example of such a non-market commodity is a human life. Because human lives do not have market values, economists must use indirect pricing techniques to value them. To convert the number of illnesses and deaths into monetary values for DREAM, value-of-life studies from the economic valuation literature were explored.

Boardman, et al. $^{4}$, priced some non-market items, such as the human life. By summarizing several studies on the subject, the authors concluded that the value of a human life is between $\$ 2.5$ million and \$3.7 million (1998 dollars). DREAM uses \$3 million for the value of a human life, and therefore a life saved as a result of the E\&P MACT regulation is valued at $\$ 3$ million per cancer death avoided.

For cancer cases that do not result in death, Tolley, et al. ${ }^{5}$ determined $\$ 48,000$ to $\$ 179,000$ (1998 dollars) per year to be the cost of "chronic morbidity." For the purposes of this model, the results of these studies are estimated at $\$ 385,000$ for a cancer case that does not result in death (calculated to be

\footnotetext{
${ }^{4}$ Boardman, Anthony, David H. Greenberg, Adrian Vining, and David Weimer. Cost-Benefit Analysis: Concepts and Practice. New Jersey: Prentice Hall, Inc., 1996.

${ }^{5}$ Tolley, George, Donald Kenkel, and Robert Fabian. Valuing Health for Policy: and Economic Approach. Chicago: The University of Chicago Press, 1994.
} 
approximately $40 \%$ of total cancer cases in the Model). This number is a weighted average of expected type of cancer, cost of treatment, and length of treatment.

\section{Conclusion/Ongoing Work}

The combination of GSAM and DREAM allows the user to estimate the effects (costs and benefits) of proposed or anticipated regulations that may affect the oil and gas E\&P industry. DREAM has a cost module and a benefits module. The final output of the cost module is a present value estimate of the social cost of the regulation. The benefits module calculates the social benefits resulting from avoided illness and loss of life in an improved environment created because of the new regulation.

The future of the environmental module involves using field specific release and cost estimates rather than expected value costs, estimates of human risk and population data specific to each production field and a more user friendly interface written in Visual Basic. Another section of code which would allow DOE to select a regulatory option which minimizes the cost-benefit ratio is also included in the future plans. 


\section{F. DATABASE UPDATES}

\section{Background}

Previous to the period of performance, the Storage Module in GSAM had an incomplete number of undiscovered natural gas storage reservoirs from the Appalachia region. In order to enhance the model, an Appalachian undiscovered storage reservoir database was developed and incorporated into the existing Storage Module. ICF constructed the database by selecting possible storage candidates from existing natural gas producing reservoirs. Since these reservoirs are not yet storage reservoirs, they are considered undiscovered storage reservoirs.

Also previous to the period of performance, some uncertainty surrounded the GSAM data on reservoir impurities, those that would be extracted in gas processing, namely $\mathrm{CO}_{2}, \mathrm{~N}_{2}$, and $\mathrm{H}_{2} \mathrm{~S}$.

\section{Results}

\section{Appalachian Storage Reservoirs}

The Department of Energy's Gas Information System (GASIS) was used to develop the undiscovered Appalachia storage database for GSAM. The GASIS data (Release 1, March 1997) cover 9,014 reservoirs throughout the Lower-48 United States, with each containing 179 entries that detail geological, engineering, production, and ultimate recovery data. All reservoirs with at least 10 billion cubic feet (Bcf) of cumulative natural gas production are included in GASIS. Reservoirs located in the Appalachia region were identified and used to compile the Appalachia database.

Before selecting storage reservoirs, the GASIS database was screened for missing or inconsistent data. In the cases where data were missing, they were replaced with default-data generating algorithms that use other parameters in the database. For example, permeabilities, when missing, were calculated using formulae based on porosity and initial water saturation. In the cases where it was not possible to calculate an estimated value, a default value was used. The following table documents the procedure for filling in missing data: 
Table III-5

Mixing Value Table for Applachian Storage Reservoirs

\begin{tabular}{|l|l|l|l|l|}
\hline Data & $1^{\text {st }}$ Value & $2^{\text {nd }}$ Value & $3^{\text {rd }}$ Value & $4^{\text {th }}$ Value \\
\hline $\begin{array}{l}\text { Initial Water } \\
\text { Saturation }\end{array}$ & GASIS & $25 \%$ & - & - \\
\hline Depth & GASIS & 2000 feet & - & - \\
\hline Porosity & GASIS & f(perm., init.watsat.) & $10 \%$ & - \\
\hline Permeability & GASIS & f(por.,init.wat.sat.) & - & - \\
\hline Initial Pressure & GASIS & f(depth) & - & - \\
\hline $\begin{array}{l}\text { Bottom Hole } \\
\text { Temperature }\end{array}$ & GASIS & f(depth) & - & - \\
\hline Gas Gravity & GASIS & 65\% & - & - \\
\hline $\begin{array}{l}\text { Original Gas-in- } \\
\text { Place }\end{array}$ & GASIS & f(ult.recov.) & $\begin{array}{l}\text { f(cum.prod., } \\
\text { reserves) }\end{array}$ & $\begin{array}{l}\text { f(area, net pay, por., } \\
\text { init.wat.sat., temp., } \\
\text { init.press.) }\end{array}$ \\
\hline
\end{tabular}

Once the GASIS database was screened, reservoirs were analyzed to test whether they were eligible for gas storage. In order to be economically viable, reservoirs needed to have a large original gas-in-place and have a high porosity, but they also could not be too deep. These and other conditions were formulated and each reservoir was analyzed. To be a candidate for storage, a reservoir had to meet all of the criteria, listed in the following table.

Table III-6

\begin{tabular}{|l|l|}
\hline Data & Condition \\
\hline Formation & Sandstone, Clinton (OH), Medina (NY), Onondaga (NY) \\
\hline Depth & $2000-10000 \mathrm{ft}$ \\
\hline Porosity & At least $10 \%$ \\
\hline Initial Water Saturation & No more than $35 \%$ \\
\hline Original Gas-in-Place & At least $5000 \mathrm{MMcf}$ \\
\hline
\end{tabular}

The reservoirs that passed all the criteria were used in the development of the undiscovered storage database. A check was then made to make sure Appalachia reservoirs that are currently used for storage or are planned for storage were included the database. Also, a review was done to verify whether the selected reservoirs substantially covered the Appalachia region. The final Appalachia undiscovered storage database contains 70 reservoirs.

\section{Reservoir Impurity Data}

The data on GSAM reservoir impurities was reviewed and compared to two other estimates, from GRI ("Chemical Composition of Discovered and Undiscovered Natural Gas in the United States-1993 Update") and from the GASIS database. This was done in order to assess consistency 
between published resource estimates, and so that the quality and reliability of the GSAM (NRG) database could be evaluated.

For some reservoirs, the impurity content data in the NRG database are incomplete. To overcome this, default values were assigned to individual reservoirs. In the context of the analysis, a "default" is an estimate of the missing parameter. The default derives from average impurity values for individual plays, calculated from reservoirs in those plays that contain data. This defaulting methodology was based on the premise that all reservoirs in a play are geologically similar.

The defaults used were from the GSAM model and were applied to all NRG impurity values wherever the NRG database contained a zero level for all three impurities. Where the NRG database contained a non-zero value for any one or more of the impurity values, no adjustments were made. The GSAM play-level average data was developed from an earlier review of existing sources.

Table III-10 shows how NRG's low quality resource base estimates compared with GRI estimates. Note that impurity threshold limits (volume basis) were as follows: $4 \%$ for $N_{2}, 4 \%$ for the sum of $\mathrm{CO}_{2}$ and $\mathrm{N}_{2}, 2 \%$ for $\mathrm{CO}_{2}$, and 4 PPM for $\mathrm{H}_{2} \mathrm{~S}$. These limits correspond to those in the GRI report, hence provided a consistent basis for comparison. The NRG database contains remaining reserves for 1993, while GRI uses 1991 reserves estimates. In order to create a consistent comparison of low quality gas resources, the GRI remaining reserves were adjusted to the year 1993 by applying a ratio to all estimates that fit the GRI remaining reserves in 1991 to the NRG remaining reserves in 1993. For completeness Table III-10 also presents the corresponding GASIS estimates. These are inherently lower than the other estimates because several basins have not yet been included in the database. 
Table III-10

Remaining Reserves Containing Low Quality Gas by Impurity, BCF.(Non-Associated Gas, Excludes Appalachia)

\begin{tabular}{lcccccccc}
\hline & $\mathrm{N}_{2}$ & $\mathrm{CO}_{2}$ & $\mathrm{~N}_{2}+\mathrm{CO}_{2}$ & $\mathrm{H}_{2} \mathrm{~S}$ & $\begin{array}{c}\text { All Low- } \\
\text { Quality }\end{array}$ Reserves \\
\hline \hline "Raw" NRG Database & 16,673 & 14,846 & 23,226 & 6,147 & 29,285 & 127,354 \\
NRG with GSAM Defaults & 17,089 & 20,992 & 25,748 & 14,745 & 42,559 & 127,354 \\
GRI Topical Report (1991) & 21,690 & 28,952 & 29,006 & 19,564 & 52,976 & 137,546 \\
GRI Adjusted to 1993 & 20,083 & 26,807 & 26,822 & 18,114 & 49,051 & 127,354 \\
GASIS $^{2}$ & 17,400 & 18,800 & N/A & 6,500 & N/A & 78,289 \\
\hline
\end{tabular}

Assuming that one-quarter of the gas that is above the limit in $\mathrm{CO}_{2}$ and $\mathrm{CO}_{2}$ and $\mathrm{H}_{2} \mathrm{~S}$ is high enough in nitrogen to push the sum of $\mathrm{CO}_{2}$ and $\mathrm{N}_{2}$ over the limit

${ }^{2}$ GASIS does not include Williston, Pacific onshore, Gulf of Mexico, or impurities in Appalachia

Based upon the information in Table III-10, the play-level average defaults in NRG provided a reasonable resource base estimate relative to other estimates.

\section{Conclusion}

The addition and successful implementation of the undiscovered Appalachian storage database makes the Storage Model more robust.

GSAM (NRG) data was consistent with other database's estimates of low-quality (high-impurity) natural gas. 


\section{G. WINDOWS INTERFACE}

\section{Background}

A major GSAM project completed in the last year was the development of a windows-based version of the model. Version 1.0 of Windows GSAM (WGSAM) was completed and installed at FETC in Morgantown in the winter of 1997-1998. WGSAM offers the user a more friendly environment in which to prepare input data and run scenarios as well as providing a set of informative tools to analyze the outputs.

WGSAM can be thought of to be in two parts: the "front-end" and the "back-end". The front-end is the user interface, this is what the user sees. The back-end is the FORTRAN programs that comprise the model. The front-end can be further subdivided into two parts: the "preparations" section and the "analysis" section. In the "preparations" part, parameters are set and assumptions for the run are made and submitted. In the "analysis" part the results from the model run are examined. A typical sequence of nunning WGSAM would first involve "preparations" (front-end), followed by back-end (FORTRAN calculations), followed by "analysis" (front-end). What follows is an overview of the major aspects of WGSAM describing its functionality.

\section{Functionality}

\section{Front-end}

\section{Preparations of Inputs}

Before a WGSAM run can be initiated, the user must define both the associated 'project' and 'scenario'. The term 'project' in this context refers to the major class of GSAM runs, for example, "Examination of Federal Lands", "GSAM Metrics Study", etc. A project is composed of a set of "scenarios", for example, a "Base Case", a "High Production Case", etc. Each of these scenarios refer to a set of inputs that are common to a project but may differ in some significant respects. Below is the first window that appears when WGSAM is started. 


\section{Figure III-11}

WGSAM Start Window

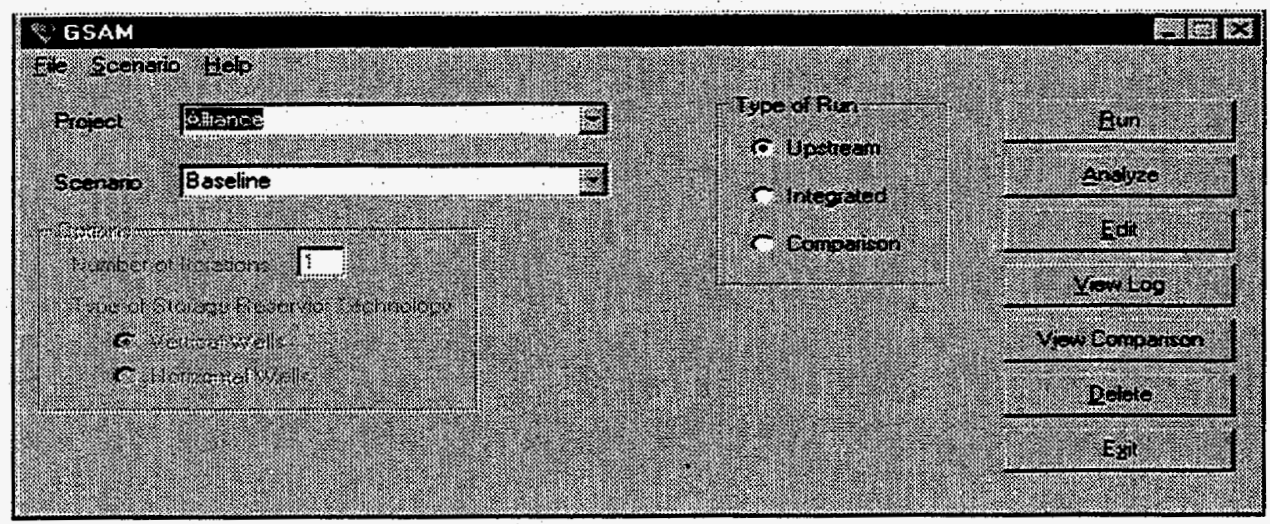

As can be seen from the window, WGSAM is quite versatile. It allows a project and a scenario name for a specific case. In addition, it allows for the type of run, i.e., Upstream, Integrated (for an integrated run one can specify the number of iterations and the type of storage reservoir technology) or a Comparison Run (this compares two cases for which data has been previously created). The rest of this section briefly explains the buttons on the right hand side of the window.

Run: After specifying the type of run etc., GSAM's back-end is invoked by clicking 'run'. After the model is finished running control returns to this window.

Analyze: This option calls the analysis section of the front-end, which is discussed in the next section.

Edit: By 'edit', the user is permitted to edit input files as shown in Figure III-12. 


\section{Figure III-12}

Input Files

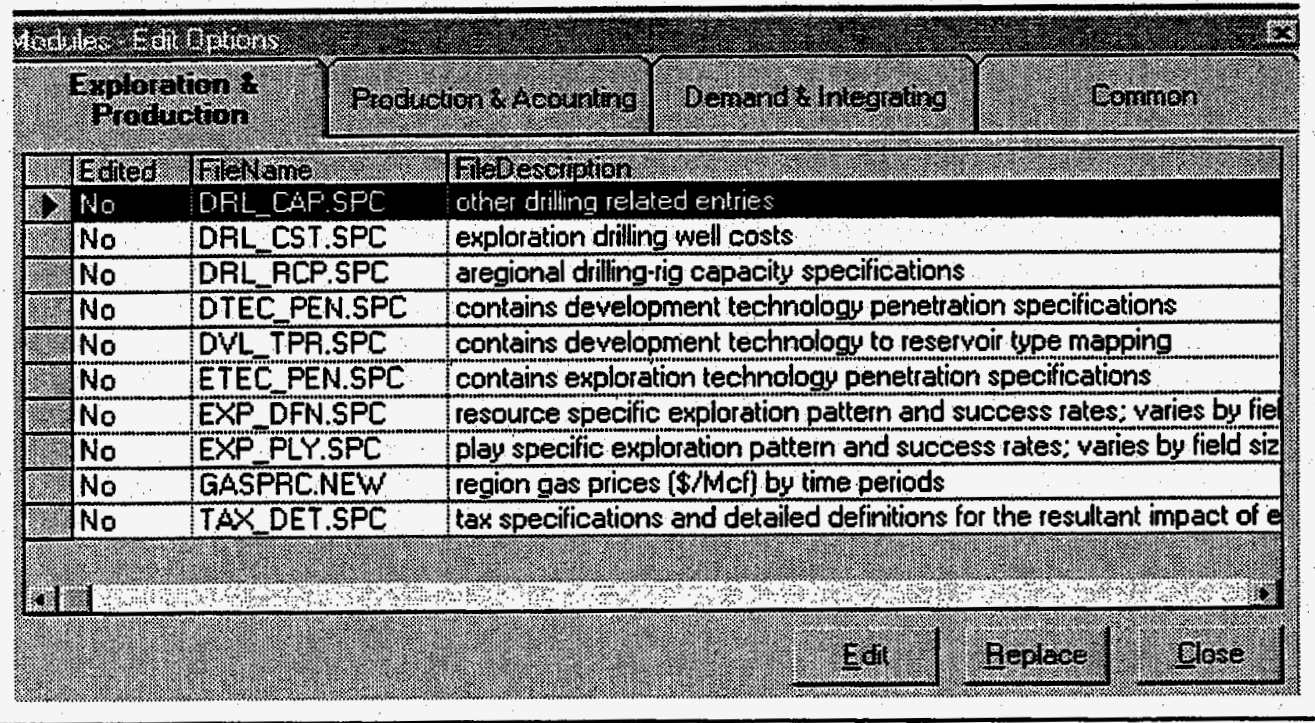

By double clicking on any of these databases one can modify the actual file. Another option is to replace the entire database by clicking on the 'replace' button. This edit function gives the user tremendous control over the input data in a very user friendly manner. Note that the data are systematically organized according to where it is used (Exploration and Production, or Production and Accounting, etc.) and can be accessed and altered in an efficient manner. The file descriptions of the data sets in the table above also enhance the efficiency of zeroing in on the file to be changed.

View Log: This button allows the user to view the log file that is created as the model runs.

View Comparison: This button allows for viewing a comparison of the results from two separate runs. This is also discussed in the next section.

Delete: Deletes a specific case.

\section{Exit: Exits WGSAM.}

WGSAM also has another feature worth pointing out before going on to the next section. In the File Manager under 'Scenario' one has the option of importing data for a run or exporting data from a run to other directories and folders. This ability allows users to exchange data across machines and shared directories. 


\section{Analysis of a WGSAM Run}

Upon setting up the inputs for a WGSAM project/scenario and running the model, the user can then analyze the output geographically, graphically, or in tabular form. This ability to view the results of a GSAM run is a major improvement over the existing DOS-based model. One can analyze the results for an upstream run, an integrated run, or a comparison run. In an upstream run the prices are read into the model and the programs for the Demand and Integrating Module in GSAM are not executed. In an integrated run all the modules in GSAM are executed. The comparison case compares the results from two integrated scenarios. The following describes each format in which the output from WGSAM can be represented, beginning with maps, going on to graphs, and concluding by describing the tabular format.

The two buttons on the main window that allow one to analyze the data are 'analyze' and 'view comparison'. To analyze the data from an upstream or integrated run, the user can click on the analyze button to see the following screen: (this is for an integrated run)

Figure III-13

Demand Regions

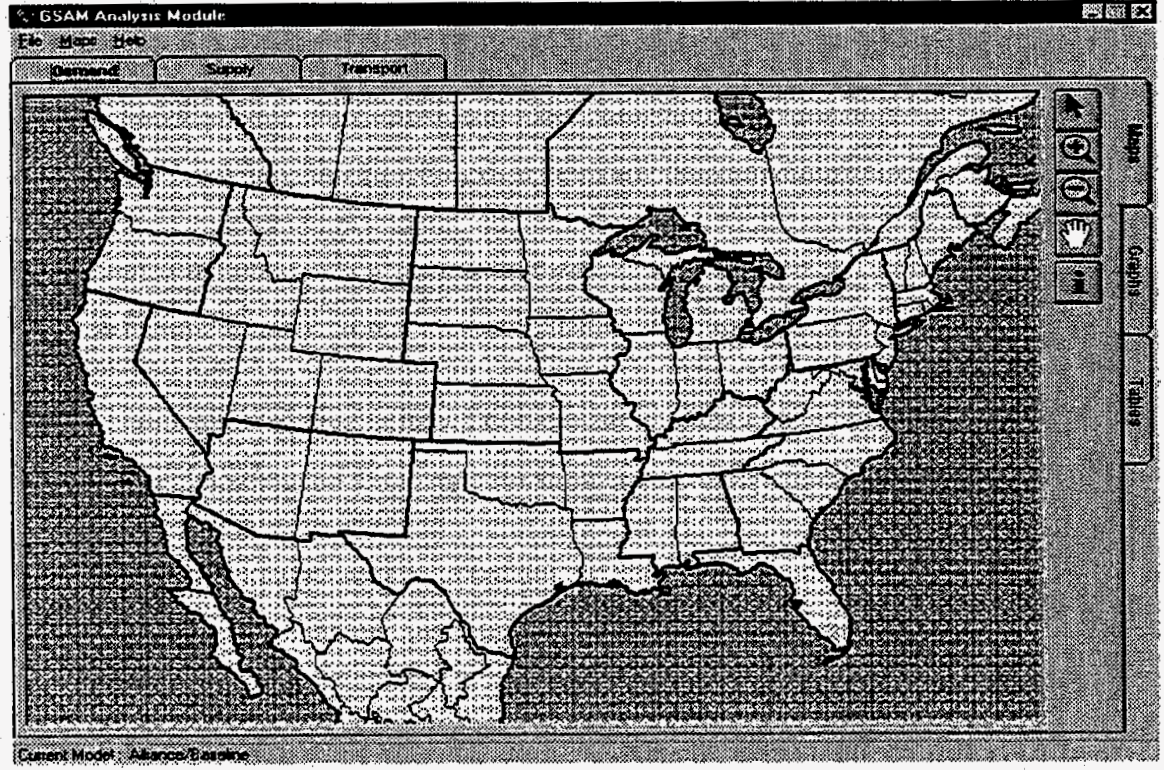

The screen for an upstream run has just the first tab for 'supply', with just the supply regions shown, as depicted below. 
Figure III-14

Supply Regions

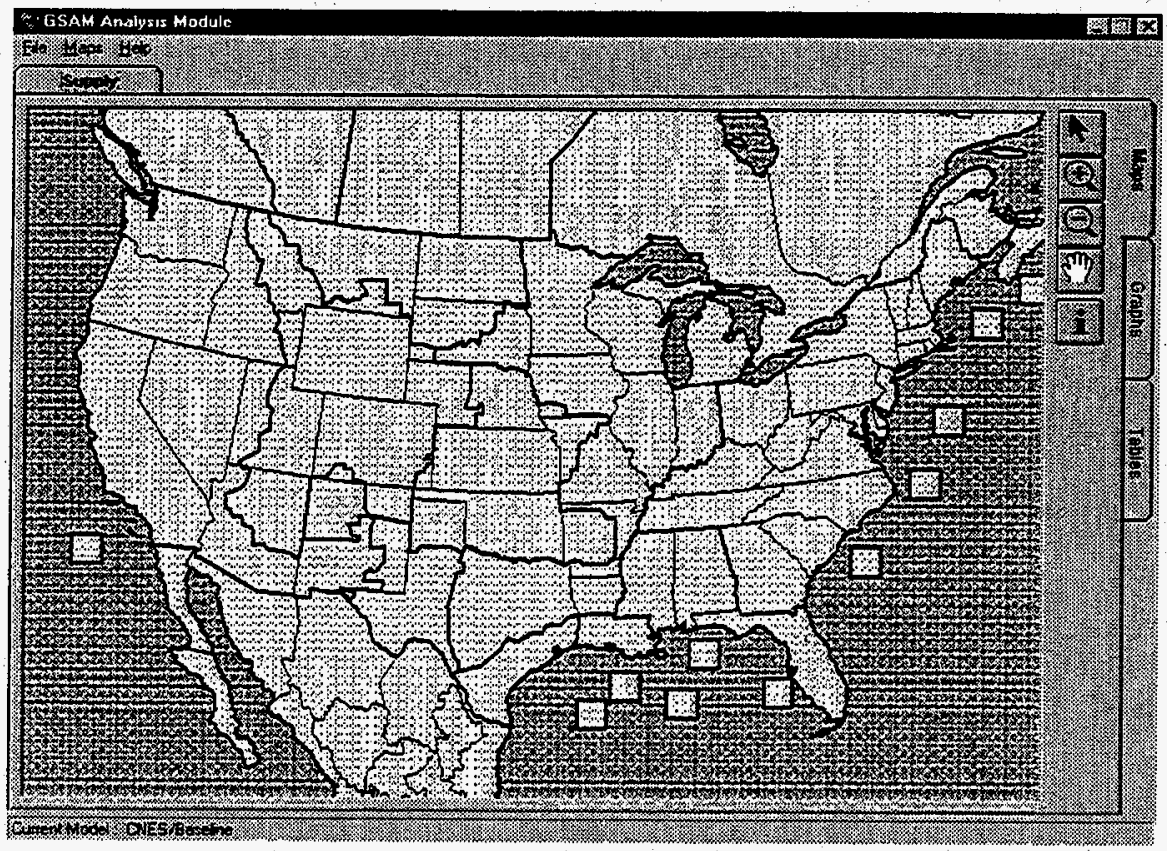

The ability to compare the results between two different runs is extremely useful when one is analyzing a specific policy and its effect on the output, for example, production levels. One can then proceed to run a series of cases altering variables and comparing production between the different cases to get an idea of how the variables affect production. Because of the versatile nature of WGSAM, one can do this analysis for a specific region across years, or for different regions in the same year, etc.

To create a comparison run, the user clicks on the 'Comparison' button to get the following window. 
Figure III-15

Comparison Window

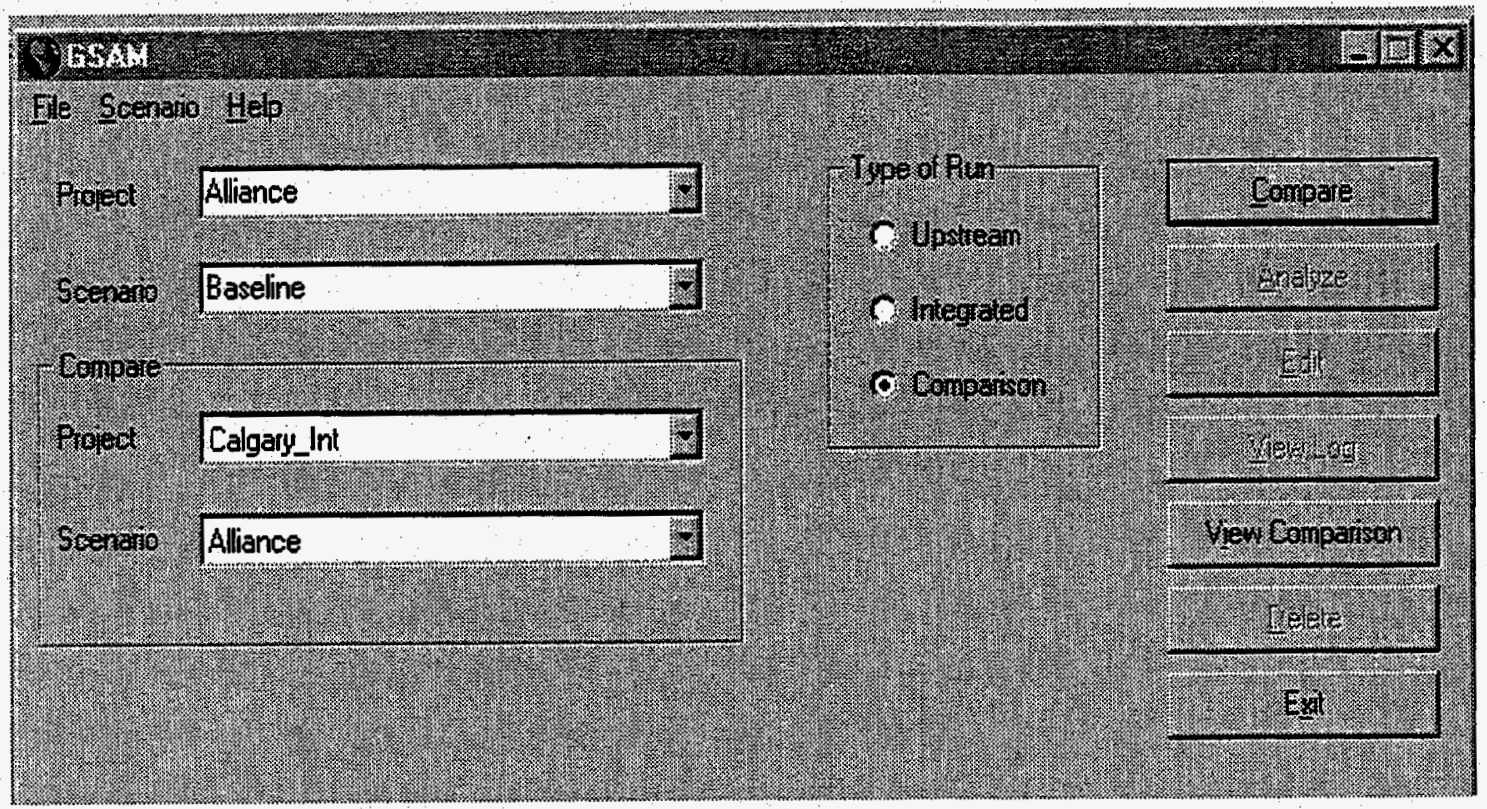

The user can then click 'Compare' and get back to the same map that one would see had one clicked 'Analyze'.

As mentioned above, the data from any of the three runs (integrated, upstream, or the comparison run) can be viewed in three formats: a map, a graph or a table. The 'map' format allows one to understand the data regionally, by clicking on the information button (explained below) one can get an accurate view of the data in a specific region. The map is color-coded and provides a quick visual regional representation of the data. The graph format allows one to represent the data in a large number of formats (Pie Charts, Bar Graphs, etc.). The table format gives a numeric representation if so desired. Clicking on the tabs on the right side of the screen allows one to choose the format. The remainder of this section will discuss each of these formats in detail. For completeness the results from an integrated run are explained here. The explanation for an upstream run is identical to the explanation for only the 'supply' section of an integrated run. The method for a comparison run is identical to that in an integrated run.

Maps: A map can be created by clicking on 'Maps' on the File Manager and choosing 'Create Thematic Map'. For 'Demand' and 'Supply' this brings up the following window. 


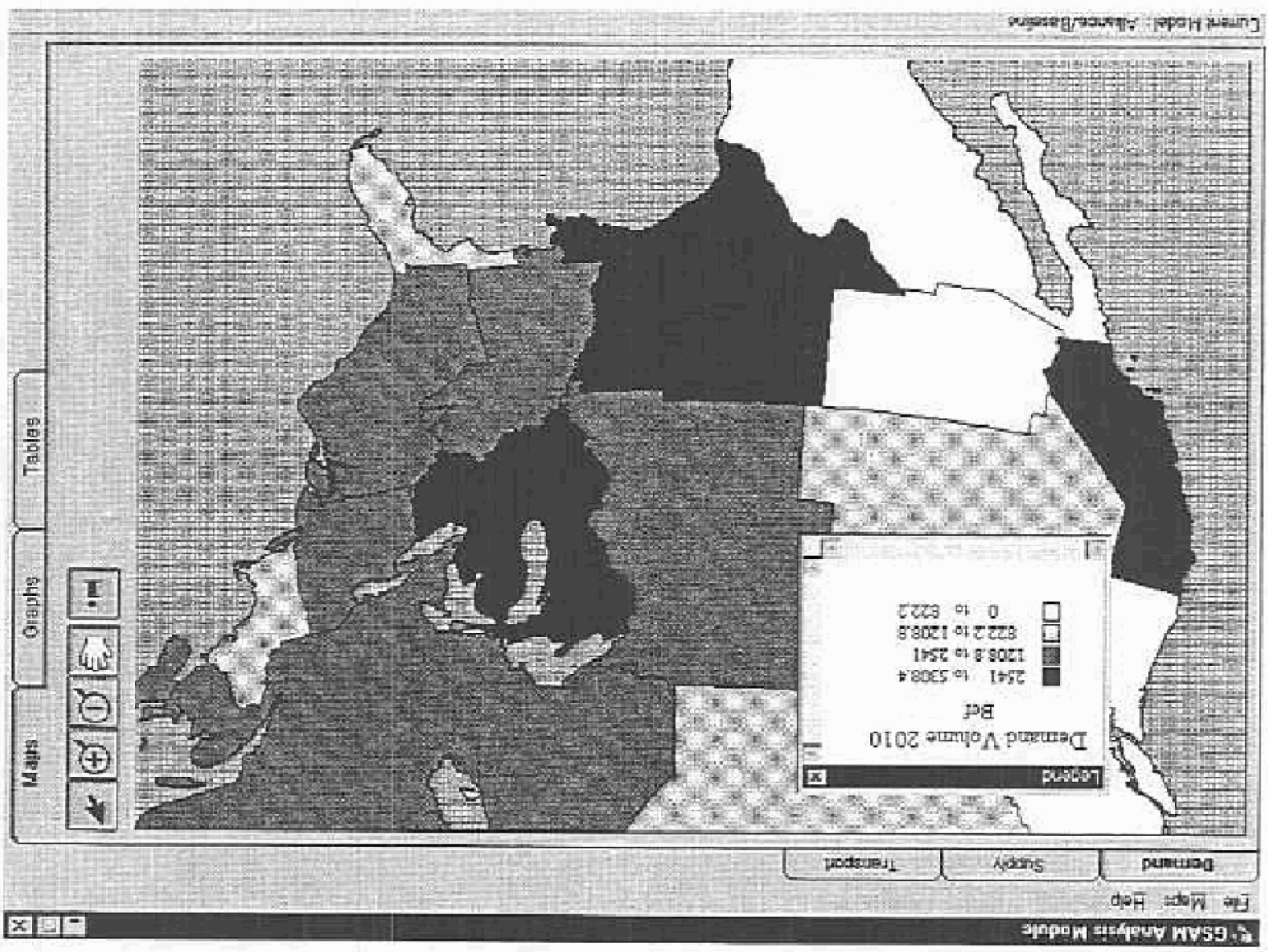

deW ṣ̣sরieuv puewso

LL=III a.n'!

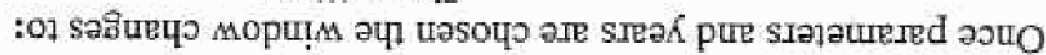

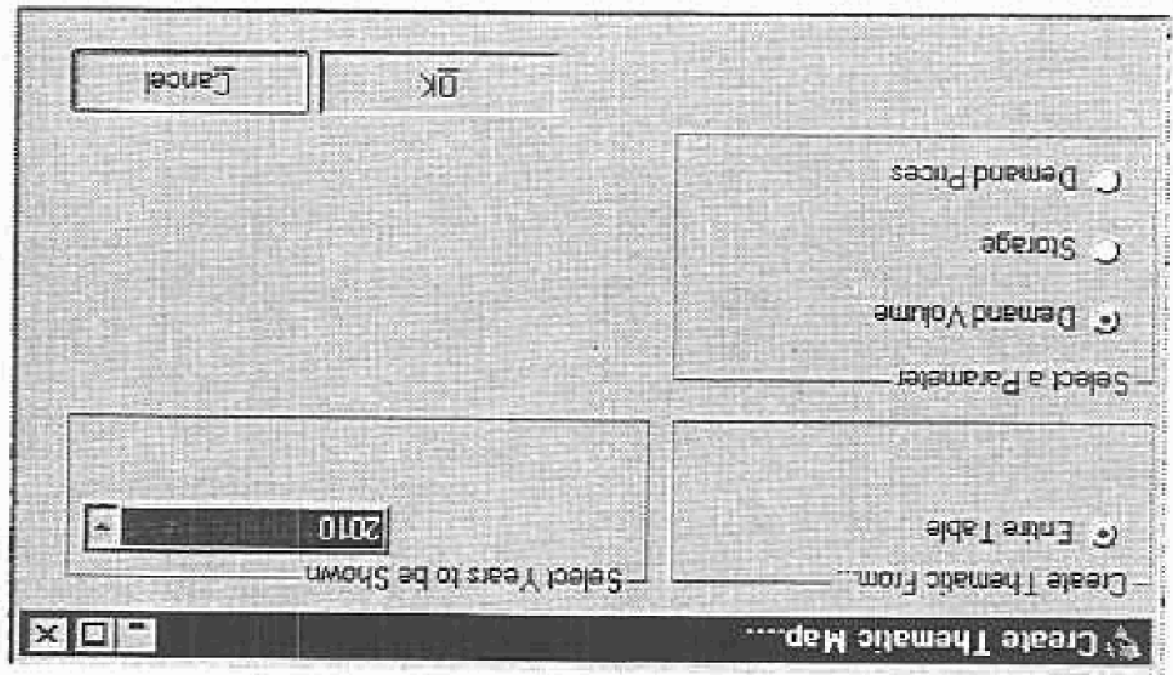

морul $M$ dew วุเอد

9L-III aนn 
The color coding can be altered by choosing 'Modify Thematic Maps' under 'Maps' in the file manager. As can be seen, this is a quick and visually appealing way to view the data. Each parameter for each year can be viewed independently to discern regional trends across years. The buttons on the right of the screen have the following function:

Arrow: Pressing this button allows one to make a selection

Positive Magnifying Glass: Zooms in

Negative Magnifying Glass: Zooms out

Hand: Moves the map

"i": Provides information about the area of interest, specifically it gives some general information about the selected region and the numerical value of the parameter under study in that region.

The map for 'Transport' differs somewhat. The regional nodes are identified on the map and differentiated on the basis of whether they are demand nodes, supply nodes or LNG nodes.

Figure III-18

Transportation Nodes

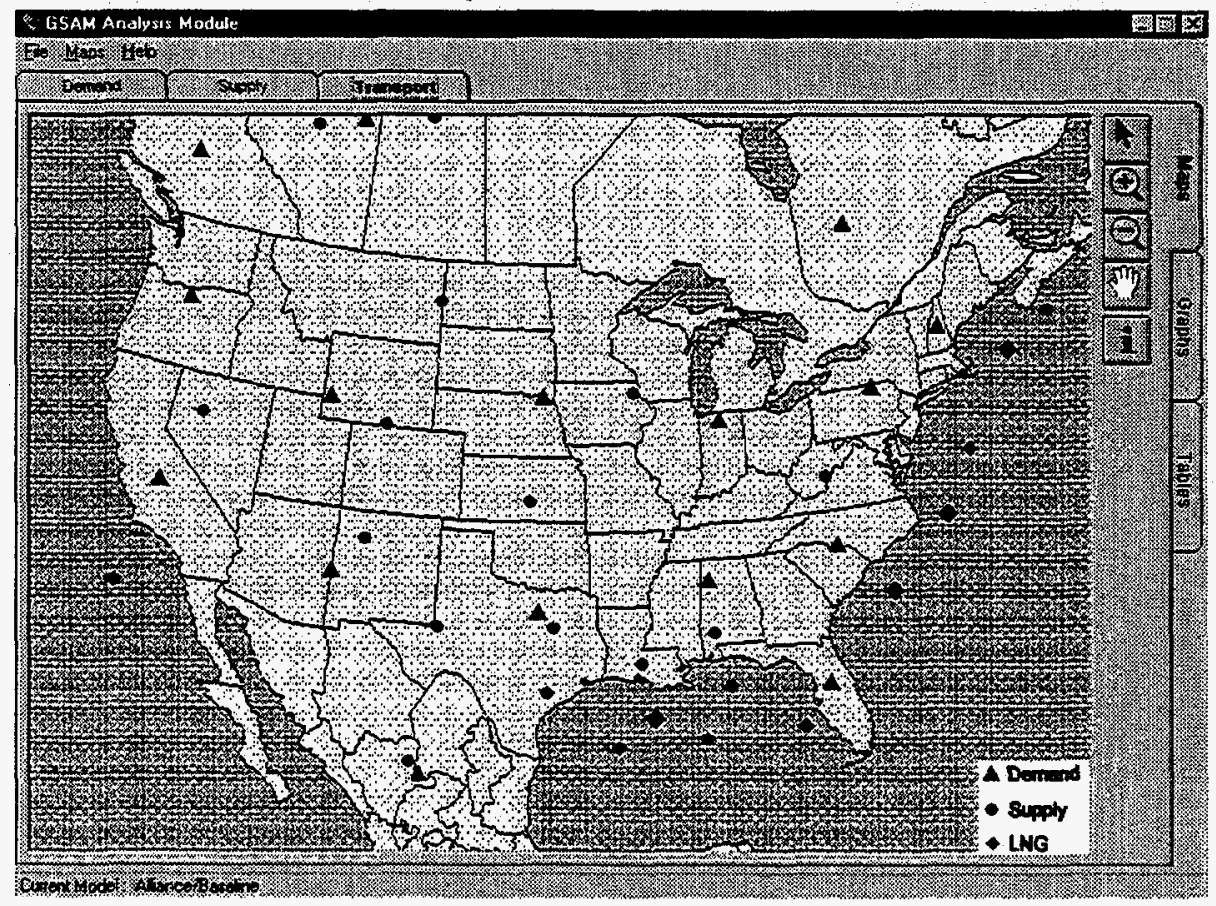

To visualize the data on the map one can select 'Create Thematic Map' under 'Maps' in the file manager and the following window appears. 
Figure III-19

Thematic Map Dialog Window

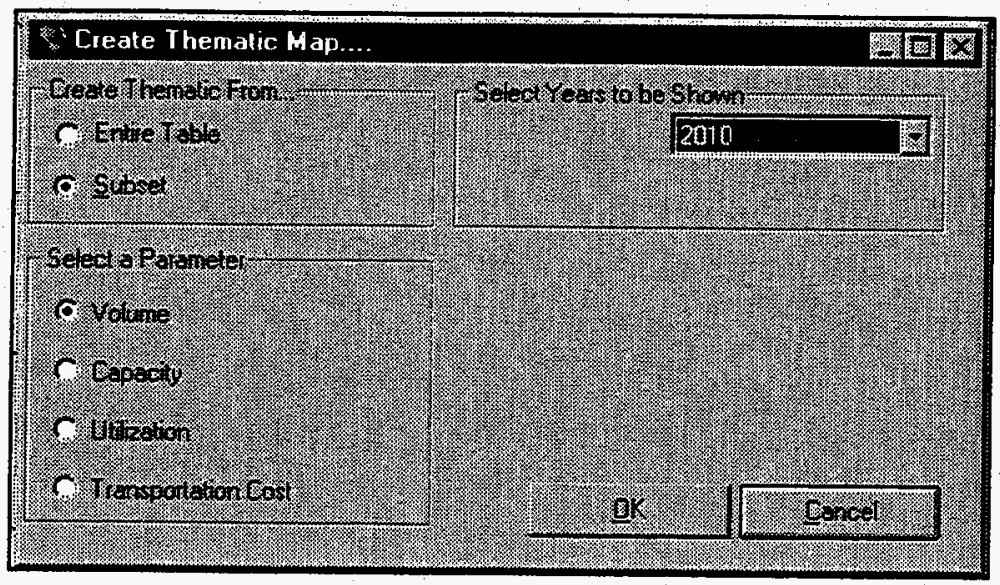

At this point if the user selects Subset, the user can follow the instructions and select a few pipeline links to only view the data from those selected links as opposed to the whole data set.

Figure III-20

Subset Interface

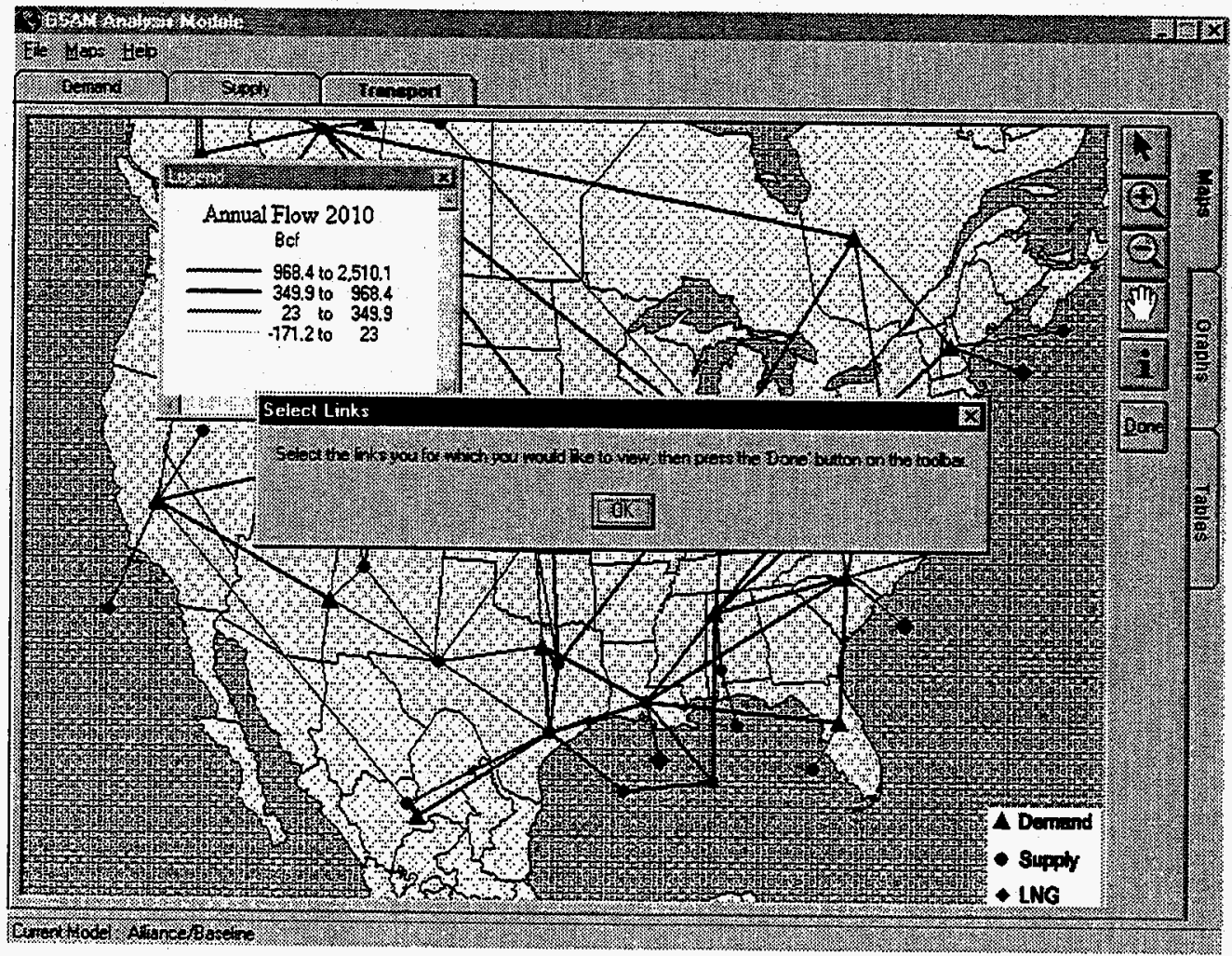

An example of a subset map is shown below. 
Figure III-21

Subset Map

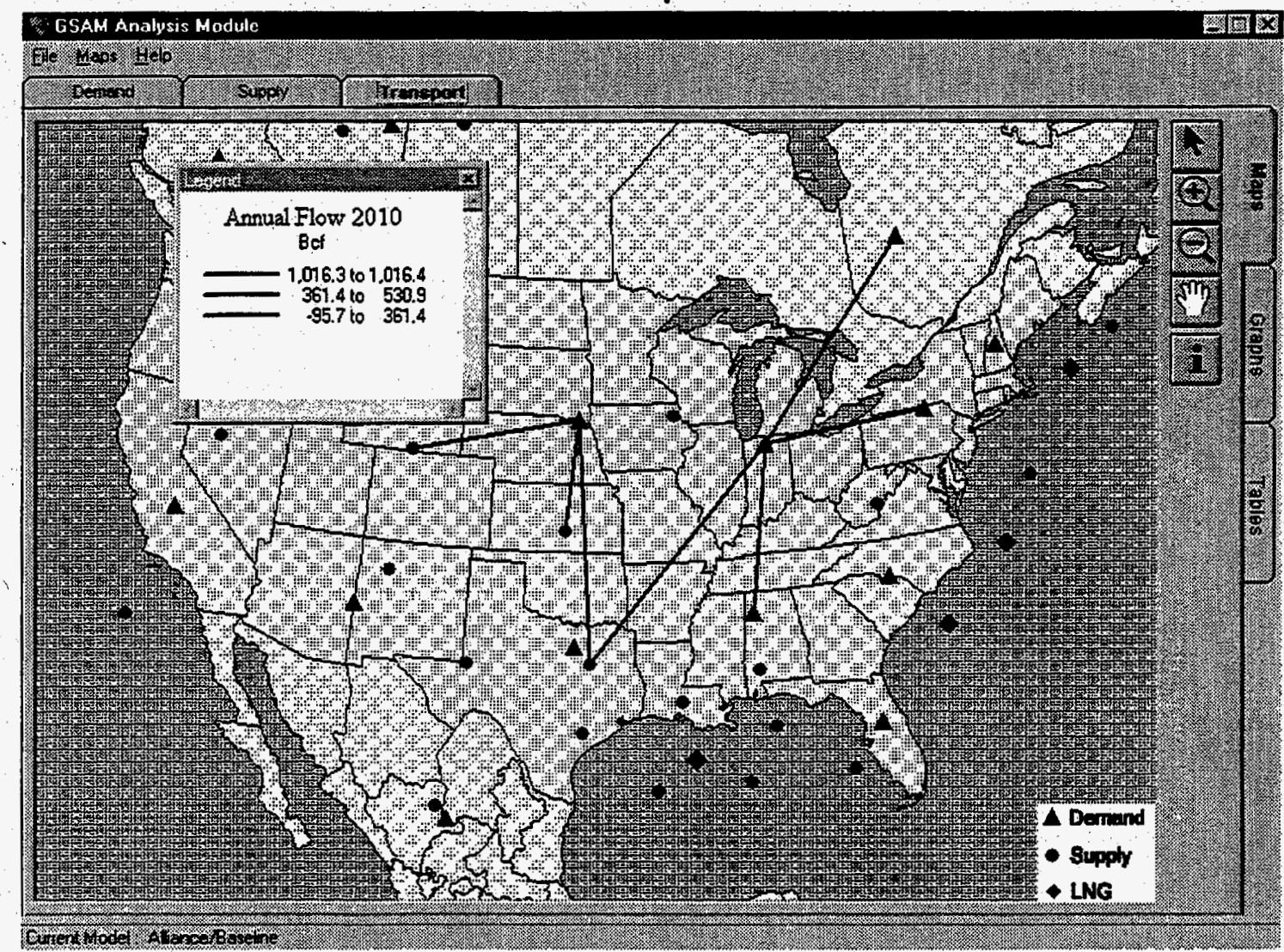

As can be seen this feature is very useful when one wants to single out and study a specific parameter across specific nodes. The next map shows the entire transportation network. 
Figure. III-22

Transportation Network

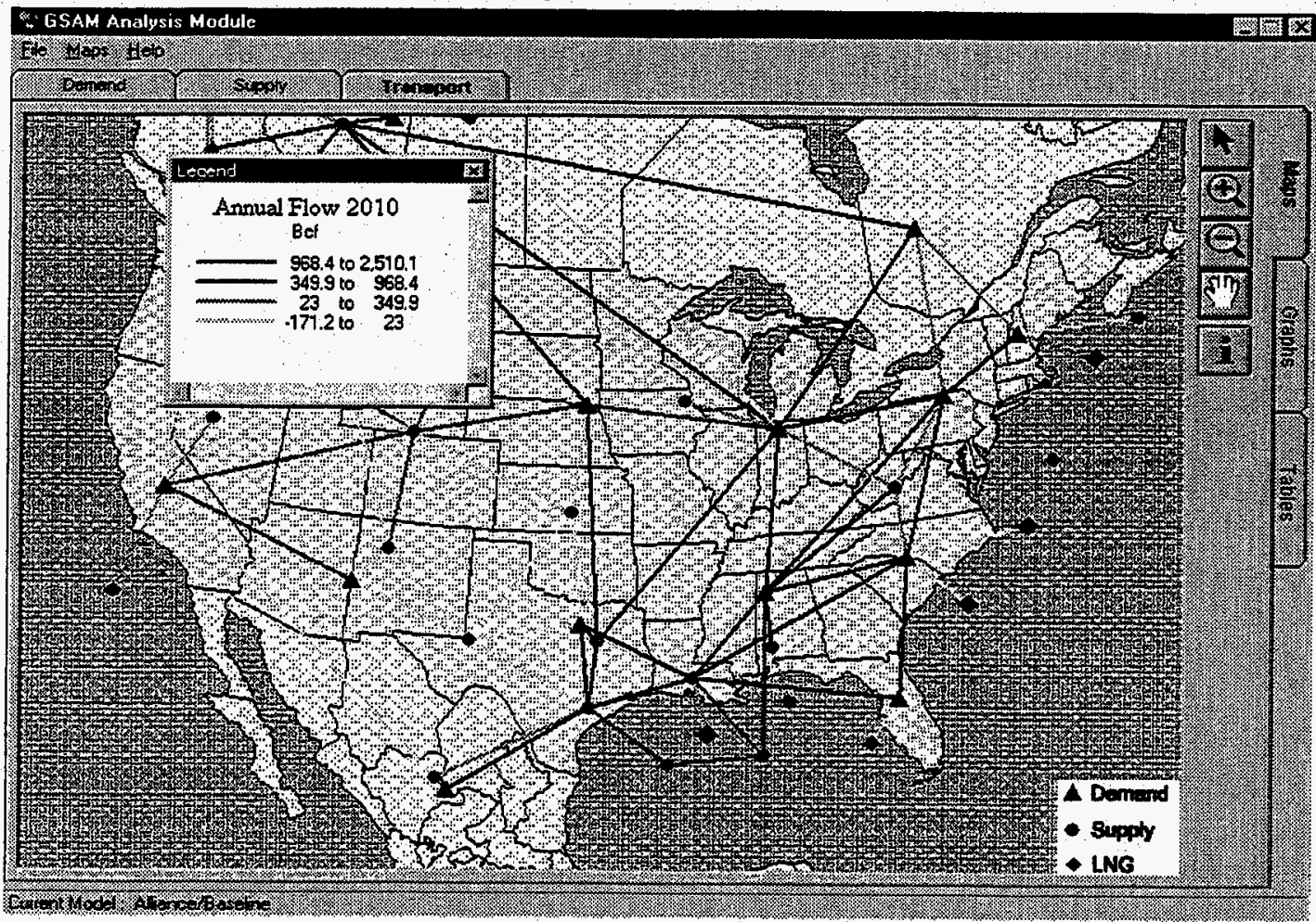

Graphs: One can create a graph by clicking 'graphs' on the File Manager and choosing 'create graph'. This brings up a window similar to the one below. 
Figure III-23

Create Graph Dialog Window

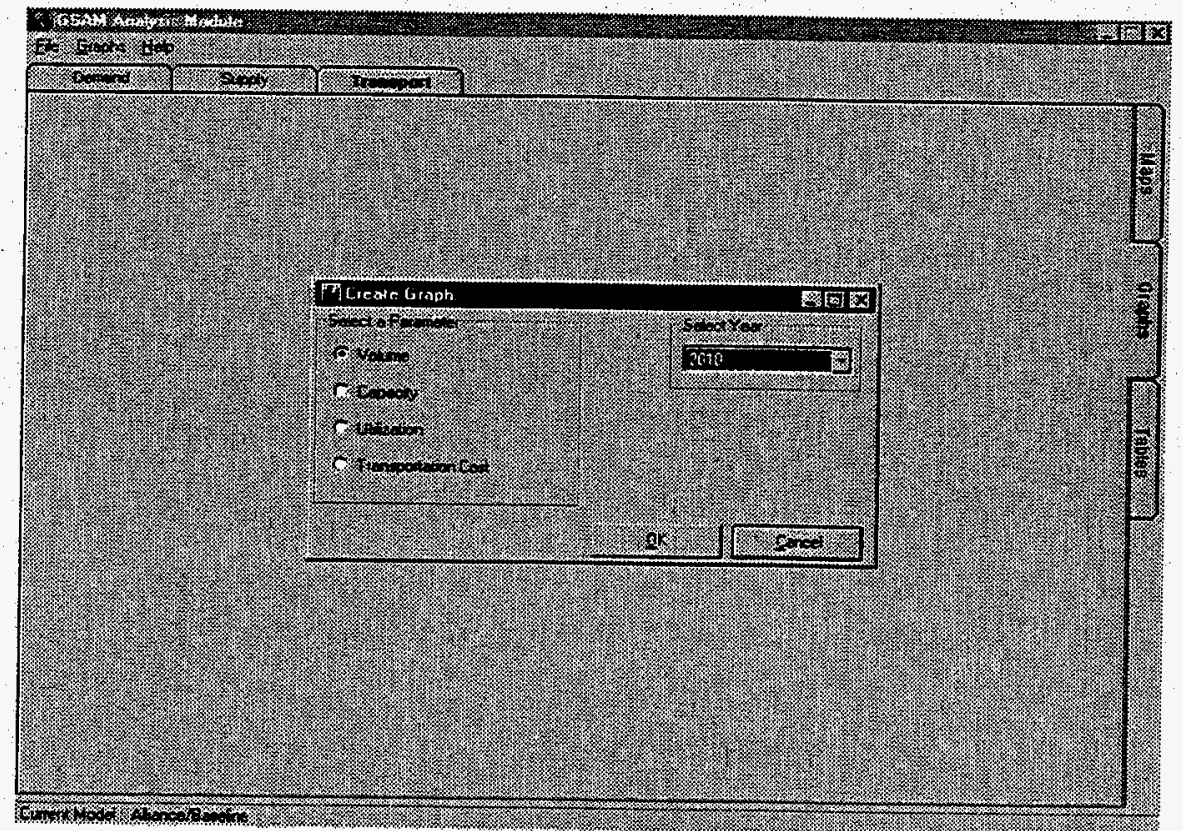

Each selected value is shown across different regions for a specific year to create a graph like the following.

Figure III-24

Graph Analysis

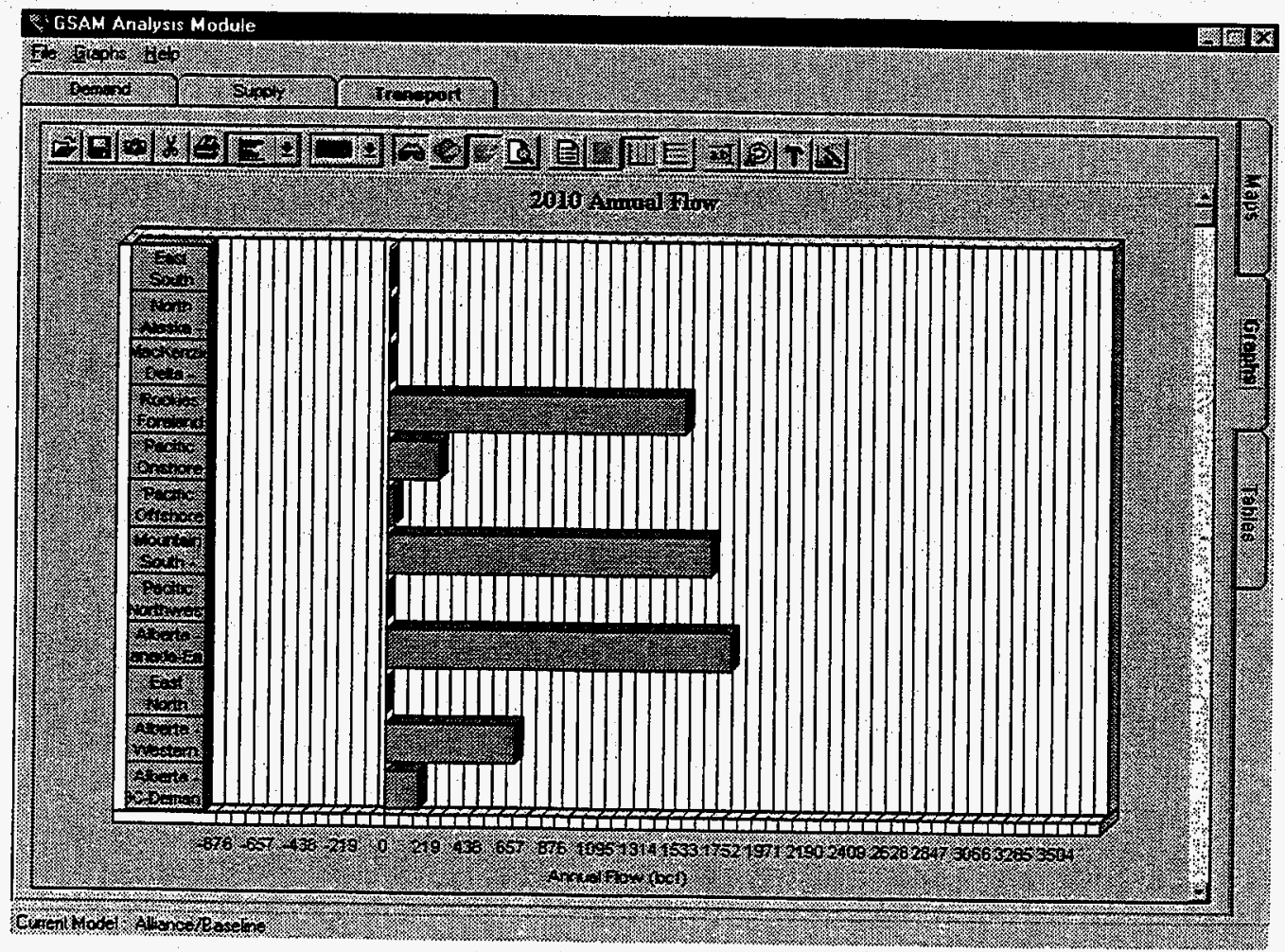


Using the right mouse button one can view the numeric data specific to that entry. The visual effects in the graph can be altered using the tool bar on the top of the screen. This allows one to visualize the data in any desired format. Bar Graphs, Pie Charts etc. can be created. This feature is useful for data presentation.

Tables: To create a table one simply clicks on 'tables' on the File Manager and chooses to 'create table'. This brings up the following window:

Figure III-25

Create Table Dialog Window

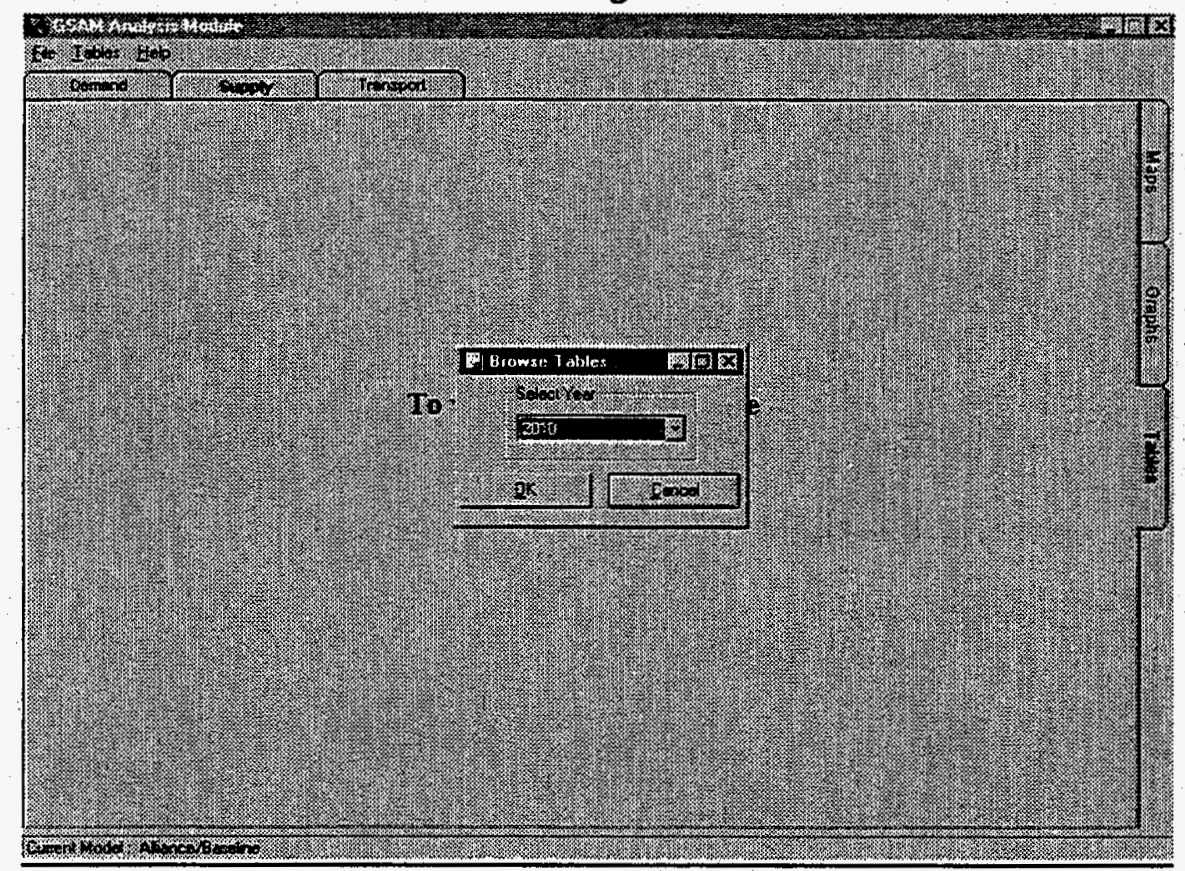

Each table has all the parameters for a specific year. A sample table is shown below. 
Figure III-26

Table Analysis

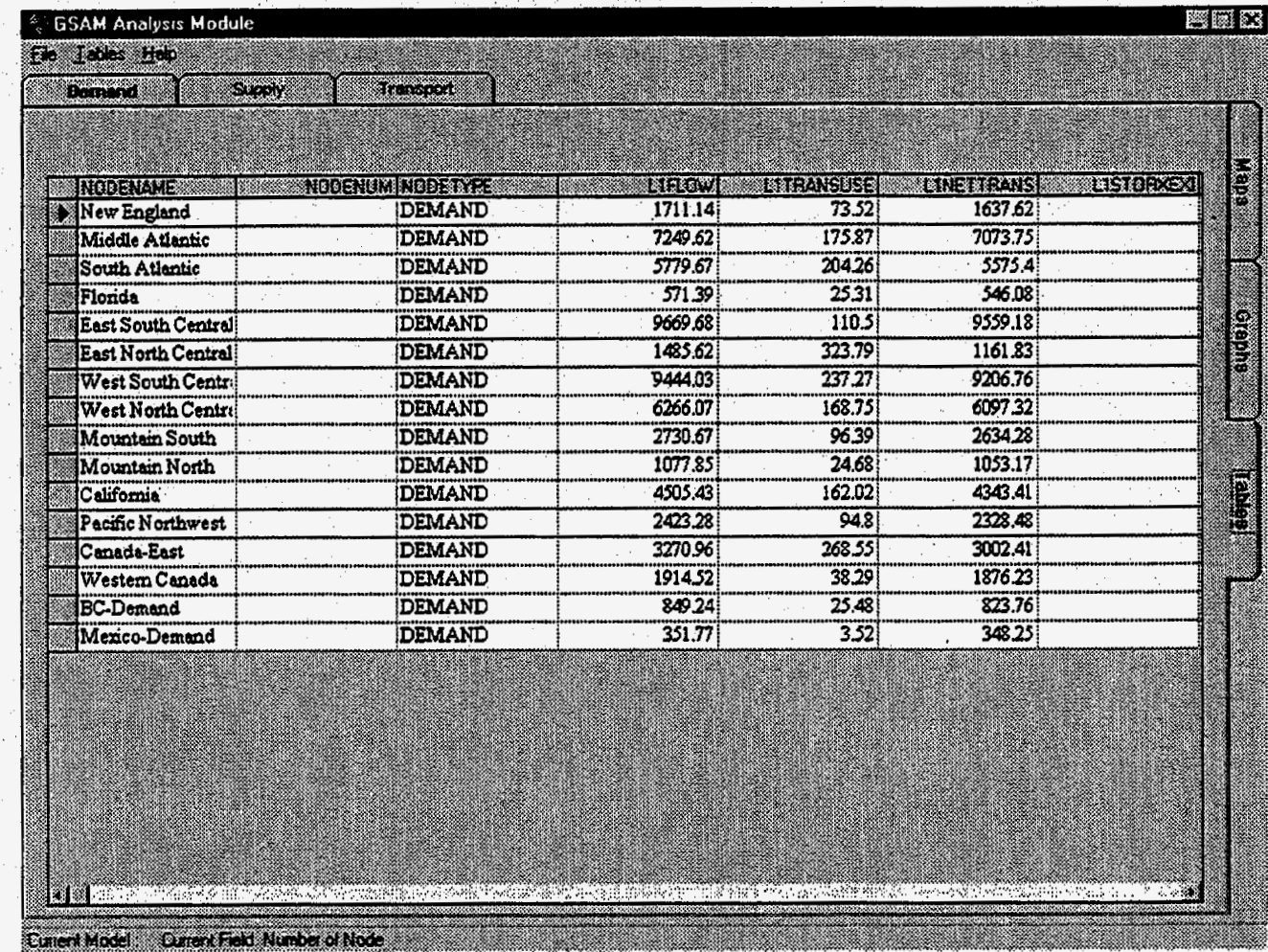

The tables contain the databases from which the graphs and maps are created. This is yet another format in which the data can be presented.

Back-end

This comprises FORTRAN code and is identical to the DOS- based GSAM.

\section{Conclusion}

Work on WGSAM was completed in the period of performance (July 1997 - June 1998). It is now a fully functional tool to aid in the setup and analysis of GSAM runs. 


\section{H. 1998 USER'S GUIDES}

\section{Background}

ICF has routinely produced and updated a GSAM User's Guide to provide users with documentation and instruction on the applications and function of the model. Changes are made in each succeeding version to serve three purposes: to document and explain changes in the model's structure, to allow ICF to revise or clarify instructions, or to expand upon some segment or function of the model.

Previous to the two 1998 updates, the latest version of the User's Guide to have been released was in January 1997.

\section{Results}

In the past year, two GSAM User's Guides have been released. The first in January 1998, and the second in June 1998. The January edition provided a complete overhaul of the main body of the User's Guide text, while the June version changed the structure of the appendix.

The January 1998 User's Guide altered the structure of the Module's chapters. A more systematic approach was used in this documentation. Each chapter now contains:

- All required files and their descriptions and locations,

- Instruction for both manual and batch file operation,

- A description of how the Module works, and

- An outline of frequently changed parameters.

Where the previous User's Guide was at times vague and incomplete in regard to input file that a Module requires, the January 1998 User's Guide is descriptive and complete. As an example of the changes that were made, the 1997 version of the User's Guide had listed the Reservoir Performance Module files as follows: 


\begin{tabular}{|c|c|c|}
\hline (a) & GSAM1.GSM & Known reservoirs in Regions $1-5$ \\
\hline (b) & GSAM2.GSM & Known reservoirs in Regions 6 \\
\hline (c) & GSAM3.GSM & Known reservoirs in Regions 7-8 \\
\hline (d) & GSAM4.GSM & Known reservoirs in Regions 9-19 \\
\hline
\end{tabular}

The January 1998 edition has the corresponding files listed in a more organized, complete fashion:

\section{B.1 Reservoir Database Files}

\section{B.7.7 Discovered U.S. Reservoir Database}

\begin{tabular}{|c|c|c|}
\hline Name & Description & Location \\
\hline GSAM1.GSM & $\begin{array}{l}\text { Known reservoirs in regions 2-5 (MAFLA Onshore, Mid- } \\
\text { West, Arkla-East Texas, So. LA.) }\end{array}$ & IRESVPERF \\
\hline GSAM2.GSM & Known reservoirs in region 6 (Texas Gulf Coast) & IRESVPERF \\
\hline GSAM3.GSM & $\begin{array}{l}\text { Known reservoirs in regions 7-8 (Permian, Mid- } \\
\text { Continent) }\end{array}$ & IRESVPERF \\
\hline GSAM4.GSM & $\begin{array}{l}\text { Known reservoirs in regions 9-19 (San Juan, Rockies, } \\
\text { Williston, Pacific Onshore, Gulf East, Gulf West, Pacific } \\
\text { Offshore, Alaska) }\end{array}$ & IRESVPERF \\
\hline GSAM5.GSM & Known coalbed methane reservoirs & IRESVPERF \\
\hline GSAM6.GSM & Known water-drive reservoirs & IRESVPERF \\
\hline GSAM7.GSM & Other producing reservoirs & IRESVPERF \\
\hline APPL.GSM & Appalachian reservoirs (GSAM region 01) & IRESVPERF \\
\hline
\end{tabular}

The January 1998 edition also organized the Appendix and provided more detail than was presented in the January 1997 edition.

The June 1998 User's Guide went a step further, particularly in the Appendix, where many Reservoir Performance Module, Exploration and Production Module, and Demand and Integrating Module input files were given "description" and "intended uses" sections. As an example, the comprehensive explanation for the E\&P Module file EXP_DFN.SPC is given below: 


\section{EXPLANATION OF EXP DFN.SPC}

The file EXP_DFN.SPC file is used in GSAM to model the uncertainty inherent in exploration practices. The uncertainty, in this case, concerns the probability of finding accumulations (reservoirs) in a specific field size class (FSC) of a play. Modeling this uncertainty is based on the premise that the remaining reservoirs that are undiscovered are of a size less than or equal to a maximum field size class already explored.

Given that a FSC is available, 15 or less in this example, the uncertainty arises in the chances of finding any reservoir; because reservoirs of FSC 15 are available, they are the most likely to be found in this case. The next most likely would be FSC 14, and so on down to FSC 5. According to this logic, a weight must be assigned to a reservoir size, indicating that it is more or less likely to be found, and this is the purpose of the EXP_DFN.SPC file's matrix. Each row in the matrix can be thought of as the exploration curve, in any year, for a given technology, for a given resource type, for a given FSC availability. As an example, Figure A shows the exploration curve for current exploration technology in conventional reservoirs with FSC 15 or less available (corresponding to the third row of the file's matrix).

Figure A

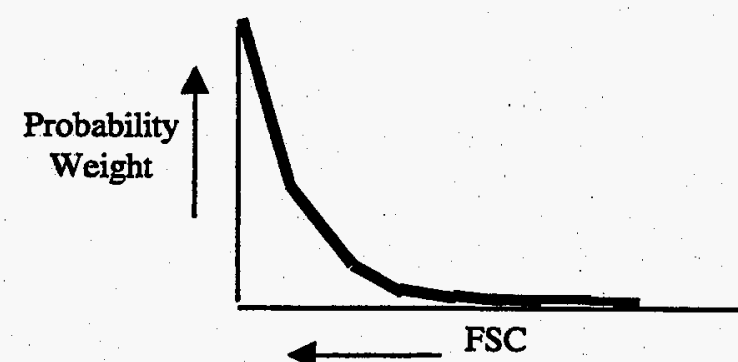

Figure $B$

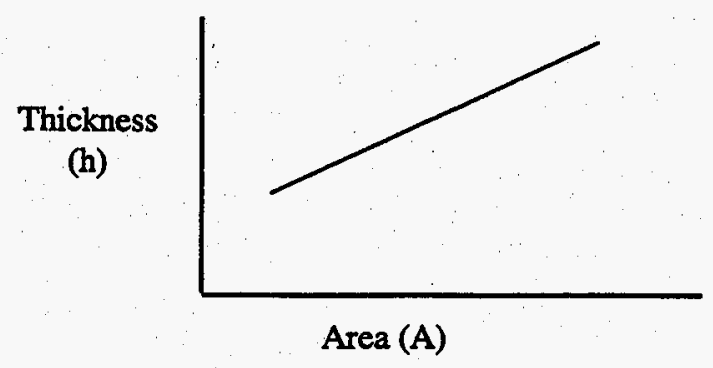

Given that a FSC is available to be discovered, the relative weights on the probablility of discovery are derived from one assumption: that the chance of finding a larger reservoir (one with a greater area) is better than the chances of discovering a smaller reservoir. Reservoirs that have a FSC of 10 or below are too small to differentiate them from one another, so that the weights on the chances of finding any of these reservoirs are based only on the area of the reservoirs in a FSC. When the area is the only factor that determines the probability of reservoir discovery, the discovery process is considered "random". Reservoirs having a FSC of 17 to 11 also base their probability weights on area, but include an additional factor that takes into account the ease of differentiation among these larger reservoirs by using technology.

As field size classes increase, the volume in the FSC doubles (FSC 10 has an average OGIP of 19.2 and FSC 11 has an average OGIP of 38.4) (1). Also, the thickness and area are assumed to be linearly related, as seen in Figure B (2). From these two pieces of information, the relative probability weights based on area can be derived. If reservoirs of FSC 10 are the largest remaining available, the relative weight on the probability of finding a reservoir of FSC 10 is 1 . The relative weight on the probability of finding a reservoir of FSC 9 is less than that of FSC 10 by a multiplying factor. This factor is $(1 / \sqrt{2})$, and is calculated by transforming the following ratio:

Note: Area*Thickness $=$ Volume or $\mathrm{Ah}=$ OGIP and $\mathrm{A}_{\mathrm{x}}$ is area in FSC $\mathrm{x}$ and $\mathrm{h}_{\mathrm{x}}$ is thickness in FSC $\mathrm{x}$ $A_{9} h_{9} / A_{10} h_{10}=1 / 2 \quad$ because of (1) above

$\mathrm{h}=\mathrm{cA}$ from (2) above; where $\mathrm{c}$ is constant of proportionality

$\mathrm{A}_{9}\left(\mathrm{cA}_{9}\right) / \mathrm{A}_{10}\left(\mathrm{cA}_{10}\right)=1 / 2$

$\mathrm{A}_{9}^{2} / \mathrm{A}_{10}^{2}=1 / 2$

$\mathrm{A}_{9} / \mathrm{A}_{10} \quad=1 / \sqrt{ } 2$ 
Thereofore, if FSC 10 is the largest available, the weight on the chances of finding a reservoir in FSC $10=1$, FSC $9=$ $1(1 / \sqrt{ } 2)=0.7071$, FSC $8=1(1 / \sqrt{ } 2)(1 / \sqrt{ } 2)=0.50$, etc. For reservoirs in a FSC above 10, the same formula applies, with an additional factor. The model assumes that for these larger reservoirs, the chances of finding a reservoir in a FSC is $25 \%$ better than random for each larger FSC in conventional, water-drive, and offhshore reservoirs and $75 \%$ better than random for each larger FSC in tight, radial and linear flow, and unconventional. So that if FSC 15 is the largest size of the remaining conventional reservoirs, the chance of finding a FSC 15 reservoir is assigned a weight of 1 . For FSC 14 the weighted chance would be $\quad 1(1 / \sqrt{ } 2)(1 / 1.25)=0.5667$. For FSC 13 the value would be $1(1 / \sqrt{ } 2)(1 / \sqrt{ }$ $2)(1 / 1.25)=0.3200$, and so forth. For tight these values would be $1(1 / \sqrt{ } 2)(1 / 1.75)=0.4041$ and so on.

As the numbers in this exploration curve do not sum to one, they are not probabilities, but weights, as mentioned above. To transform the weights into probabilities, sum the values in an exploration curve, take the reciprocal, and multiply the reciprocal by each weights for the individual probabilites of finding a reservoir in a specific field size class. To calculate the overall probability of finding a reservoir of a certain FSC multiply each of the individual probabilities by the exploration success rate, in the second column, to incorporate the chance of drilling a dry hole in exploration. As an example, the probability of successfully finding and drilling a FSC 13 reservoir when the largest conventional reservoir available is size 15 is :

(Reciprocal of sum of weights) (Individual FSC weight) (Success rate)

$(1 / 2.3422)(0.3200)(.14)=0.01913=1.9 \%$ probability

Advanced technology will generally have a higher success rate than current.

\section{Intended Uses of EXP_DFN.SPC}

This file can be used in modeling the effects of better seismic technology, improving the resolution of smaller field size classes. This could be done by changing (increasing) the relative probability weights of smaller(less than 10) field size classes. The exploration success rate could also be changed to model alternative scenarios.

\section{Conclusions/Ongoing Work}

As the model continues to grow, new User's Guides will be created to reflect the changes. The next version of the User's Guide will contain details on GSAM's new reserve growth, Federal technology penetration, annual, and 4-seasons components. 


\section{Conclusion}

The development of GSAM continues on track. Work based on the 1997 Peer Review was a critical element in the development of GSAM over the past 12 months. The reviewers who participated in the two-day workshop recommended several improvements. The recommendations including improvements to reservoir data and to the E\&P, Demand and Integrating, and Storage Modules were implemented. Guidance on the design and implementation of the Environmental Module was also used in development.

GSAM is designed as a multi-function tool, able to provide analysis on a variety of issues, and can be especially useful in analyzing the impacts of public policy. In this regard, GSAM was updated to incorporate reservoirs on Federal lands and a separate technology penetration curve.

The issue of the "hump" in the production curve was resolved, through a careful study of the model's components, and the incorporation of the "reserve growth" concept.

In line with the recommendations of the Peer Review, a 4-season model was developed for the storage model, which led to the development of a 4-season based Demand Module. This work also led to the development of an annual GSAM.

The next year should see GSAM as an increasingly utilized planning and policy tool. The components installed into the model in the past year add a tremendous amount of analytical power and potential to GSAM. 